\title{
Front line antioxidant defenses in the freeze tolerant wood frog, Rana sylvatica: An in-depth analysis of mechanisms of enzyme regulation.
}

\author{
Neal J. Dawson \\ B.Sc. S.Sp. Honours Biochemistry \\ Queen's University, 2006 \\ M.Sc. Biology \\ Carleton University, 2009
}

\begin{abstract}
A Thesis Submitted to the Faculty of Graduate Studies and Research in partial fulfillment of the requirements for the degree of
\end{abstract}

\author{
Doctor of Philosophy \\ Department of Biology
}

Carleton University

Ottawa, Ontario, Canada

C) Copyright 2014

Neal J. Dawson 
The undersigned hereby recommend to the Faculty of Graduate Studies and Research acceptance of this thesis

\title{
Front line antioxidant defenses in the freeze tolerant wood frog, Rana sylvatica: An in-depth analysis of mechanisms of enzyme regulation.
}

\author{
submitted by \\ Neal J. Dawson, B.Sc., M.Sc. \\ in partial fulfillment of the requirements for the degree of Doctor of Philosophy
}

Chair, Department of Biology

Thesis Supervisor

External Examiner

Carleton University 


\begin{abstract}
The wood frog, Rana sylvatica, is one of few species that can survive whole-body freezing during overwintering. Frogs endure freezing of up to $70 \%$ of their total body water, and demonstrate a complete lack of respiration, heart beat and brain activity. Freezing imposes multiple stresses including anoxia/ischemia, cellular dehydration when water is lost to extracellular ice masses, wide temperature changes, and potential physical damage by ice. One crucial adaptation for freezing survival is well-developed antioxidant defenses to protect tissues from abiotic stress while frozen and deal with rapid changes in the generation of reactive oxygen species associated with anoxia and reoxygenation over freeze/thaw cycles.

This thesis explores the properties and regulation of key antioxidant enzymes, purified via novel schemes, from frog muscle - both $\mathrm{Cu} / \mathrm{Zn}$ - and $\mathrm{Mn}$-dependent isoforms of superoxide dismutase (SOD), glutathione reductase (GR), and catalase (CAT). The studies show that changes in activity, stability, and substrate affinity of antioxidant enzymes during the frozen state may be significant preparatory mechanisms employed by R. sylvatica to support the transition from frozen to thawed states and deal effectively with oxidative stress accompanying reperfusion. Moreover, reversible protein phosphorylation plays a central role in regulating the activity of these enzymes to suit physiological needs throughout freeze-thaw cycles. For example, $\mathrm{CuZnSOD}$ from muscle of frozen frogs showed a significantly higher $\mathrm{V}_{\max }$ compared to the control enzyme. Muscle MnSOD from frozen frogs showed a significantly lower $\mathrm{K}_{\mathrm{m}}$ for $\mathrm{O}_{2}{ }^{-}$, higher phosphorylation, and increased enzyme stability compared to control MnSOD. GR from
\end{abstract}


frog muscle showed a significantly lower $\mathrm{K}_{\mathrm{m}}$ for GSSG in the face of physiological levels of glucose encountered during freezing, as well as the potential for phosphorylation via endogenous kinases. CAT from muscle of frozen frogs showed a significantly lower $\mathrm{K}_{\mathrm{m}}$ for $\mathrm{H}_{2} \mathrm{O}_{2}$ and a higher level of phosphorylation; furthermore, stimulation of endogenous kinases decreased $\mathrm{K}_{\mathrm{m}} \mathrm{H}_{2} \mathrm{O}_{2}$ similar to what occurred in muscle of frozen animals. This thesis provides compelling evidence for regulation of antioxidant enzymes via reversible protein phosphorylation and augmentation of key antioxidant enzymes during freezing of the frog, likely in preparation to endure oxidative stress encountered during reperfusion over winter freeze-thaw cycles. 


\section{ACKNOWLEDGEMENTS}

I have lived a truly full life up to this point, and I cannot possibly thank all those who have helped shape me into the person I am today. I apologize in advance for leaving out those who deserve my thanks. To my friends, you are all incredible people that I have had the pleasure of knowing and learning from.

I would specifically like to thank Ken Storey for taking a chance on a student interested in "functional proteins." I thank you for the opportunity you afforded me, the enthusiasm you instilled in me, and for introducing me to the wonders of the comparative world of science. I cannot thank you enough for my time under your guidance. I offer a special thanks to Jan Storey for her fascinating discussions and endless editorial support, not only for myself, but the entire Storey lab. Unfortunately I have been in the Storey lab for far too long to list all those that have guided, assisted, and simply kept me sane throughout it all. However, I would like to give a special thanks to Kyle Bigger, Ryan Bell and Ben Lant. You have had an immeasurable impact on my scientific career thus far, and I hope to continue to learn, wonder, and explore with you for years to come.

Lastly I would like to thank my family. To my mother and father, Joan and Donald Dawson, you provided a home life so incredibly loving, that I am only now starting to understand how truly lucky I was to have you as parents. Jennifer, Debbie, Dan and Olivia, I thank you for the love and laugher you shared with me, and for always supporting me throughout my life. Finally, Dominique, I can't thank you enough for your patience and support throughout my studies. You are my rock, my love, and I look forward to embarking together on the adventures life has yet to throw our way. 


\section{TABLE OF CONTENTS}

Title Page

Acceptance Sheet ii

Abstract

$\begin{array}{lll}\text { Acknowledgements } & \text { v }\end{array}$

Table of Contents vi

List of Abbreviations vii

List of Figures $\quad$ ix

List of Tables $\quad$ xii

List of Appendices $\quad$ xiii

$\begin{array}{lll}\text { Chapter } 1 & \text { General Introduction } & 1\end{array}$

Chapter 2 Free-radical first responders: The characterization of $\mathrm{CuZnSOD}$ and MnSOD regulation during freezing of the freeze tolerant North American wood frog, Rana sylvatica.

Chapter 3 Passive regeneration of glutathione: Purification and properties of glutathione reductase regulation from the freeze tolerant North American wood frog, Rana sylvatica.

Chapter 4

A hydrogen peroxide safety valve: The reversible phosphorylation of catalase from the freeze tolerant North American wood frog, Rana sylvatica.

Chapter 5

General Discussion 


\section{LIST OF ABBREVIATIONS}

\begin{tabular}{|c|c|}
\hline AMP & adenosine monophosphate \\
\hline AMPK & 5' adenosine monophosphate-activated protein kinase \\
\hline BSA & bovine serum albumin \\
\hline CAT & catalase \\
\hline cDNA & complementary deoxyribonucleic acid \\
\hline $\mathbf{C}_{\mathbf{m}}$ & concentration at which half of the protein is unfolded \\
\hline CuZnSOD & copper and zinc containing SOD \\
\hline DEAE $^{+}$ & diethylaminoethyl cellulose \\
\hline DEPC & diethylpyrocarbonate \\
\hline dNTP & deoxyribonucleotide triphosphate \\
\hline DSF & differential scanning fluorimetry \\
\hline DTT & dithiothreitol \\
\hline $\mathbf{E}_{\mathbf{a}}$ & activation energy \\
\hline EDTA & ethylenediaminetetraacetic acid \\
\hline EGTA & ethylene glycol tetraacetic acid \\
\hline $\mathbf{E R}$ & endoplasmic reticulum \\
\hline ETS & electron transport system \\
\hline FeSOD & iron containing superoxide dismutase \\
\hline GMP & guanosine monophosphate \\
\hline GPx & glutathione peroxidase \\
\hline GR & glutathione reductase \\
\hline GSH & reduced glutathione \\
\hline GSSG & oxidized glutathione \\
\hline GST & glutathione-s-transferase \\
\hline $\mathbf{I}_{\mathbf{5 0}}$ & half maximal inhibitory concentration \\
\hline IMAC & immobilized metal ion affinity chromatography \\
\hline $\mathbf{I P}_{\mathbf{3}}$ & inositol trisphosphate \\
\hline $\mathbf{K}_{\mathbf{a}}$ & half maximal activation concentration \\
\hline
\end{tabular}




$\begin{array}{ll}\text { Km } & \text { Michaelis-Menten constant } \\ \text { KPi } & \text { potassium phosphate } \\ \text { MAPK } & \text { mitogen activated protein kinase } \\ \text { MnSOD } & \text { manganese containing superoxide dismutase } \\ \text { mRNA } & \text { messenger ribonucleic acid } \\ \text { NAD(P)H } & \text { reduced form of nicotinamide adenine dinucleotide } \\ & \text { (phosphate) } \\ \text { NBT } & \text { nitrotetrazolium blue } \\ \text { NiSOD } & \text { nickel containing superoxide dismutase } \\ \text { PCR } & \text { polymerase chain reaction } \\ \text { PKA } & \text { protein kinase A } \\ \text { PKC } & \text { protein kinase C } \\ \text { PKG } & \text { protein kinase G } \\ \text { PMSF } & \text { phenylmethylsulfonyl fluoride } \\ \text { PP1 } & \text { protein phosphatase 1 } \\ \text { PP2A } & \text { protein phosphatase 2A } \\ \text { PP2C } & \text { protein phosphatase 2C } \\ \text { PVDF } & \text { polyvinylidene difluoride } \\ \text { RNA } & \text { ribonucleic acid } \\ \text { ROS } & \text { reactive oxygen species } \\ \text { rRNA } & \text { ribosomal ribonucleic acid } \\ \text { RT } & \text { room temperature } \\ \text { SDS } & \text { sodium dodecyl sulfate } \\ \text { SDS-PAGE } & \text { sodium dodecyl sulfate polyacrylamide gel electrophoresis } \\ \text { TBARS } & \text { thiobarbituric acid reactive substances } \\ \text { TBST } & \text { tris buffered saline with tween } \\ \text { T } & \text { the melting point } \\ \text { V }_{\text {max }} & \text { maximal velocity } \\ \text { XO } & \text { xanthine oxidase } \\ \text { XDH } & \text { xanthine dehydrogenase } \\ & \end{array}$




\section{LIST OF FIGURES}

Figure 1.1. Single electron reduction of oxygen and the ROS

Page 3

intermediates that arise as a result.

Figure 1.2. A simple overview of the primary antioxidant pathways and $\quad$ Page 7 free radical producing reactions.

Figure 1.3. Composite freezing curve for R. sylvatica.

Page 11

Figure 2.1. (A) Typical elution profile for control SOD on a DEAE+

Page 61 column. (B) Typical elution profile for control SOD on a copper chelate column.

Figure 2.2. Copper chelate column elution profile for SOD superimposed with western blot analysis showing the cross-reactivity of anti-CuZnSOD (dotted line) and anti-MnSOD (dashed line) with individual fractions.

Figure 2.3. Immunoblot analysis of (A) purified $\mathrm{CuZnSOD}$ from the muscle of control R. sylvatica and (B) purified MnSOD from the muscle of control R. sylvatica.

Figure 2.4. (A) RT-PCR analysis of sod transcript levels in frog muscle.

(B) Western blotting analysis of the amount of SOD protein in frog muscle.

Figure 2.5. Relative phosphorylation levels of MnSOD from muscle of control and $24 \mathrm{~h}$ frozen frogs using Pro-Q diamond phosphoprotein staining to analyze relative total phosphorylation of the enzyme, and dot-blot analysis of residue-specific phosphorylation.

Figure 2.6. $\quad$ Predicted phosphorylation sites for CuZnSOD and MnSOD.

Page 66 (A) Partial amino sequence for $\mathrm{CuZnSOD}$, highlighting predicted phosphorylation sites (bold, underlined). (B) Kinases predicted to phosphorylate $\mathrm{CuZnSOD}$ at the amino acid sites highlighted in A. (C) Partial amino sequence for MnSOD, highlighting predicted phosphorylation sites (bold, underlined). (D) Kinases predicted to phosphorylate MnSOD at the amino acid sites highlighted in $\mathrm{C}$.

Figure 2.7. Stability of CuZnSOD from crude extracts of frog muscle. Samples were incubated for $24 \mathrm{~h}$ at $4^{\circ} \mathrm{C}$ with varying concentrations of urea then treated with pulse proteolysis to digest denatured $\mathrm{CuZnSOD}$. 
Figure 2.8. Stability of MnSOD from crude extracts of frog muscle.

Page 68 Samples were incubated for $24 \mathrm{~h}$ at $4^{\circ} \mathrm{C}$ with varying concentrations of urea then treated with pulse proteolysis to digest denatured MnSOD.

Figure 3.1. (A) Typical elution profile for GR on a hydroxyapatite

Page 101 column. (B) Typical elution profile for GR on a Cibacron blue column.

Figure 3.2. DEAE+ elution profiles for purified GR from control and $24 \mathrm{~h}$ frozen muscle after incubation to stimulate protein kinases.

Figure 3.3. Purified GR from the muscle of control R. sylvatica.

Page 103

Figure 3.4. Absence of bands indicates no apparent phosphorylation of muscle GR from either control or $24 \mathrm{~h}$ frozen frogs as assessed by Pro-Q diamond phosphoprotein staining.

Figure 3.5. Relative phosphorylation levels of GR from control and $24 \mathrm{~h}$ frozen frog muscle after total kinase incubations as assessed by Pro-Q diamond phosphoprotein staining.

Figure 3.6. Relative phosphorylation levels of wood frog muscle GR after incubations to stimulate total kinases; control and $24 \mathrm{~h}$ frozen conditions are compared using Western-blot analysis of sitespecific phosphorylation.

Figure 3.7. A comparison of the predicted serine (S), threonine (T) and tyrosine (Y) phosphorylation sites on GR that are shared between $X$. tropicalis and $X$. laevis.

Figure 3.8. Arrhenius plot for purified GR from the muscle of control and $24 \mathrm{~h}$ frozen R. sylvatica.

Page 104

Page 104

Page 105

Page 106 Differential scanning fluorimetry analysis of the thermal stability of purified GR from control and $24 \mathrm{~h}$ frozen frog muscle.

Figure 4.1. (A) Typical elution profile for CAT on a hydroxyapatite column. (B) Typical elution profile for CAT on a Cibacron blue column. (C) Typical elution profile for CAT from control muscle on a DEAE+ column. (D) Typical elution profile for CAT from frozen muscle on a DEAE+ column. 
Figure 4.2. Stepwise purification ofCAT samples from the muscle of control R. sylvatica. (A) CAT-containing eluant after hydroxylapatite chromatography, (B) CAT-containing eluant after Cibacron blue chromatography, (C) molecule weight standards, and (D) purified CAT from DEAE+ chromatography.

Figure 4.3. Relative phosphorylation levels of CAT as assessed from incubations of frog muscle extracts from control and $24 \mathrm{~h}$ frozen frogs with detection using ProQ Diamond phosphoprotein stain or Western blotting for site-specific phosphorylation.

Figure 4.4. Relative phosphorylation levels of control muscle CAT from Peak I and Peak II as assessed by Pro-Q diamond phosphoprotein staining.

Figure 4.5. DEAE+ elution profiles for muscle CAT from control frogs and incubated under conditions that stimulated protein phosphatases (A) or protein kinases (B).

Figure 4.6. Effects of in vitro incubations of purified CAT of muscle under conditions which stimulated the activities of endogenous protein kinases or phosphatases on the resulting $\mathrm{Km}$ values for $\mathrm{H} 2 \mathrm{O} 2$ of CAT from control and frozen $\mathrm{R}$. sylvatica.

Figure 4.7. A comparison of the predicted phosphorylation sites for CAT from $X$. tropicalis and X. laevis which are shared between the two frog species. Predicted phosphorylation sites are shown in bold and underlined.

Figure 4.8. Differential scanning fluorimetry analysis of the thermal stability of purified CAT from control and $24 \mathrm{~h}$ frozen frog muscle. 


\section{LIST OF TABLES}

Table 2.1. Typical purification and yield of Rana sylvatica muscle

Page 59 CuZnSOD

Table 2.2. Typical purification and yield of Rana sylvatica muscle

Page 59 MnSOD.

Page 60

Table 2.3. CuZnSOD and MnSOD kinetic parameters from purified control and frozen $R$. sylvatica muscle.

Table 3.1. Typical purification and yield of Rana sylvatica muscle GR. $\quad$ Page 99

Table 3.2. Kinetic parameters of GR purified from muscle of control and Page 100 frozen $R$. sylvatica.

Table 4.1. Typical purification and yield of Rana sylvatica muscle CAT. Page 139

Table 4.2. Kinetic parameters of CAT purified from muscle of control Page 140 and frozen R. sylvatica. 


\section{LIST OF APPENDICES}

Appendix A

Appendix B

Appendix B
List of Publications

Communications at Scientific Meetings

Contributions to Chapters
Page 167

Page 170

Page 173 
Chapter 1:

General Introduction 


\section{Introduction}

\subsection{Oxygen and Oxygen Radicals}

Oxygen has been present in the earth's atmosphere for an estimated 2 billion years, and is believed to have had a biological origin (Embley and Martin, 2006). Specifically, the production of oxygen is thought to be due to the photosynthesis reaction of primitive plant life, likely cyanobacteria. It was only after this event that early eukaryotes would have acquired mitochondria and evolved to use oxygen as the final electron acceptor for the electron transport system (Embley and Martin, 2006). Oxygen has a high redox potential which facilitates the transfer of electrons from reduced molecules, making it an excellent participant in energy production. The use of oxygen as the terminal electron acceptor is vital for complex life forms as it allows for a greater extraction of energy from organic molecules by using oxygen-linked substrate catabolism and ATP production in mitochondria. As a consequence of this oxygen-dependent life, many animals then became highly sensitive to oxygen deprivation. Animal organ systems (particularly mammals) have evolved to function under relatively high oxygen levels, and often remain functional only within a narrow range of oxygen levels. Prolonged situations of hypoxia or anoxia can lead to rapid tissue damage and if extended further, the outcome is death for hypoxia/anoxia intolerant organisms (Brierley, 1977).

Under normal oxygen levels, another consequence of oxygen dependence is the formation of harmful oxygen radicals, or reactive oxygen species (ROS). Gerschmann et al. (1954) first proposed that ROS may be responsible for the toxic effects of oxygen. It is now generally accepted that ROS are produced in all aerobic systems in a process where 
oxygen is reduced by one electron at a time (univalent reduction) as opposed to the tetravalent reduction of oxygen by cytochrome oxidase. Single electron reduction of oxygen results in the production of ROS intermediates as seen in Figure 1.1 (Sies, 1983).

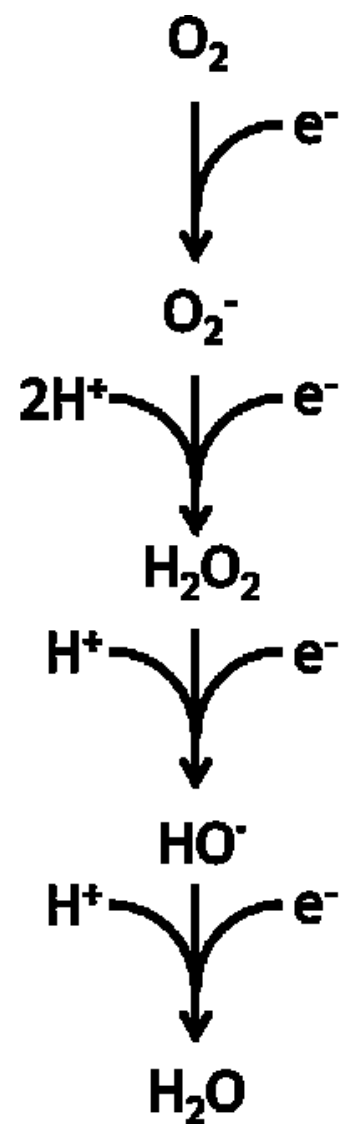

Figure 1.1. Single electron reduction of oxygen and the ROS intermediates that arise as a result.

One of the prominent sources of ROS formation is the electron transport system (ETS) (Yu, 1994). Typically $>95 \%$ of oxygen in cells is used by cytochrome oxidase but oxygen is also consumed by a variety of oxygenase enzymes and a small percentage (about 1-3\%) also escapes the ETS in the form of ROS (Reiter, 1995). Complex I 
(NADH-ubiquinone oxidoreductase) and III (ubiquinol-cytochrome $c$ oxidoreductase) of the ETS are capable of one or two electron reductions of oxygen, and can therefore generate superoxide $\left(\mathrm{O}_{2}{ }^{-}\right)$and hydrogen peroxide $\left(\mathrm{H}_{2} \mathrm{O}_{2}\right)$. These are also produced enzymatically by various oxidases including xanthine oxidase (XO), glucose oxidase, NADPH oxidase, and some metabolites such as catecholamines and flavins which are susceptible to auto-oxidation (Yu, 1994; Reiter, 1995). Although $\mathrm{O}_{2}{ }^{-}$and $\mathrm{H}_{2} \mathrm{O}_{2}$ are potentially damaging to cells, they are most damaging when either $\mathrm{H}_{2} \mathrm{O}_{2}$ alone or $\mathrm{O}_{2}{ }^{-}$and $\mathrm{H}_{2} \mathrm{O}_{2}$ are converted to form hydroxyl radicals $\left(\mathrm{OH}^{*}\right)$ (Figure 1.1) through catalysis by transition metals (iron, copper) in the Fenton and Haber-Weiss reactions (Basaga, 1990). Although mitochondrial production of $\mathrm{O}_{2}{ }^{-}$is considered the lmajor source of production, many studies have shown that a substantial conversion of xanthine dehydrogenase $(\mathrm{XDH})$ to $\mathrm{XO}$ can occur under ischemic conditions (Mink et. al., 1990; Hossain et. al., 1995; Korthius and Granger, 1986). During ischemic stress, increased use of ATP leads to a degradation of ATP to hypoxanthine (Dorion et. al., 1993). XO/XDH can lead to the formation of $\mathrm{O}_{2}{ }^{-}$and $\mathrm{H}_{2} \mathrm{O}_{2}$ by converting hypoxanthine to xanthine or urate (one and two electron reduction, respectively). However, $\mathrm{XDH}$ achieves this using either one or two molecules of $\mathrm{NAD}^{+}$, whereas XO simply uses $\mathrm{O}_{2}$, generating $\mathrm{O}_{2}{ }^{-}$and $\mathrm{H}_{2} \mathrm{O}_{2}$. Therefore, a conversion of XDH to XO potentially acts as a predictor of ROS formation and ROS-induced tissue damage. This coupled with the fact that iron and copper can be mobilized during ischemic reperfusion can lead to a rapid increase in $\mathrm{OH}^{*}$ formation (Chevion et al., 1993). The activity of XO, however, was not significantly higher in frozen frogs in comparison to control frogs, and the ratio of $\mathrm{XO}$ to $\mathrm{XDH}$ remained unchanged (Joanisse and Storey, 1996). Other species that withstand reduced 
oxygen or blood flow have exhibited changes in either $\mathrm{XO}$ activity or the $\mathrm{XO} / \mathrm{XDH}$ ratio when in the stressed state ((Hermes-Lima and Storey, 1998; Grundy and Storey, 1998). In addition to $\mathrm{XO} / \mathrm{XDH}$ ratios, tests used to measure oxidative damage reported that oxidative damage was noticeably absent in frozen and thawed frogs, as assessed using the TBARS test (which measures the terminal breakdown of organic hydroperoxide products) and the xylenol orange test (which measures lipid hydroperoxide content of tissues) (Joanisse and Storey, 1996). Taken together, this suggests an increased level of control over oxidative damage, possibly due to augmented antioxidant enzyme regulation.

To minimize ROS damage, cells maintain enzymatic and non-enzymatic antioxidant defenses that are constantly scavenging free radicals and converting them to non-toxic species. One of the ways to prevent ROS formation is to control the concentrations and locations of free transition metals by using ion binding proteins such as transferrin, desferrioxamine and ferritin to sequester them in nonreactive forms (Gutteridge and Quinlan, 1992; Gutteridge and Halliwell, 1990). ROS formation is also regulated by the subcellular localization of the enzymes of the ETS in the mitochondria, as well as selected antioxidant enzymes themselves to detoxify ROS before they can escape the mitochondria.

\subsection{Antioxidant Enzymes}

The primary antioxidant enzymes involved directly with ROS detoxification are superoxide dismutase (SOD) that converts $\mathrm{O}_{2}{ }^{-}$to $\mathrm{H}_{2} \mathrm{O}_{2}$, and catalase (CAT) and several 
peroxidases that process hydrogen peroxide to non-radical species. Peroxidases are also linked to the detoxification of lipid hydroperoxides, and whereas CAT has also been shown to exhibit similar activity, this is still largely not understood (Fridovich, 1976; Palcic and Dunford, 1980). Another important enzyme family in ROS management is the glutathione-S-transferases (GSTs) that have a primary role in the detoxification of xenobiotics via coupling with GSH (Salinas and Wong, 1999). GSTs catalyse the conjugation of glutathione (GSH) to electrophiles; however, GSH can also spontaneously conjugate with electrophiles and directly detoxify oxygen free radicals (Salinas and Wong, 1999). The secondary antioxidant enzyme, glutathione reductase (GR), is charged with the regeneration of reduced GSH from the oxidized (GSSG) form via a NADPHdependent reaction; this replenishes the GSH pool and the cell's free radical buffering ability (Mullineaux and Creissen, 1997). Figure 1.2, shows a simplified schematic of the relationship of the main players in the antioxidant mitigating pathway. 


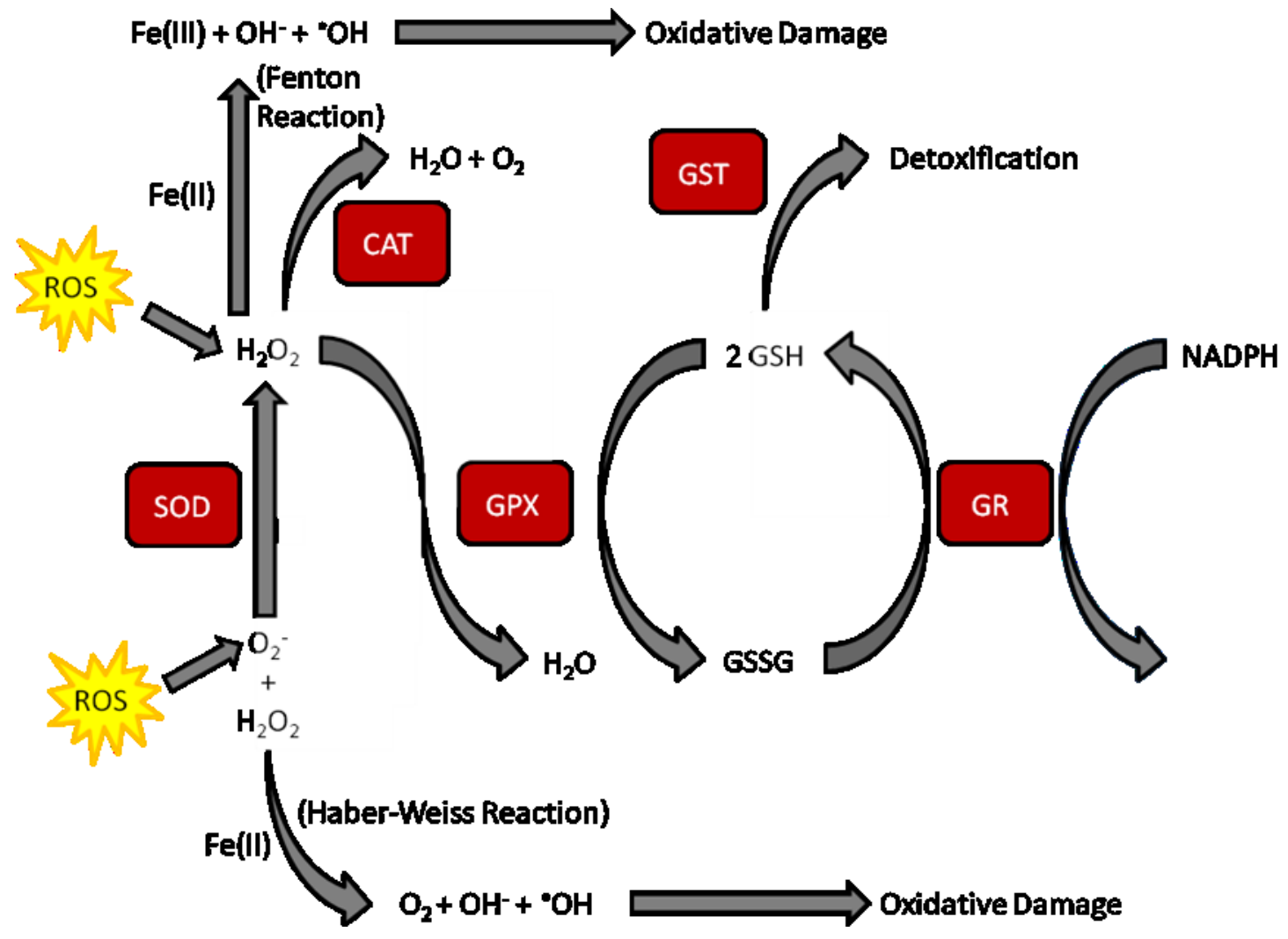

Figure 1.2. A simple overview of the primary antioxidant pathways and free radical producing reactions.

Changes in antioxidant enzyme activity, specifically those addressed in this thesis, have been observed during low oxygen stress in a wide variety of animals. Organisms experiencing changes in antioxidant enzyme regulation under oxygen deprived states or experiencing reduced blood flow include: the red eared slider turtle (Trachemys scripta elegans) which shows fluctuations in GR activity as well as decreased GSH levels in the liver, heart and muscle, decreases in SOD activity in the liver and brain, and decreased CAT activity in the heart kidney and brain during anoxia (Willmore and Storey, 1997); the leopard frog (Rana pipiens) which shows a reduction in GR and SOD activity in 
muscle tissue during severe dehydration, and shows an increase in CAT activity in muscle tissue during severe dehydration and anoxic conditions (Hermes-Lima and Storey, 1998); the ground squirrel (Spermophilus citellus) which shows increased CAT expression and a reduction in CuZnSOD expression during hibernation (Vucetic et al., 2013); the African clawed frog (Xenopus laevis) which exhibits increased SOD and CAT expression in both the muscle and liver in response to whole body dehydration (Malik and Storey, 2011); the common carp (Cyprinus carpio) which shows increases in GR activity in the brain, increases in SOD activity in kidney and skeletal muscle, and increased CAT activity in the brain and kidneys during hypoxia (Lushchak et al., 2005); the garter snake (Thamnophis sirtalis parietalis) which shows an increase in SOD activity during freezing (Hermes-Lima and Storey, 1993); the spadefoot toad (Scaphiopus couchii) where GR activity in the liver, heart and kidney was significantly lower during estivation while CAT activity in the liver and heart were significantly higher, while being lower in the kidney during estivation, and SOD activity decreased upon exit from estivation (Grundy and Storey, 1998); the marine periwinkle (Littorina littorea) where GR and SOD activity decreased in the hepatopancreas during anoxia as well as foot muscle upon exit from anoxia, and where CAT activity increased in the hepatopancreas during anoxia as well as in hepatopancreas and foot muscle upon exit from anoxia (Pannunzio and Storey, 1998); and the land snail (Otala lactea) where SOD activity rose in hepatopancreas and foot muscle, and where CAT activity decreases in foot muscle during estivation during estivation (Hermes-Lima and Storey, 1995). 


\subsection{Seasonal Freezing and the Wood Frog}

Throughout the history of our planet subzero temperatures have been an unforgiving and often deadly force claiming the lives of individual animals, and often whole species, that are not adapted to endure these harsh conditions. However, some animals have adapted to live in seasonally cold environments and have developed many different methods to survive prolonged exposure to subzero temperatures. Endothermic animals (mammals, birds) generally use one of three methods; remaining active, migration to warmer climates, or hibernating through the winter. Ectotherms also have three general methods of their own for survival; hibernation in locations that do not experience subzero temperatures (under water or deep underground), or two methods that deal with subzero exposure: freeze-avoidance and freeze-tolerance. Marine fish and many terrestrial invertebrates use freeze-avoidance by amassing high concentrations of antifreeze metabolites and proteins in their internal fluids which allow them to suppress their freezing and supercooling points below environmental temperatures (Storey, 2004). Freeze-tolerance involves a delicate process in which organisms allow ice crystals to form in extracellular spaces while maintaining an intracellular liquid state. This latter method of cold hardiness is used by many insects, intertidal molluscs, and some amphibians and reptiles (Storey and Storey, 2004).

Subzero temperatures and freezing are highly damaging and often lethal for most animals, including humans. To understand the reasons for freezing injury, the stresses that accompany freezing of an organism must be fully explored. These include: (a) freezing causes muscle-based physiological processes such as movement, breathing, and heart beat to grind to a halt; (b) ice crystals can cause severe physical damage to delicate 
tissues, particularly rupturing delicate capillaries; (c) ice formation in extracellular spaces sets up an osmotic stress that leads to severe cellular dehydration due to the outflow of water into the extracellular spaces; (d) freezing of body fluids halts blood flow which cuts off of oxygen supply, nutrient flow, waste removal, and the transmission of blood-borne signal hormones/signals to tissues (Storey, 1990; Rubinsky et al., 1987). Furthermore, thawing adds another set of problems such as how to reactivate vital organs, reestablishment of osmotic balance (so as to not swell or burst cells), and dealing with a sudden increase in reactive oxygen species (ROS) formation that is a consequence of the rapid reperfusion of oxygenated blood into tissues.

One organism that has demonstrated an ability to survive these complications of freeze/thaw is the wood frog, Rana sylvatica. Previous studies from our lab have demonstrated high survival rates $(\sim 100 \%)$ of frogs during freezing exposures to temperatures as low as about $-5^{\circ} \mathrm{C}$ (Storey and Storey, 1984) and with ice accumulation in extracellular spaces of up to $65-70 \%$ of total body water (Costanzo et al, 1993). Indeed, control over ice nucleation seems to be one of the most important adaptations for freezing survival. By taking control over nucleation and initiating ice formation at a relatively high subzero temperature (e.g. around $-2^{\circ} \mathrm{C}$ ), frogs can minimize the speed of ice formation and allow adequate time for their tissues to adapt to coming stressors. Ice nucleation can be triggered by contact with environmental ice which can trigger ice nucleation across the skin, by ice nucleating bacteria found on the skin and in the gut, or by endogenous ice nucleating agents (INAs) found in the plasma (Layne et al, 1990; Lee et al, 1995; Storey, 1990). Figure 1.3 shows the freezing process for R. sylvatica highlighting ice nucleation, and the subsequent exotherm that accompanies controlled ice 
formation in R. sylvtica (Storey and Storey, 1985).

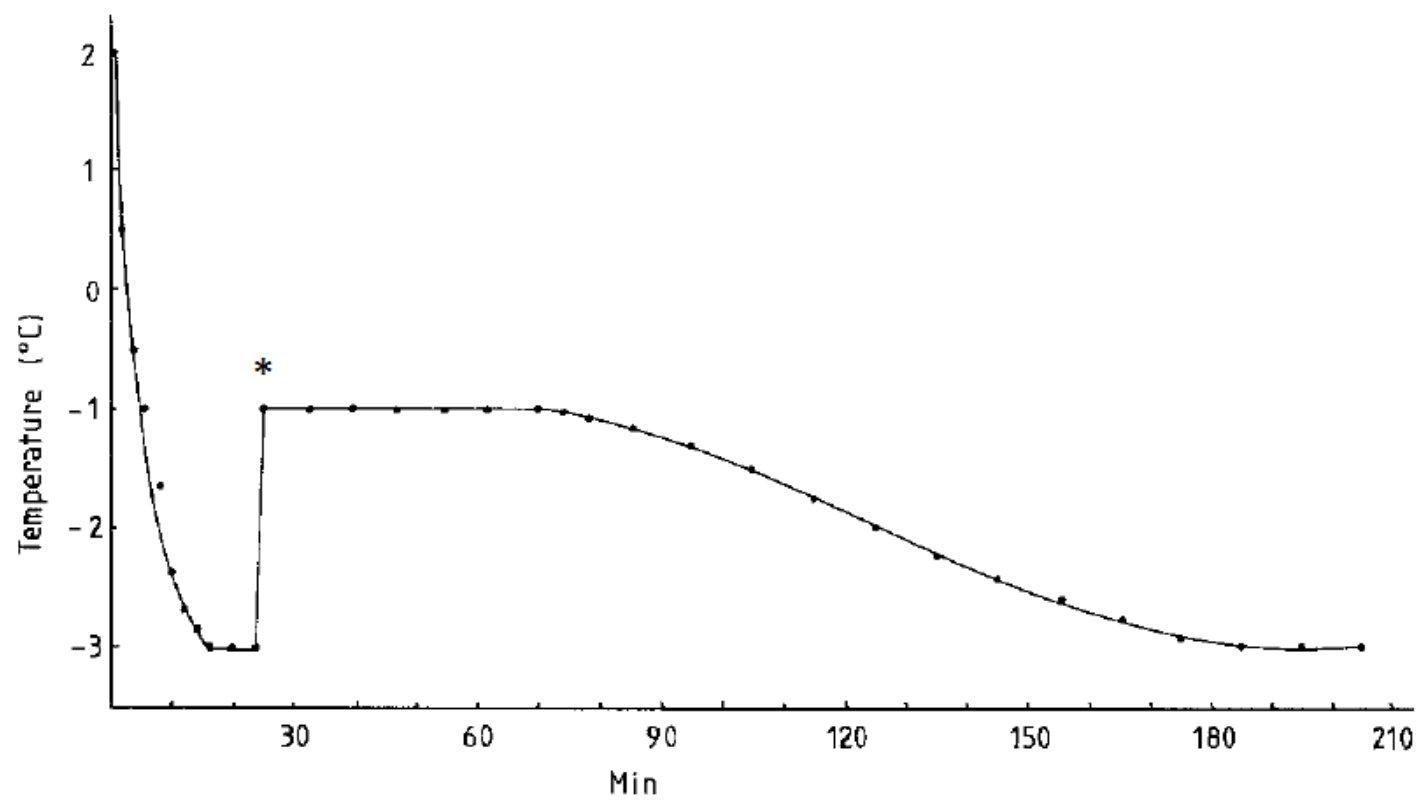

Figure 1.3. Composite freezing curve for $R$. sylvatica. * - Indicates ice nucleation event. (Storey and Storey, 1985).

Ice formation in the extracellular spaces of the frog's body during freezing leads to osmotic stress and dehydration of cells. However, the wood frog limits the amount of dehydration and quells subsequent damage to cell shape and membrane integrity by accumulating and distributing low molecular weight carbohydrate cryoprotectants, primarily glucose, to reduce these osmotic pressures (Storey and Storey, 1984). The production of glucose, among other cryoprotectants, is achieved rapidly during the initial stages of freezing (first few hours) before blood circulation is halted. 


\subsection{State of Protein Kinases and Protein Phosphatases in the Wood Frog}

The biosynthesis of glucose as a cryoprotectant is initiated within minutes of freezing exposure in wood frogs, whereas catabolic pathways including glycolysis are suppressed (Storey and Storey, 1986; Cowan and Storey, 2001; Storey, 1987). Glucose production in the liver begins with activation of $\beta$-adrenergic membrane receptors which then trigger the production of cyclic AMP that in turn activates cyclic AMP-dependent protein kinase (PKA). PKA then activates phosphorylase kinase which converts glycogen phosphorylase to its active form and initiates the breakdown of glycogen in the liver. Activation of phosphorylase along with inhibitory controls on other enzymes contributes to channelling carbon flow from glucose-1-phosphate to glucose-6-phosphate to glucose which is then exported to the blood (Storey, 1987; Holden and Storey, 1996). Other protein kinases including the mitogen-activated protein kinases (MAPKs), the AMPactivated protein kinase (AMPK) and cyclic GMP-dependent protein kinase (PKG) also show differential regulation in wood frog tissues during freezing, implicating protein kinase regulation in the implementation of multiple survival mechanisms in wood frogs (Cowan and Storey, 2003; Holden and Storey, 1996; Rider et al., 2006). The second messenger of protein kinase $\mathrm{C}(\mathrm{PKC}), \mathrm{D}-m y o$-inistol 1,4,5-trisphosphate $\left(\mathrm{IP}_{3}\right)$, was also observed to continuously increase (measured between 2 minutes and 24 hours) during freezing in the wood frog, implicating PKC involvement in freeze tolerance (Holden and Storey, 1996). This pattern of PKC second messenger changes was markedly different from that of cyclic AMP which rises immediately upon freezing exposure, before falling gradually over time to as little as $55 \%$ of the control value after 24 hours in frozen muscle. Therefore, whereas PKA has an immediate role in activating cryoprotectant 
production, $\mathrm{PKC}$ seems to have a role in regulating events that occur later in the freezing episode and they are both reasonable candidate protein kinases for controlling antioxidant enzymes during freezing.

\subsection{Hypothesis}

Key antioxidant enzymes are regulated, likely via post-translational control, over freeze-thaw cycles in tissues of $\boldsymbol{R}$. sylvatica. This control will allow for rapid changes in activity, kinetic properties, or structural stabilization of the enzymes to support fine-tuned rapid changes in antioxidant buffering capacity in response to freezing stress on the organism. The proposed mechanism underlying this is protein phosphorylation mediated by specific serine/threonine protein kinases and protein phosphatases.

To address this hypothesis, I investigated the properties and regulation of specific antioxidant enzymes involved in the detoxification of oxygen radicals and their byproducts, as listed in the following objectives:

\section{Objective 1: Detoxification of superoxide by superoxide dismutase}

Although studies have previously demonstrated increased antioxidant capacity in R. sylvatica tissues in comparison to freeze intolerant frogs, including increased overall SOD activity, it is not clear how CuZnSOD or MnSOD are independently affected. Since the mitochondria are a major site of ROS production, it would make sense that the 
activity of MnSOD would be modified in order to bolster $\mathrm{O}_{2}{ }^{-}$detoxification capacity at the main site of its production. In this regard, I expect there to be different forms of regulation governing the activities of each form of SOD that are independent and unique.

Specific Hypothesis 1: SOD will be modified in order to increase the ability of $R$. sylvatica muscle to disproportionate $\mathrm{O}_{2}{ }^{-}$molecules as they are formed, with specific attention to the mitochondrial SOD form, since $\mathrm{O}_{2}^{-}$production is most concentrated in the mitochondria.

Objective 2: Recycling of glutathione by glutathione reductase

It has been previously reported that GSH levels in $R$. sylvatica are elevated in comparison to freeze intolerant frogs, and that oxidized GSH levels remain largely unchanged across freeze-thaw episodes. This discovery suggests that glutathione recycling could possibly be elevated during freeze-thaw in order to sustain constant GSSG levels, and to provide the capacity to deal with increased GSSG formation due to rapid ROS formation experienced during freeze thaw cycles.

Specific Hypothesis 2: GR will be modified in order to increase the ability of $R$. sylvatica muscle to recycle GSH levels that are needed for detoxification of globally produced reactive oxygen species.

Objective 3: Breakdown of hydrogen peroxide by catalase 
CAT is often considered to work in conjunction with SOD to completely detoxify ROS production. In this thesis, catalase function is assumed to be linked with increases in SOD activity to act in tandem, breaking down excess $\mathrm{H}_{2} \mathrm{O}_{2}$ formed from the dismutation of $\mathrm{O}_{2}^{-}$in the mitochondria. In this regard, I predict that there will be regulation of CAT that likely parallels any changes in SOD activity.

Specific Hypothesis 3: Catalase will be modified in order to increase the ability of $R$. sylvatica muscle to breakdown high levels of $\mathrm{H}_{2} \mathrm{O}_{2}$, likely produced by an elevated production of $\mathrm{H}_{2} \mathrm{O}_{2}$ in the mitochondria due to increased SOD activity. 


\section{References}

Ahmad, S. and Pardini, R.S. (1988) Evidence for the presence of glutathione peroxidise activity towards an organic hydroperoxide in larvae of the cabbage looper moth, Trichoplusia ni. Insect Biochem. 18:861-866.

Basaga, H.S. (1990) Biochemical aspects of free radicals. Biochem Cell Biol. 68:989-998.

Brierley, J.B. (1977) Experimental hypoxic brain damage. J Clin Path. 11:181-187.

Chevion, M., Jiang, Y., Har-El, R., Berenshtein, E., Uretzky, G. and Kitrossky, N. (1993) Copper and iron are mobilised following myocardial ischemia: Possible predictive criteria for tissue injury? Proc Nat Ann Sci USA. 90:1102-1106.

Costanzo, J.P., Lee, R.E. and Lortz, P.H. (1993) Glucose concentration regulates freeze tolerance in the wood frog Rana sylvatica. J Exp Biol. 181:245-255.

Cowan, K.J. and Storey, K.B. (2001) Freeze-thaw effects on metabolic enzymes in wood frog organs. Cryobiology. 43:32-45.

Cowan, K. J. and Storey, K.B. (2003) Mitogen-activated protein kinases: new signaling pathways functioning in cellular responses to environmental stress. $J$ Exp Biol. 206:1107-1115.

Di Ilio, C., Polidoro, G., Arduini, A., Muccini, A. and Federici, G. (1983) Glutathione peroxidase, glutathione reductase, glutathione S-transferase and gamma-glutamyl transpeptidase activities in the human early pregnancy placenta. Biochem Med. 29:143-148.

Dieni, C.A. and Storey, K.B. (2008) Regulation of 5'-adenosine monophosphate deaminase in the freeze-tolerant wood frog, Rana sylvatica. BMC Biochem. 9:12.

Dieni, C.A. and Storey, K.B. (2009) Creatine kinase regulation by reversible phosphorylation in frog muscle. Comp Biochem Physiol B. 152:405-412.

Dieni, C.A. and Storey, K.B. (2010) Regulation of glucose-6-phosphate dehydrogenase by reversible phosphorylation in liver of a freeze tolerant frog. J Comp Physiol B. 180:1133-1142. 
Dorion, D., Zhong, A., Chiu, C., Forrest, C.R., Boyd, B. and Pang, C.Y. (1993) Role of xanthine oxidase in reperfusion injury of ischemic skeletal muscles in the pig and human. J Appl Physiol. 75:246-255.

Embley, M.T. and Martin, W. (2006) Eukaryotic evolution, changes and challenges. Nature. 440:623-630.

Fridovich, I. (1976) Oxygen radicals, hydrogen peroxide and oxygen toxicity. In:Free Radicals in Biology (Pryor, W.A., ed), 1:239-277. Academic Press, New York.

Gutteridge, J.M.C. and Quinlan G.J. (1983) Oxygen toxicity, oxygen radicals, transition metals and disease. J Appl Biochem. 5:293-299.

Gutteridge, J.M.C. and Halliwell, B. (1990) The measurement and mechanisms of lipid peroxidation in biological systems. Trends Biochem Sci. 15:129-135.

Grundy, J.E. and Storey, K.B. 1998. Antioxidant defenses and lipid peroxidation damage in estivating toads, Scaphiopus couchiii. J Comp Physiol B. 168:132-142.

Habig, W.H. and Jakoby, W.B. (1981) Glutathione S-transferases (rat and human). Meth Enzymol. 77:218-231.

Hermes-Lima, M. and Storey, K.B. 1993. Antioxidant defenses in the tolerance of freezing and anoxia by garter snakes. Am J Physiol. 265:R646-R652.

Hermes-Lima, M. and Storey, K.B. 1995. Antioxidant defenses and metabolic depression in a pulmonate land snail. Am J Physiol. 268:R1386-R1393.

Hermes-Lima, M. and Storey, K.B. 1998. Role of antioxidant defenses in the tolerance of severe dehydration in anurans. The case of the leopard frog Rana pipiens. Mol Cell Biochem. 189:79-89.

Hermes-Lima, M., Storey, J.M. and Storey, K.B. 1998. Antioxidant defenses and metabolic depression. The hypothesis of preparation for oxidative stress in land snails. Comp Biochem Physiol B. 120:437-448. 
Holden, C.P. and Storey, K.B. (1996) Signal transduction, second messenger, and protein kinase responses during freezing exposures in the wood frog. Am J Physiol. 271:R1205-R1211.

Hossain, M.A., Hamamoto, I., Todo, S., Maeba, T. and Tanaka, S. (1995) Comparison of warm and cold ischemia of the canine small intestine. Eur Surg Res.27:234-240.

Joanisse, D.R. and Storey, K.B. (1996) Oxidative damage and antioxidants in Rana sylvatica, the freeze tolerant wood frog. Am J Physiol. 271:R545-R553.

Korthius, R.J. and Granger, D.N. (1986) Ischemia-reperfusion injury: role of oxygenderived free radicals. In: Physiology of Oxygen Radicals (Taylor, A.E., Matalon, S and Ward, P.A., eds.) 217-249. Am Physiol Soc Bethesda, MD.

Layne, J.R., Lee, R.E. and Huang, J.L. (1990) Inoculation triggers freezing at high subzero temperatures in a freeze-tolerant frog (Rana sylvatica) and insect (Eurosta solidaginis). Can J Zool. 68:506-510.

Lee, M.R., Lee, R.E., Strong-Gunderson, J.M. and Minges, S.R. (1995) Isolation of icenucleating active bacteria from the freeze-tolerant frog, Rana sylvatica. Cryobiology. 32:358-365.

Lushchak, V.I., Bagnyukova, T.V., Lushchak, O.V., Storey, J.M. and Storey, K.B. 2005. Hypoxia and recovery perturb free radical processes and antioxidant potential in common carp (Cyprinus carpio) tissues. Int J Biochem Cell Biol. 37(6):1319-1330.

Macdonald, J.A. and Storey, K.B. (1999) Protein phosphatase responses during freezing and thawing in wood frogs: Control of liver cryoprotectant metabolism. Cryo- Lett. 20:297-306.

Maira, Di. G., Salvi, M., Arrigoni, G., Marin, O., Sarno, S., Brustolon F., Pinna L.A. and Ruzzene, M. (2005) Protein kinase CK2 phosphorylated and upregulates Akt/PKB. Cell Death Different. 12:668-677.

Mink, R.B., Dutka, A.J., Kumaroo, K.K. and Hallenbeck, J.M. (1990) No conversion of xanthine dehydrogenase to oxidase in canine cerebral ischemia. Am J Physiol. 259:H1655-H1659. 
Mullineaux, P. and Creissen, G.P. 1997. Glutathione reductase: regulation and role in oxidative stress. Oxidative stress and the molecular biology of antioxidant defences. Cold Spring Harbor Monograph Archive. 34(0).

Palcic, M.M. and Dunford, H.B. 1980. The reaction of human erythrocyte catalase with hydroperoxides to form compound I. J Biol Chem. 255(13):6128-32.

Pannunzio, T.M. and Storey, K.B. 1998. Antioxidant defenses and lipid peroxidation during anoxia stress and aerobic recovery in the marine gastropod, Littorina littorea. J Exp Mar Biol Ecol. 221:277-292. Paoletti F., Aldinucci D., Mocali A., and Caparrini A. 1986. A sensitive spectrophotometric method for the determination of superoxide dismutase activity in tissue extracts. Anal Biochem. $154(2): 536-541$.

Reiter, R.J. (1995) Oxidative process and antioxidative defense mechanisms in the aging brain. FASEB J. 9:526-533.

Rider, M.H., Hussain, N., Horman, S., Dilworth, S.M. and Storey, K.B. (2006) Stressinduced activation of the AMP-activated protein kinase in the freeze-tolerant frog Rana sylvatica. Cryobiology. 53:297-309.

Rubinsky, B., Lee, C.Y., Bastacky, J. and Onik, J. (1987) The process of freezing and the mechanism of damage during hepatic cryosurgery. Cryobiology. 27:85-97.

Salinas, A.E. and Wong, M.G. (1999) Glutathione S-transferases--a review. Curr Med Chem. 6(4):279-309.

Sies, H. (1986) Biochemistry of oxidative stress. Agnew Chem Int Ed Engl. 25:10581071.

Stirpe, F. and Della Corte, E. (1969) The regulation of rat liver xanthine oxidase. J Biol Chem. 244:3855-3863.

Storey, K.B. and Storey, J.M., (1984) Biochemical adaptation for freezing tolerance in the wood frog, Rana sylvatica. J Comp Physiol B. 155:29-36. 
Storey, K.B. and Storey, J.M. (1985) Biochemistry of freeze tolerance in terrestrial frogs. Cryo-Lett. 6:406-409.

Storey, K.B. and Storey, J.M. (1985) Triggering of cryoprotectant synthesis by the initiation of ice nucleation in the freeze tolerant frog, Rana sylvatica. $J$ Comp Physiol B. 156:191-195.

Storey, K.B. and Storey, J.M. (1986) Freeze tolerant frogs: Cryoprotectants and tissue metabolism during freeze/thaw cycles, Can J Zool. 64:49-56.

Storey, K.B. (1987) Organ-specific metabolism during freezing and thawing in a freeze tolerant frog. Am J Physiol. 253:R292-R297.

Storey, K.B. (1990) Life in a frozen state: adaptive strategies for natural freeze tolerance in amphibians and reptiles, Am J Physiol. 258:R559-R568.

Storey, K.B. (2004) Vertebrate freeze tolerance: role of freeze-responsive gene expression. In: Life in the Cold: Evolution, Mechanisms, Adaptation, and Application. 12th International Hibernation Symposium. (Barnes, B.M. and Carey, H.V., eds.) Biological Papers of the University of Alaska, \#27, Fairbanks. pp. 299306.

Vasquez, D.M. and Storey, K.B. (1993) 6-Phosphofructo-2-kinase and control of cryoprotectant synthesis in freeze tolerant frogs. Biochem Biophys Act. 1158:29-32.

Vucetic, M., Stancic, A., Otasevic, V., Jankovic, A., Korac, A., Markelic, M., Velickovic, K., Golic, I., Buzadzic, B., Storey, K.B. and Korac B. 2013. The impact of cold acclimation and hibernation on antioxidant defenses in the ground squirrel (Spermophilus citellus): an update. Free Radic Biol Med. 65:916-924.

Willmore, W.G. and Storey, K.B. 1997. Antioxidant systems and anoxia tolerance in a freshwater turtle Trachemys scripta elegans. Mol Cell Biochem. 170(1-2):177185.

Yu, B.P. (1994) Cellular defences against damage from reactive oxygen species. Physiol Rev. 74:139-162. 


\section{Chapter 2:}

Free-radical first responders: Characterization of CuZnSOD and MnSOD regulation during freezing of the freeze-tolerant North American wood frog, Rana sylvatica. 


\section{Introduction}

The wood frog withstands ischemic stress imposed on cells and tissues due to the freezing of blood plasma. The importance of antioxidant enzymes for freeze tolerance stems from the fact that ischemic events are accompanied by the buildup of ROS during, and upon exit from ischemia (Sinclair et al., 2013). Although ROS are generated in several ways, one of the most prominent sources is the electron transport system (ETS) (Yu, 1994). Typically $>95 \%$ of oxygen in cells is used by cytochrome oxidase but oxygen is also consumed by a variety of oxygenase enzymes and a small percentage also escapes the ETS in the form of ROS (Reiter, 1995). Complexes 1 (NADH-ubiquinone oxidoreductase) and III (ubiquinol-cytochrome $c$ oxidoreductase) are capable of one or two electron reductions of oxygen, and can therefore generate superoxide $\left(\mathrm{O}_{2}^{-} \cdot\right)$ and hydrogen peroxide $\left(\mathrm{H}_{2} \mathrm{O}_{2}\right)$. It is estimated that about $1-4 \%$ of consumed oxygen is converted to $\mathrm{O}_{2}{ }^{-} \cdot$ due to electron leaks from the mitochondria (Turrens et al., 1982; Konstantinov et al., 1987). $\mathrm{O}_{2}^{-} \cdot$ and $\mathrm{H}_{2} \mathrm{O}_{2}$ are also produced enzymatically by various oxidases including xanthine oxidase (XO), glucose oxidase, NADPH oxidase, and some metabolites such as catecholamines and flavins which are susceptible to auto-oxidation (Yu, 1994; Reiter, 1995). Although $\mathrm{O}_{2}{ }^{-} \cdot$ and $\mathrm{H}_{2} \mathrm{O}_{2}$ are potentially damaging to cells, they are most damaging when either $\mathrm{H}_{2} \mathrm{O}_{2}$ alone or $\mathrm{O}_{2}{ }^{-} \cdot$ and $\mathrm{H}_{2} \mathrm{O}_{2}$ are converted to form hydroxyl radicals $(\mathrm{OH})$ through catalysis by transition metals (iron, copper) in the Fenton and Haber-Weiss reactions (Basaga, 1990).

Superoxide dismutases (SOD)(E.C. 1.15.1.1) are crucial enzymes involved in the mitigation of oxidative damage by catalyzing the disproportionation of superoxide $\left(\mathrm{O}_{2}^{-} \cdot{ }^{-}\right)$ into oxygen and hydrogen peroxide. Specifically, SOD catalyzes the following reactions: 


$$
\begin{gathered}
\mathrm{M}^{+}-\mathrm{SOD}+\mathrm{O}_{2}^{-} \cdot \rightarrow \mathrm{M}-\mathrm{SOD}+\mathrm{O}_{2} \\
\mathrm{M}-\mathrm{SOD}+\mathrm{O}_{2}^{-} \cdot+2 \mathrm{H}^{+} \rightarrow \mathrm{M}^{+}-\mathrm{SOD}+\mathrm{O}_{2}+\mathrm{H}_{2} \mathrm{O}_{2} \\
\left(\text { where } \mathrm{M}=\mathrm{Cu}^{+}, \mathrm{Zn}^{+} \text {or } \mathrm{Mn}^{2+}\right)
\end{gathered}
$$

$\mathrm{O}_{2}^{-} \cdot$ is one of the main reactive oxygen species found ubiquitously across tissues and organisms. SOD enzymes play critical antioxidant roles in all cells and in every known organism. There are several forms of SOD found in nature, these unique metalloproteins are identified through their metal cofactors: 1) copper and zinc containing SOD (CuZnSOD), are typically found in the cytosol of nearly all eukaryotic cells; 2) manganese SOD (MnSOD) is found in the mitochondria or peroxisomes, or 3) nickel (NiSOD) or iron (FeSOD) containing SODs are typically found in prokaryotes, protists and select eukaryotes (Ryan et al., 2010; Bannister et al., 1987; Fridovich, 1975; Ahmad et al., 1988). Of the many forms of SOD, only CuZnSOD and MnSOD are known to exist in frogs (Schinina et al., 1989; Klein et al., 2002; Hudson et al., 2005; Purello et al., 2005). It has been suggested that the cytoplasmic form, CuZnSOD, acts like a buffer against the buildup of intracellular $\mathrm{O}_{2}^{-}$, whereas the mitochondrial form, MnSOD, plays a pivotal role in the disproportionation of $\mathrm{O}_{2} \cdot \cdot$ at the major site of production, the electron transport system (Kokoszka et al., 2001). CuZnSOD and MnSOD have been sequenced from the African clawed frog, Xenopus laevis, and exist as homodimers with a molecular weights of approximately $32 \mathrm{kDa}$ and $46 \mathrm{kDa}$, respectively (Schinina et al., 1989; Purrello et al., 2005). The CuZnSOD and MnSOD proteins bind their respective catalytic metal cofactors with only N/O-donors. For MnSODs, the active-site environments include three histidine (His) residues, one aspartate (Asp) side chain, and a $\mathrm{H} 2 \mathrm{O} / \mathrm{OH}-$ ligand, whereas the $\mathrm{Cu}$ center in CuZnSOD is ligated by three imidazole ligands, an 
imidazolate, and a water molecule (Bordo et al., 1999; Borgstahl et al., 1992; Lah et al., 1995; Tierney et al., 1995). Studies have shown the importance of functional CuZnSOD, since many disease states can be attributed to mutations in the sodl gene (Noor et al., 2002). The role of MnSOD in disease is less understood but knockout experiments involving sod2 show that oxidative stress quickly rises to lethal amounts in knockout animals (Scott et al., 2010; Li et al, 1995, Kokoszka et al., 2001, Duttaroy et al, 2003). SOD has been widely studied and characterized from traditional animal models (human, rat mouse), however, less is known about its role in aiding survival in the freeze tolerant frog. There is evidence to support the posttranslational modification of enzymes via reversible phosphorylation as a potential control mechanism for altering enzymatic activity in $R$. sylvatica in response to freezing in muscle. This includes changes in the activity and kinetic parameters of protein kinases (AMPK, PKA, PKC, PKG and MAPK) and phosphatases (PP1, PP2A and PP2C) during freezing (Holden and Storey, 1996; Rider et al., 2006; Greenway and Storey, 2000; Macdonald and Storey, 1999). In addition to changes in kinases and phosphatases, freezing-induced changes in the phosphorylation state of various metabolic enzymes have been observed including: lactate dehydrogenase (Abboud and Storey, 2013), hexokinase (Dieni and Storey, 2011), glucose-6-phosphate dehydrogenase (Dieni and Storey, 2010), creatine kinase (Dieni and Storey, 2009), and 5'-adenosine monophosphate deaminase (Dieni and Storey,2008). This chapter presents the first investigation of the potential regulation CuZnSOD and MnSOD in the leg muscle of R. sylvatica comparing control and frozen states and provides evidence for post-translational modification as the mechanism of enzyme regulation. 


\section{Materials and Methods}

\subsection{Chemicals}

All biochemicals were from BioShop (Burlington, ON, Canada) with a few exceptions; xanthine and xanthine oxidase were from Sigma (St. Louis, MO), immobilized metal ion affinity chromatography (IMAC) chelating fast flow column was from (Pharmacia, Uppsala, SE), and potassium phosphate, monobasic was from J.T. Baker Chemical Company (London, UK).

\subsection{Animals}

Male wood frogs were obtained from the Ottawa area and were washed in a tetracycline bath before being placed in plastic containers with damp sphagnum moss at $5^{\circ} \mathrm{C}$ for one week. Control frogs were sampled from this condition. For freezing exposure, frogs were placed in closed plastic boxes with damp paper toweling on the bottom, and put in an incubator set at $-3^{\circ} \mathrm{C}$. A 45 min cooling period was allowed during which body temperature of the frogs cooled to below $-0.5^{\circ} \mathrm{C}$, and nucleation triggered due to skin contact with ice crystals formed on the wet toweling. Frogs were exposed to freezing conditions for 24 hours. Control and frozen frogs were euthanized by pithing. Muscle tissues were quickly excised and flash frozen in liquid $\mathrm{N}_{2}$. All tissue samples were stored at $-80^{\circ} \mathrm{C}$ until use. The Carleton University Animal Care Committee, in accordance with the Canadian Council on Animal Care guidelines, approved all animal handling protocols used during this study. 


\subsection{Preparation of muscle tissue lysates for protein purification}

For protein purification, samples of frozen muscle tissue were homogenized 1:5 w:v in ice-cold homogenizing buffer A [20 mM potassium phosphate (KPi) buffer, $\mathrm{pH}$ 7.2, containing $15 \mathrm{mM} \beta$-glycerophosphate, $1 \mathrm{mM}$ EGTA, $1 \mathrm{mM}$ EDTA, 5\% v:v glycerol and $1 \mathrm{mM}$ phenylmethylsulfonyl fluoride (PMSF)]. Homogenates were then centrifuged at $13,500 \times g$ at $4{ }^{\circ} \mathrm{C}$ and the supernatant was collected for use in protein purification.

\subsection{Preparation of muscle tissue lysates for determination of relative protein levels}

Samples of muscle tissue were crushed under liquid nitrogen and then homogenized 1:2.5 w:v in homogenizing buffer B (20 mM HEPES, pH 7.5, $200 \mathrm{mM}$ $\mathrm{NaCl}, 0.1 \mathrm{mM}$ EDTA, $10 \mathrm{mM} \mathrm{NaF}, 1 \mathrm{mM} \mathrm{Na} \mathrm{VO}_{4}, 10 \mathrm{mM} \beta$-glycerophosphate) with a few crystals of PMSF and $1 \mu \mathrm{L} / \mathrm{mL}$ Sigma protease inhibitor cocktail (104 mM AEBSF, $80 \mu \mathrm{M}$ Aprotinin, 4 mM Bestatin, 1.4 mM E-64, 2 mM Leupeptin, 1.5 mM Pepstatin A). Samples were homogenized on ice with a Polytron PT1000 homogenizer and centrifuged at $4{ }^{\circ} \mathrm{C}$ for $15 \mathrm{~min}$ at $10,000 \times \mathrm{g}$. Soluble protein concentrations were assessed using the BioRad protein assay with bovine serum albumin (BSA) as the standard according to manufacturer's instructions. All samples were adjusted to $10 \mu \mathrm{g} / \mu \mathrm{L}$ by adding a calculated small volume of homogenizing buffer B. Aliquots of samples were then mixed 1:1 v:v with $2 \times$ SDS loading buffer (100 mM Tris-base, $4 \%$ w/v SDS, $20 \%$ v/v glycerol, $0.2 \% \mathrm{w} / \mathrm{v}$ bromophenol blue, $10 \% \mathrm{v} / \mathrm{v} 2$-mercaptoethanol). Final sample concentrations 
were $5 \mu \mathrm{g} / \mu \mathrm{L}$. Proteins were denatured by placing the tubes in boiling water for $5 \mathrm{~min}$. Samples were stored at $-80^{\circ} \mathrm{C}$ until use.

\subsection{Purification of CuZnSOD and MnSOD}

A $3 \mathrm{~mL}$ aliquot of crude supernatant was applied to a $\mathrm{DEAE}^{+}$column $(1.5 \mathrm{~cm} \times$ $20 \mathrm{~cm}$ ), previously equilibrated with $50 \mathrm{~mL}$ of homogenization buffer A. The $\mathrm{DEAE}^{+}$ column was then washed with $50 \mathrm{~mL}$ of buffer A to remove unbound protein. SOD was eluted from the $\mathrm{DEAE}^{+}$column with a linear gradient of $0-1 \mathrm{M} \mathrm{KCl}$ in homogenization buffer A. Fractions of $1.24 \mathrm{~mL}$ were collected and $5 \mu \mathrm{L}$ from each fraction was assayed to detect SOD activity (see kinetic assays section below for methodology). The fractions of peak SOD activity were pooled and applied to Sephadex G-50 gel buffer exchange columns equilibrated with buffer C (20 mM KPi buffer, $\mathrm{pH} 7.2$ containing $15 \mathrm{mM} \beta$ glycerophosphate, 5\% v:v glycerol). A $5 \mathrm{~cm}$ column of Sephadex G-50 in a syringe barrel was equilibrated in buffer $\mathrm{C}$ and centrifuged at $500 \times \mathrm{g}$ in a bench-top centrifuge for 2 min to remove excess buffer. Then a $500 \mu \mathrm{L}$ aliquot of SOD eluant was applied to each buffer exchange column and centrifuged again. The resulting eluant was collected and applied to an IMAC column pre-charged with $1 \mathrm{mg} / \mathrm{mL} \mathrm{CuSO}_{4} \cdot \mathrm{H}_{2} \mathrm{O}(1.5 \mathrm{~cm} \times 10 \mathrm{~cm})$, equilibrated in homogenization buffer $\mathrm{C}$. The copper chelate affinity column was then washed with $50 \mathrm{~mL}$ of homogenization buffer $\mathrm{C}$ to remove unbound protein. Bound proteins were eluted with a linear gradient of $0-1 \mathrm{M} \mathrm{KCl}$ in homogenization buffer $\mathrm{A}$. Fractions of $1.24 \mathrm{~mL}$ were collected and $10 \mu \mathrm{L}$ from each fraction was assayed to detect SOD activity. Fractions containing the highest SOD activity from the copper chelate 
affinity column were pooled and used for further study. The purity of SOD was determined by combining samples with equal volume of $2 \times$ SDS loading buffer, boiling for $5 \mathrm{~min}$, and then running $20 \mu \mathrm{L}$ of sample purified from each successive purification on SDS-PAGE (see below gel electrophoresis and Western Blotting section). Protein banding was visualized with Coomassie blue.

\subsection{Kinetic assays}

SOD activity was assayed based on the generation of superoxide radicals formed by xanthine and xanthine oxidase: $100 \mathrm{mM} \mathrm{KPi}$ buffer (pH 7.4), $1 \mathrm{mM}$ xanthine, $2 \mathrm{U}$ xanthine oxidase, $2 \mathrm{mM}$ nitrotetrazolium blue (NBT). This assay mixture generates $\mathrm{O}_{2}{ }^{-}$, which oxidizes NBT to form formazan dye. SOD (contained within the tissue homogenate supernatant) inhibits the oxidation of NBT by catalyzing the dismutation of $\mathrm{O}_{2}{ }^{-} \cdot$ generated in the xanthine oxidase reaction. One unit of enzyme activity is the amount of SOD that inhibits the reduction of nitrotetrazolium blue by $50 \%$ at $25^{\circ} \mathrm{C}$. The formation of formazan was measured at $545 \mathrm{~nm}$ in a Thermo Labsystems Multiskan spectrophotometer (Thermo Scientific, Waltham, MA, USA). Data were analyzed using the Kinetics v.3.5.1 program (Brooks 1992).

\section{7. $\quad$ Gel electrophoresis and Western blotting}

Protein separation was achieved by running samples on $12 \%$ (samples from protein purification steps) or 15\% (samples from protein stability assays or from tissue lysates) SDS-PAGE gels. Sample aliquots were loaded onto polyacrylamide gels together 
with pre-stained molecular weight standards (FroggaBio; Cat\# PM005-0500) and separated using a discontinuous buffer system. Electrophoresis was carried out at $185 \mathrm{~V}$ for 45 min using the BioRad Mini-Protean 3 system with 1x Tris-glycine running buffer. Proteins on the gel were then electroblotted onto polyvinylidene difluoride (PVDF) membrane (Millipore, Bedford, MA) using a BioRad mini Trans-Blot cell. The transfer was carried out at $160 \mathrm{~mA}$ for $1.5 \mathrm{~h}$. Following the transfer, membranes were washed in TBST (10 mM Tris, $\mathrm{pH} 7.5,150 \mathrm{mM} \mathrm{NaCl}, 0.05 \% \mathrm{v} / \mathrm{v}$ Tween-20) for $3 \times 5 \mathrm{~min}$. The membranes were blocked using $2.5 \%$ skim milk in TBST for 30 min. After blocking, the membranes were probed with primary antibody diluted 1:1000 v:v for SOD1 or 1:2000 $\mathrm{v}: \mathrm{v}$ for SOD2 in TBST for $3 \mathrm{~h}$ at room temperature (RT). Primary antibodies were rabbit anti-SOD1 (GenScript, A01005) and rabbit anti-SOD2 (Stress Marq BioSciences, SPC118C). The membranes were washed $3 \times 5$ min with TBST at RT and probed with goat anti-rabbit-peroxidase secondary antibody for $30 \mathrm{~min}$. Membranes were washed again 3 $\times 5$ min in TBST at RT and were then developed using enhanced chemiluminescence. Sod1 and $\operatorname{sod} 2$ antibodies cross-reacted with bands corresponding to molecular weights of $\sim 15 \mathrm{kDa}$ and $\sim 26 \mathrm{kDa}$, respectively. Blots were developed with enhanced chemiluminescence reagents. Images were captured using a ChemiGenius Bio-Imaging system with GeneSnap software and densitometry analysis performed using GeneTools software (Syngene, Frederick, MD). The intensity of the immunoreactive bands were standardized against a group of at least 3 bands, not located close to the band of interest, in the corresponding Coomassie blue stained membrane. The intensity of the immunoreactive bands from control muscle tissue was set to a reference value of 1 to 
which the intensity of standardized immunoreactive bands from frozen muscle tissue was expressed as a fold change.

\subsection{Determination of protein stability}

Frog muscle tissue was homogenized as previously described in section 2.2, without the use of PMSF. To assess the possibility of structural/conformational changes in MnSOD or CuZnSOD between the control and $24 \mathrm{~h}$ frozen conditions, the susceptibility of both forms of SOD to denaturation by urea (0-7 M) was evaluated. Four separate preparations of crude muscle extracts were incubated with different concentrations of urea for $24 \mathrm{~h}$ at $4^{\circ} \mathrm{C}$ in buffer A without the addition of PMSF. After incubation, each sample was subjected to pulse proteolysis as outlined by Park and Marqusee (2005) to cleave unfolded, denatured enzyme. To do this, thermolysin (0.40 $\mathrm{mg} / \mathrm{mL}$ in $50 \mathrm{mM}$ Tris, $\mathrm{pH} 8.0,2.5 \mathrm{M} \mathrm{NaCl}, 10 \mathrm{mM} \mathrm{CaCl}_{2}$ ) was added to initiate proteolysis. Various incubation times with thermolysin were explored to discover the optimum amount of digestion time required, resulting in the use of a 30 min incubation optimum. Following a $30 \mathrm{~min}$ pulse reaction time at $4^{\circ} \mathrm{C}$, the reaction was quenched by mixing samples 1:1 v:v with 6x SDS loading buffer (375 mM Tris buffer, $\mathrm{pH} 6.8,9 \%$ w/v SDS, $50 \% \mathrm{v} / \mathrm{v}$ glycerol, $0.03 \% \mathrm{w} / \mathrm{v}$ bromophenol blue, $10 \% \mathrm{v} / \mathrm{v} 2$-mercapotethanol) and subsequently boiled for 5 minutes and stored at $-20^{\circ} \mathrm{C}$ until used. Western blotting was then performed as above and MnSOD and CuZnSOD band intensities were quantified to reveal the amount of undigested enzyme remaining. From this, $\mathrm{C}_{\mathrm{m}}$ values were calculated, representing the amount of urea that reduced the amount of folded 
protein by one-half.

\subsection{ProQ Diamond Phosphoprotein Staining}

Enzyme extracts from both control and frozen frog muscle for MnSOD and CuZnSOD were purified as described in section 2.4. The top three fractions based on activity were pooled, and protein levels in the pooled fractions were quantified using the Coomassie blue dye-binding method. Aliquots of the pooled fractions were then mixed 1:1 v:v with SDS loading buffer (100 mM Tris buffer, $\mathrm{pH} 6.8,4 \% \mathrm{w} / \mathrm{v}$ SDS, $20 \% \mathrm{v} / \mathrm{v}$ glycerol, $0.2 \% \mathrm{w} / \mathrm{v}$ bromophenol blue, $10 \% \mathrm{v} / \mathrm{v} 2$-mercapotethanol) and subsequently boiled for 5 minutes and stored at $-20^{\circ} \mathrm{C}$ until used.

Equal volumes of each sample were loaded on a $12 \%$ SDS-PAGE gel. The gel was run at $185 \mathrm{~V}$ for $45 \mathrm{~min}$ in running buffer ( $0.5 \mathrm{M}$ Tris, $5 \mathrm{M}$ glycine, $0.5 \% \mathrm{w} / \mathrm{v} \mathrm{SDS}$ ). The gel was removed and washed in fixing solution $(50 \% \mathrm{v} / \mathrm{v}$ methanol, $10 \% \mathrm{v} / \mathrm{v}$ acetic acid) twice for $10 \mathrm{~min}$, then left in fixing solution overnight at $4^{\circ} \mathrm{C}$ followed by 3 washes with $\mathrm{ddH}_{2} \mathrm{O}$ for $10 \mathrm{~min}$. The gel was then stained with ProQ Diamond Phosphoprotein stain (Invitrogen, Eugene, OR) for 90 min and washed 3 times with $\mathrm{ddH}_{2} \mathrm{O}$ for $10 \mathrm{~min}$. The gel was covered during staining (and for the remainder of the protocol) with aluminum foil to prevent the photosensitive stain from interacting with light. To minimize non-specific background, the gel was washed in ProQ Diamond destaining solution $(20 \% \mathrm{v} / \mathrm{v}$ acetonitrile, $50 \mathrm{mM}$ sodium acetate, $\mathrm{pH} 4)$ for $45 \mathrm{~min}$, and washed 3 times in $\mathrm{ddH}_{2} \mathrm{O}$ for $10 \mathrm{~min}$. Bands on the gel were then visualized and quantified using the Chemi-Genius. 


\subsection{Dot blotting}

The phosphorylation of MnSOD was further assessed by applying equal amounts of purified enzyme from the muscle of control and frozen frogs onto nitrocellulose membranes (Bio-Rad, Hercules, CA, USA) using a Bio-Dot micro-filtration apparatus (Bio-Rad, Hercules, CA, USA), as previously described (Dawson et al., 2013). Primary antibodies (diluted 1:1000 v:v) were then applied to different wells and membranes were allowed to incubate overnight at $4^{\circ} \mathrm{C}$ with gentle rocking. Primary antibodies used were: (1) rabbit anti-phosphoserine (Cat \#618100, Invitrogen, Carlsbad, CA, USA); (2) rabbit anti-phosphothreonine (Cat. \# 718200, Invitrogen, Carlsbad, CA, USA); or (3) rabbit anti-phosphotyrosine (Cat \# 615800, Invitrogen, Carlsbad, CA, USA).

\subsection{RNA isolation}

Total RNA from frog muscle tissues was extracted using Trizol $^{\mathrm{TM}}$ reagent (Invitrogen) according to manufacturer's instructions and as described previously (Katzenback et al., 2014). The RNA concentration of each sample was determined on a GeneQuant Pro spectrophotometer (Pharmacia, Markham, Ontario, Canada) at $260 \mathrm{~nm}$. RNA purity was assessed using a ratio of absorbance at 260/280 nm, while RNA quality was examined by observing the integrity of $18 \mathrm{~S}$ and $28 \mathrm{~S}$ ribosomal RNA (rRNA) bands on a native agarose gel following electrophoresis with SYBR green staining. Total RNA was isolated from the muscle of 4-5 control frogs and 4-5 frozen frogs for use in cDNA synthesis. 


\subsection{2. cDNA synthesis}

Five $\mu \mathrm{g}$ of total RNA in a volume of $10 \mu \mathrm{L}$ was used for first strand cDNA synthesis. One $\mu 1$ of oligo-dT (200 ng/ $\mu \mathrm{L}$; 5'-TTTTTTTTTTTTTTTTTTTTTV-3'; V = A or G or C) (Sigma Genosys) was added to each sample before samples were incubated at $65^{\circ} \mathrm{C}$ for $5 \mathrm{~min}$ in a thermocycler (Mastercycler Eppendorf) and then chilled on ice for 5 min. Four $\mu \mathrm{L}$ of $5 \times$ first strand buffer (Invitrogen), $2 \mu \mathrm{L} 100 \mathrm{mM}$ DTT (Invitrogen), 1 $\mu \mathrm{L} 10 \mathrm{mmol} / \mathrm{L}$ dNTPs (Bio Basic), and $1 \mu \mathrm{L}$ Superscript II reverse transcriptase (Invitrogen) were added to each reaction and further incubated at $42^{\circ} \mathrm{C}$ for $45 \mathrm{~min}$ in an Eppendorf thermocycler (Mississauga, Ontario, Canada). Synthesized cDNA samples were stored at $-20^{\circ} \mathrm{C}$ until use.

\subsection{RT-PCR}

Synthesized cDNA samples were checked for potential genomic contamination using the $\alpha$-tubulin primer set that was designed to span an intron. All cDNA samples were negative for genomic contamination. For gene expression studies, serial dilutions of cDNA $\left(10^{-1}\right.$ and $\left.10^{-2}\right)$ were made to identify the dilution that produced non-saturating yet visible bands for the gene of interest following PCR amplification for quantification purposes. The primer sequences for target genes were (1) sod 1 sense 5'tgaaggcvgtgtgtgtghtgaaggga-3', antisense 5'-ccaatnacdccacaagccaracg-3', (2) sod2 sense 5'-ctggacaaacctctctccta-3', antisense 5'-cttgtaagcggttagattctttg-3', and (3) $\alpha$-tubulin sense 5'-aaggaagatgctgccaataa-3', antisense 5'-ggtcacatttcaccatctg-3'. 
PCR reactions consisted of $5 \mu \mathrm{L}$ of diluted cDNA, $15 \mu \mathrm{L}$ of DEPC treated water, $1.25 \mu \mathrm{L}$ of primer mixture $(0.03 \mathrm{nmol} / \mu \mathrm{L}), 0.75 \mu \mathrm{L}$ of $10 \times$ PCR buffer (Invitrogen), 1.5 $\mu \mathrm{L}$ of $50 \mathrm{mmol} / \mathrm{L} \mathrm{MgCl}_{2}, 0.5 \mu \mathrm{L}$ of $10 \mathrm{mmol} / \mathrm{L} \mathrm{dNTPs}$, and $1 \mu \mathrm{L}$ of Taq polymerase. Thermocycling conditions were: (1) $10 \mathrm{~min}$ at $94^{\circ} \mathrm{C}, 20$ cycles of $94^{\circ} \mathrm{C}$ for $30 \mathrm{~s}, 56^{\circ} \mathrm{C}$ for $30 \mathrm{~s}, 72^{\circ} \mathrm{C}$ for $45 \mathrm{~s}$ for sodl, (2) $10 \mathrm{~min}$ at $94^{\circ} \mathrm{C}, 24$ cycles of $94^{\circ} \mathrm{C}$ for $30 \mathrm{~s}, 62^{\circ} \mathrm{C}$ for $30 \mathrm{~s}$, $72^{\circ} \mathrm{C}$ for $45 \mathrm{~s}$ for $\operatorname{sod} 2$, or (3) $10 \mathrm{~min}$ at $94^{\circ} \mathrm{C}, 22$ cycles of $94^{\circ} \mathrm{C}$ for $30 \mathrm{~s}, 53.2^{\circ} \mathrm{C}$ for $30 \mathrm{~s}$, $72^{\circ} \mathrm{C}$ for $45 \mathrm{~s}$ for a-tubulin. All thermocycling protocols included a final elongation of $72^{\circ} \mathrm{C}$ for $7 \mathrm{~min}$. Following amplification, $3 \mu \mathrm{L}$ of DNA loading dye $\left(1 \mu \mathrm{L} 2 \mathrm{x} \mathrm{SYBR}^{\circledR}\right.$ Green I nucleic acid gel stain (Invitrogen) $+2 \mu \mathrm{L}$ of loading buffer $(0.25 \%$ bromophenol blue, $0.25 \%$ xylene cyanol $\mathrm{FF}$, and $40 \%$ sucrose in $\mathrm{ddH}_{2} \mathrm{O}$ ) was added to each PCR reaction. A $14 \mu \mathrm{L}$ aliquot of each sample was loaded into $1.5 \%$ ( $\alpha$-tubulin and sodl) or $2.0 \%(\operatorname{sod} 2)$ agarose gels and electrophoresed in $1 \times \mathrm{TAE}$ buffer $(2 \mathrm{~mol} / \mathrm{L}$ Tris base, 1.1 $\mathrm{mL}$ acetic acid/L, $1 \mathrm{mmol} / \mathrm{L}$ EDTA, $\mathrm{pH} 8.5$ ) for 25-30 min. PCR-amplified products were visualized using the Chemi-Genius BioImaging system. The intensity of the $\operatorname{sod} 1$ or $\operatorname{sod} 2$ PCR products were expressed as a ratio against the corresponding band intensities of $\alpha$ tubulin amplified from the same cDNA sample to correct for any minor variations in sample loading. The ratio of target gene to the reference gene (a-tubulin) from the muscle of control frogs was set to a reference value of 1 , to which the relative mRNA levels of the target gene in the muscle of frozen frogs was expressed as a fold change. Each data bar represents the means \pm s.e.m. derived from $n=4-5$ different animals per group.

The PCR products were isolated from gel slices using the freeze/squeeze method and sequenced at Bio Basic (Markham, ON, Canada) as previously described 
(Katzenback et al., 2014). Sequence identities were confirmed by sequence comparison in BLASTn.

\subsection{Statistical analysis}

Comparison of enzyme kinetics, relative protein and mRNA levels were performed using a Student's t test, two-tailed, assuming unequal variances. A probability of $\mathrm{P}<0.05$ was considered significant.

\section{Results}

\subsection{Purification of CuZnSOD and MnSOD from the muscle of control and frozen} frogs

The purification schemes used for wood frog muscle CuZnSOD and MnSOD are shown in Table 2.1 and Table 2.2, respectively. The procedure used ion exchange chromatography on DEAE Sephadex (Figure 2.1A), a buffer exchange step to remove EDTA/EGTA, and copper chelate affinity chromatography. The buffer exchange step was crucial to this purification procedure, since the EGTA and EDTA that were in homogenization buffer A caused the copper to dissociate from the copper chelate column. CuZnSOD eluted from the copper chelate affinity column at approximately $200 \mathrm{mM} \mathrm{KCl}$ whereas MnSOD eluted at approximately $400 \mathrm{mM} \mathrm{KCl}$ (Figure 2.1B). Frog muscle CuZnSOD was purified 209 fold with an overall yield of activity of $10.8 \%$ (Table 2.1). The final specific activity of CuZnSOD was $1385 \mathrm{mU} / \mathrm{mg}$ protein (Table 2.1). Frog 
muscle MnSOD was purified 234 fold with an overall yield of activity of 20.1\% (Table 2.2). The final specific activity of MnSOD was $1550.69 \mathrm{mU} / \mathrm{mg}$ protein (Table 2.2).The success of the purification process was assessed using SDS-PAGE gel stained with Coomassie blue staining in conjunction with western blotting. This showed that both CuZnSOD and MnSOD enzymes were purified to near homogeneity as there was one band corresponding to correct molecular weight of $\sim 15 \mathrm{kDa}$ for CuZnSOD and $\sim 26 \mathrm{kDa}$ for MnSOD (Figure 2.3).

\subsection{Kinetic characterization of $\mathrm{CuZnSOD}$ and MnSOD}

Kinetic parameters of purified muscle SOD were assessed to determine if the enzyme's properties differed between control and frozen animals. For both CuZnSOD and MnSOD, kinetic parameters changed during freezing in comparison to the control enzyme $(\mathrm{p}<0.05)$ (Table 2.3). The frozen form of MnSOD had an apparent $\mathrm{K}_{\mathrm{m}}$ for $\mathrm{O}_{2}{ }^{-}$. that was $34 \%$ lower than the control enzyme. In the case of CuZnSOD, however, there was no significant change in the apparent $\mathrm{K}_{\mathrm{m}}$ of $\mathrm{O}_{2}{ }^{-} \cdot$ between control and frozen groups. The $\mathrm{V}_{\max }$ did not change significantly for MnSOD in frozen muscle in comparison to control muscle tissue; however, there was a significant 1.52 fold increase in the $V_{\max }$ for CuZnSOD during freezing.

\section{3. mRNA levels of sod 1 and $\operatorname{sod} 2$}

Using homology based primers, partial sequences for $\operatorname{sod} 1$ and $\operatorname{sod} 2$ in $R$. sylvatica were obtained. The partial sequences of $R$. sylvatica sod 1 and $\operatorname{sod} 2$ were 
submitted to NCBI Genbank, accession numbers KJ847420 and KJ87421, respectively. The $R$. sylvatica sodl partial open reading frame was $392 \mathrm{bp}$, corresponding to 130 amino acids (representing $84.4 \%$ of the 154 aa of human CuZnSOD, $86.6 \%$ of 150 aa of Rana catesbeiana CuZnSOD, $86.1 \%$ of 151 aa of X. tropicalis CuZnSOD, or $86.1 \%$ of 151 aa of X. laevis CuZnSOD), as predicted by the Translate Tool (ExPASy, http://web.expasy.org/translate/). The 130 aa obtained for $R$. sylvatica $\mathrm{CuZnSOD}$ correspond with aa 3-134 of human CuZnSOD. R. sylvatica sod2 partial open reading frame was $393 \mathrm{bp}$, corresponding to 130 amino acids (representing $58.6 \%$ of 222 aa of human MnSOD, 58.0\% of 224 aa of X. tropicalis MnSOD, or 58.0\% of 224 aa of $X$. laevis MnSOD), as predicted by the Translate Tool (ExPASy, http://web.expasy.org/translate/). The 130 aa obtained for R. sylvatica MnSOD correspond with aa 61-190 of human MnSOD.

A blastp search of the partial R. sylvatica CuZnSOD predicted protein sequence against the NCBI database showed the sequence to have $94 \%$ identity to Rana catesbeiana CuZnSOD (Genbank accession number AC051906) and 69\% identity to Xenopus tropicalis CuZnSOD (Genbank accession number XP_007247311). Similarly, a blastp search of the partial R. sylvatica MnSOD predicted protein sequence showed the highest similarity to X. tropicalis MnSOD (Genbank accession number NP_001005694) with $90 \%$ identity.

Primers were designed based on the R. sylvatica sodl and soda sequences for use in relative quantitation of mRNA levels in the muscle of control and frozen frogs. Alphatubulin was amplified from the same samples as an endogenous control. Transcript levels 
of sodl or sodl in the muscle of $24 \mathrm{~h}$ frozen frogs were not significantly different from those in the muscle of control frogs (Fig. 4A, $p>0.05$ ).

\subsection{Relative protein levels of $\mathrm{CuZnSOD}$ and $\mathrm{MnSOD}$}

Western blotting was used to evaluate the relative amount of CuZnSOD and MnSOD protein in muscle from control versus frozen frogs. The antibodies for CuZnSOD or MnSOD each cross-reacted with one band corresponding to the known molecular weights of $\sim 15 \mathrm{kDa}$ and $\sim 26 \mathrm{kDa}$, for CuZnSOD and MnSOD, respectively (Figure 2.3). No significant differences were detected between the protein levels in muscle of control versus frozen frogs for either CuZnSOD or MnSOD (Figure 2.4B).

\subsection{Post-translational modification of $C u Z n S O D$ and $M n S O D$}

To test whether or not reversible phosphorylation was the mechanism by which SOD kinetic parameters changed during anoxia, the top activity fractions from the purification profiles for the control and frozen forms of CuZnSOD or MnSOD were combined, run on an SDS-PAGE gel, and stained with ProQ Diamond phosphoprotein stain. CuZnSOD did not react with the ProQ Diamond phosphoprotein stain, resulting in no apparent banding (data not shown). MnSOD was easily identified as a strong band found at $\sim 23 \mathrm{kDa}$. When band densities were quantified, they showed a 2.87 fold higher band intensity $(\mathrm{p}<0.05)$ for MnSOD from muscle of frozen frogs when compared to the enzyme from control frogs (Figure 2.5). 
Immunoblotting using a dot blot apparatus was used to assess the possible differences in the amino acid-specific phosphorylation of muscle MnSOD between control and frozen states. Phosphorylation of serine residues of MnSOD from frozen frogs was $2.37 \pm 0.37$ fold higher compared to control SOD $(1 \pm 0.14, \mathrm{P}<0.05$; Figure 2.5). Phosphorylation via tyrosine residues of frozen SOD was $1.27 \pm 0.05$ fold higher compared to control MnSOD $(1 \pm 0.06, \mathrm{P}<0.05$; Figure 2.5$)$. The phosphorylation levels of threonine residues between control MnSOD and frozen MnSOD did not differ ( $\mathrm{P}>$ 0.05; Figure 2.5).

\subsection{Scansite Prediction of Phosphosites}

The Scansite application from the Massachusetts Institute of Technology (http:// scansite.mit.edu/) was used to analyze the obtained partial protein sequences for CuZnSOD and MnSOD for putative phosphorylation sites. Putative consensus sequences for phosphorylation sites of Erk1 kinase (threonine) and protein kinase C delta (PKC delta) (serine) were predicted for CuZnSOD (Figure 2.6A, 2.6B). Putative consensus sequences for phosphorylation sites of Akt kinase (threonine), calmodulin dependent kinase 2 (threonine), casein kinase 1 (serine), Erk1 kinase (serine), PKC alpha (serine), PKC beta (serine), PKC gamma (serine), PKC delta (serine, threonine), PKC epsilon (serine, threonine), PKC zeta (serine), and PKC mu (serine, threonine) were predicted for MnSOD (Figure 2.6C, 2.6D).

Human CuZnSOD was analyzed for comparison using Scansite, resulting in the following putative consensus sequences for phosphorylation sites: casein kinase 1 
(threonine), PKC alpha (serine), PKC beta (serine), PKC gamma (serine), and PKC mu (serine). Human MnSOD was also analyzed using Scansite, the following putative consensus sequences for phosphorylation sites were obtained: AMP kinase (serine), calmodulin dependent kinase 2 (serine), casein kinase 1 (serine), Erk1 kinase (serine), Cdk2 kinase (serine), Cdk5 kinase (serine) PKC alpha (serine, threonine), PKC beta (serine, threonine), PKC gamma (serine, threonine), PKC delta (serine, threonine), PKC epsilon (threonine), and PKC zeta (serine). In all cases, except for casein kinase 1 for CuZnSOD, the obtained sequences for $R$. sylvatica encompassed the predicted putative phosphorylation sites for both CuZnSOD and MnSOD in humans.

\subsection{Structural stability of CuZnSOD and MnSOD}

The structural stability of CuZnSOD and MnSOD was evaluated by testing enzyme sensitivity to urea denaturation. This was evaluated by incubating muscle extracts from both control and frozen frogs for $24 \mathrm{~h}$ at $\sim 4^{\circ} \mathrm{C}$ in the presence of $0-7 \mathrm{M}$ urea. Urea-denatured protein was then catabolized by 30 min proteolysis with thermolysis and then the remaining amount of native protein was assessed by Western blotting. The calculated $\mathrm{C}_{\mathrm{m}}$ value (concentration of urea that results in a $50 \%$ loss of folded enzyme) was $0.72 \mathrm{M}$ for CuZnSOD from muscle of frozen frogs, which was not significantly different than the value of $0.62 \mathrm{M}$ for $\mathrm{CuZnSOD}$ in control muscle extracts (Table 2.3; Figure 2.7). The calculated $\mathrm{C}_{\mathrm{m}}$ value was $2.53 \mathrm{M}$ for MnSOD from frozen frog muscle extracts, which was not significantly different than the value of $2.92 \mathrm{M}$ for MnSOD in control muscle extracts (Table 2.3; Figure 2.8). 


\section{Discussion}

SOD is ubiquitous among living organisms, from prokaryotes to eukaryotes, and protects organisms from superoxide radicals that can oxidize and damage cellular macromolecules (Fridovich, 1995; McCord, 1995; Iqbal et al., 1989). Diverse human disease states are associated with abnormalities in the structure, function or levels of SOD including: several forms of anemia, thalassemia, molecular dystrophy and cystic fibrosis; dengue fever; lateral sclerosis; rheumatoid arthritis; ischemic injury; Parkinson's disease; Alzheimer's disease and cancer (Panchencko et al., 1979; Mavelli et al., 1984; Mizuno, 1984; Ratovski et al., 1996; Concetti et al., 1976; Ray et al., 1984; Gonzales et al., 1999; Stieber et al., 2000; Famulari et al., 1990; Zemlan et al., 2000; Rhodin et al., 2000). Given the importance of SOD function for the survival and quality of life in humans, as well as other organisms, there is great interest in characterizing unique forms SOD, as well as the elucidation of SOD regulation under conditions that mimic disease-like states. Many of the diseases mentioned above have in common fluctuations in oxygen levels or a reduction in blood flow. To identify the importance of SOD action in both normal and disease states, various experimental approaches have been used such as knockout experiments (Scott et al., 2010; Li et al, 1995; Kokoszka et al., 2001). These have had varying success; for example, MnSOD knockout experiments with animals are uniformly lethal, making it difficult to assess the actual role of MnSOD in the disease state (Melov et al., 1999; Kokoszka et al., 2000). Another way to better understand the role of SOD in disease, specifically the role of MnSOD, is to characterize the behavior and properties of CuZnSOD and MnSOD from animals that can withstand extreme conditions such as oxygen limitation, reduced blood flow, dehydration and ischemia. Studies examining the 
characteristics of SOD regulation in different situations of environmental stress have included: the red eared slider (Trachemys scripta elegans) which shows decrease in SOD activity in the liver and brain during anoxia (Willmore and Storey, 1997), the leopard frog (Rana pipiens) which shows a reduction in SOD activity in muscle tissue during severe dehydration (Hermes-Lima and Storey, 1998), the ground squirrel (Spermophilus citellus) which show a reduction in CuZnSOD expression in white adipose tissue during hibernation (Vucetic et al., 2013), the African clawed frog (X. laevis) which shows MnSOD protein and transcript levels rose in the liver during estivation, the common carp (Cyprinus carpio) which shows increases in SOD activity in kidney and skeletal muscle during hypoxia (Lushchak et al., 2005), the garter snake (Thamnophis sirtalis parietalis) which shows an increase in SOD activity during freezing (Hermes-Lima and Storey, 1993), the spadefoot toad (Scaphiopus couchii) where SOD activity decreased upon exit from estivation (Grundy and Storey, 1998), the marine periwinkle (Littorina littorea) where SOD activity decreased in the hepatopancreas as well as foot muscle during anoxia (Pannunzio and Storey, 1998), and the land snail (Otala lactea) where SOD activity rose in hepatopancreas and foot muscle during estivation (Hermes-Lima and Storey, 1995). In the case of freeze-tolerance, ischemic stress is imposed on the cells of $R$. sylvatica (Storey and Storey, 1986). The link between free radical production in disease-induced and naturally occurring ischemic events has been widely characterized, from oxidative stress experienced during the ischemic episode, to the burst production of ROS upon reoxygenation during reperfusion (Ferrari et al., 1991; Simpson and Lucchesi, 1987; Zweier and Talukder, 2006). It is clear from these studies that SOD plays a unique role in animal ability to overcome stressful conditions, and the data presented in this chapter not 
only agree with this, but suggest another level of complexity in the mitigation of free radical damage sustained by overwintering frogs.

\subsection{Kinetic changes of CuZnSOD and MnSOD during freezing}

The kinetic properties of wood frog skeletal muscle SODs changed significantly between control and frozen conditions, indicating possible regulation during freezing. Past studies have shown a potential decrease in total SOD activity in muscle, kidney and heart of $R$. sylvatica during freezing, but those experiments used the method of Paoletti et al. (1986) which measures SOD activity using the reduction of NADH (Joanisse and Storey, 1996). That method of measuring total SOD activity has been shown to elicit different activity profiles than the NBT reduction method used in this experiment (Paoletti et al., 1986). The use of NADH as a reporter molecule could well be associated with a high degree of background activity due to the presence of many NADH utilizing enzymes found endogenously in tissues. In the present study, $\mathrm{CuZn}$ and Mn SODs were explored independently and in a purified state, CuZnSOD exhibited a 1.52 fold higher maximal activity in the muscle of frozen frogs in comparison to control frogs, whereas MnSOD showed no change in maximal activity during freezing. An increased CuZnSOD activity could allow for increased cytoplasmic superoxide scavenging potential during freezing, as well as during reperfusion.

The apparent $\mathrm{K}_{\mathrm{m}}$ for $\mathrm{O}_{2}^{-} \cdot$ of CuZnSOD did not change significantly between control and frozen states (Table 2.3). However, in the case of MnSOD, the apparent $\mathrm{K}_{\mathrm{m}}$ decreased from $0.201 \mathrm{mM}$ under control conditions to $0.133 \mathrm{mM}$ during frozen 
conditions. This reduction in the apparent $\mathrm{K}_{\mathrm{m}}$ of $\mathrm{O}_{2}{ }^{-} \cdot$ would suggest that MnSOD has a higher affinity for $\mathrm{O}_{2}^{-} \cdot$ during freezing. An increase in affinity for superoxide would increase the scavenging ability of MnSOD, and increase the protection against the formation of superoxide at a major site of production, the mitochondria. Since superoxide is a charged molecule, it is not thought to be membrane permeable (Florian et al., 2004; Mao and Poznansky, 1992). Therefore, an increase in mitochondrial production of superoxide could lead to a compromised mitochondrial membrane, and ultimately the destruction of the cell due to oxidative damage. Mitochondrial superoxide production has been shown to trigger apoptosis, while cytosolic production of $\mathrm{O}_{2}{ }^{-} \cdot$ has been linked to many cell signaling events (Thannickal and Fanburg, 2000). This would suggest that $\mathrm{CuZnSOD}$ is more likely to have a role in regulating cell signaling events, whereas MnSOD is more likely to have a role in keeping $\mathrm{O}_{2}^{-} \cdot$ levels in the mitochondria low, staving off apoptotic cell death. This is of special interest to wood frogs since the muscle tissue thaws later than internal organs such as the heart or liver (Rubinsky et al., 1994). Since muscle thaws last in $R$. sylvatica, during the spring thaw, rapid and successful disproportionation of $\mathrm{O}_{2}{ }^{-} \cdot$ would aid a rapid recovery of muscle functionality. Improved affinity for $\mathrm{O}_{2}{ }^{-}$by MnSOD in the frozen frog may aid the peripheral tissue during thawing, allowing for reintroduction of re-oxygenated blood into the tissue without sustaining a buildup of oxidative stress. 


\subsection{Regulation of CuZnSOD and MnSOD transcript and protein levels during freezing}

The CuZnSOD sequence discovered in this study showed $62 \%$ amino acid identity when compared to human MnSOD (accession number NP_000445) at 90\% coverage whereas wood frog MnSOD showed $84 \%$ amino acid identity as compared to human (accession number NP_000627) at 99\% coverage. Frog transcript and protein levels did not change significantly between control and $24 \mathrm{~h}$ frozen frog muscle for either $\mathrm{CuZnSOD}$ or MnSOD. This is important as it highlights the probable importance of kinetic modification of both forms of SOD during freezing as the means of adjusting SOD functionality. Since protein amounts do not change, the $\mathrm{V}_{\max }$ difference for CuZnSOD from control versus frozen frogs cannot be attributed to an enhanced amount of $\mathrm{CuZnSOD}$ in the frozen state, and therefore, is likely due to a true functional difference in enzyme activity. Since MnSOD maximal activity did not change significantly during freezing, this result simply highlights the importance of the decreased $\mathrm{K}_{\mathrm{m}}$ for $\mathrm{O}_{2}{ }^{-}$. During periods of stress, like freezing, it is too energetically costly to increase the amounts of enzymes present and it is more energetically favourable to modify the existing enzyme to achieve a more active state (Storey and Storey, 1984; Storey and Storey, 2004; Storey, 2004). Since there were no significant changes in the transcript levels for either CuZnSOD or MnSOD, it would appear that an increase in production of new SOD molecules either during freezing, or immediately following freezing is unlikely.

The fact that there was no decrease in mRNA or protein levels of SOD could be indicative of the importance of SOD for freezing survival. Furthermore, SOD activity 
levels have already been shown to be more than three times greater in $R$. sylvatica muscle when compared to R. pipiens, a freeze intolerant frog (Joanisse and Storey, 1996). This may be sufficient to overcome $\mathrm{O}_{2}{ }^{-}$. production produced by freezing and subsequent thawing in conjunction with the increase in $\mathrm{O}_{2}{ }^{-}$affinity outlined in this study.

\subsection{Phosphorylation of CuZnSOD and MnSOD}

Investigation into the relative phosphorylation state of CuZnSOD did not give any evidence for a phosphorylated form of CuZnSOD. This suggests that the $\mathrm{V}_{\max }$ difference discovered for CuZnSOD during freezing is not controlled by reversible phosphorylation. $\mathrm{V}_{\max }$ changes can arise for many reasons, one of which may be a result of allosteric regulation. Although no mechanism for control is proposed in this chapter, allosteric regulation of CuZnSOD has been proposed in disease states such ALS, and lateral sclerosis have been reported to change the activity of CuZnSOD (Schuyler et al., 2011; Das and Plotkin, 2013). It is unclear at this time what caused the change in $V_{\max }$ for CuZnSOD during freezing, although the changes remain an important point of investigation for future studies.

Investigation into the relative phosphorylation state of MnSOD identified a significant difference in global phosphorylation levels ( 2.87 fold) between control and frozen states, as well as significant differences in the relative phosphorylation of serine (2.37 fold) and tyrosine (1.27 fold) residues (Figure 2.5$)$. This suggests that the phosphorylation of MnSOD is a strong candidate for eliciting the increase in affinity for superoxide. Although it is impossible to discern the exact cause of the change in 
phosphorylation, it is clear that the more phosphorylated from of MnSOD is more active. Increased affinity for $\mathrm{O}_{2}{ }^{-}$. would likely enable MnSOD from the frozen frog to prevent freeze-induced free radical damage, as well as prepare for the eventual burst production of free radicals during reperfusion.

Previous studies have shown that levels of IP3, a second messenger of PKC, increase as freezing progresses (Holden and Storey, 1996), adding credence to the possibility that SOD may be controlled by phosphorylation, and that it may be phosphorylated by PKC. This would suggest that PKC may become more active as freezing progresses, suggesting that phosphorylation of MnSOD by PKC would benefit the frog as freezing intensifies, or as a preparatory mechanism to deal with reperfusion. Investigation into the putative phosphorylation sites of MnSOD, based on the predicted protein sequence (Figure 2.6C) yielded several PKC phosphorylation sites, supporting $\mathrm{PKC}$ as a candidate to phosphorylate MnSOD during freezing. Interestingly, human MnSOD also demonstrated a larger number of potential PKC phosphorylation sites, suggesting the possibility for PKC mediated phosphorylation in humans. In all cases, except for casein kinase 1 for CuZnSOD, the obtained sequences for $R$. sylvatica encompassed the predicted putative phosphorylation sites for both CuZnSOD and MnSOD in humans.

\subsection{Stability of CuZnSOD and MnSOD}

Stability analysis of CuZnSOD did not show any significant differences between the enzymes from control and $24 \mathrm{~h}$ frozen muscle (Figure 2.7). When comparing 
$\mathrm{CuZnSOD}$ and MnSOD, it is clear that MnSOD is far more resistant to urea denaturation in comparison to $\mathrm{CuZnSOD.} \mathrm{Upon} \mathrm{closer} \mathrm{observation} \mathrm{of} \mathrm{the} \mathrm{tertiary} \mathrm{structure} \mathrm{of} \mathrm{both}$ CuZnSOD and MnSOD from $X$. laevis, it can be seen that MnSOD has more structured regions than $\mathrm{CuZnSOD}$ which may lead to its apparent greater stability (Carugo et al., 1996; Purello et al., 2005). Greater stability may aid MnSOD as it is found at a major site of superoxide production, the mitochondria. Furthermore, MnSOD did show a significantly different $\mathrm{C}_{\mathrm{m}}$ between control and frozen muscle, suggesting a more stable form of MnSOD in the frozen state (Figure 2.8). Covalent modifications of proteins can result in either a more rigid or a more fluid structure. There is evidence of a correlation between phosphorylation events and a subsequent stabilization of protein, as has previously been seen for the enzymes hexokinase, creatine kinase and glucose-6phosphate dehydrogenase in R. sylvatica (Dieni and Storey, 2009, 2010, 2011). Covalent modification via phosphorylation may also increase accessibility of the active site, which can affect kinetic parameters. The observed phosphorylation event may then be affecting stability as well as increasing accessibility to the active site, thereby increasing the affinity for $\mathrm{O}_{2}^{-}$. in response to freezing.

\subsection{Conclusion}

The regulation of SOD in the freeze tolerant frog, $R$. sylvatica can provide useful insights into the effects of ischemia on free radical mediation. CuZnSOD may have increased capacity to deal with free radical production, although the exact mechanism of control is not understood. MnSOD from frozen frogs has a lower $\mathrm{K}_{\mathrm{m}}$, is more stable, and 
exhibits increased phosphorylation at serine and tyrosine residues as compared with controls. The evidence presented in this chapter suggests that phosphorylation may stabilize and activate MnSOD during freezing. Augmented MnSOD activity may increase the ability of $R$. sylvatica to overcome oxidative stress associated with ischemia or reperfusion. This study can also provide valuable insight into disease pathology by offering a unique observation of the role of MnSOD during ischemia. MnSOD, along with many mitochondrial proteins, has a high degree of similarity across species. In this experiment, MnSOD from R. sylvatica was found to have $84 \%$ amino acid identity when compared to human MnSOD, as well as many predicted phosphorylation sites for PKC phosphorylation. This striking similarity suggests that researchers should explore possible phosphorylation events in human disease states as a method for reactivating MnSOD mutants, or in the case of ischemic tumour growth, exploring the possibility of deactivating MnSOD via de-phosphorylation as a method of triggering apoptosis. 


\section{References}

Abboud, J. and Storey, K.B. 2013. Novel control of lactate dehydrogenase from the freeze tolerant wood frog: role of posttranslational modifications. Peer J. 1:e12

Ahmad, S., Pritsos, C. A., Bowen, S. M., Heisler, C. R., Blomquist, G. J. and Pardini, R. S. 1988. Subcellular distribution and activities of superoxide dismutase, catalase, glutathione peroxidase, and glutathione reductase in the southern armyworm, Spodoptera eridania. Arch Insect Biochem Physiol. 7:173-186.

Bannister, J.V., Bannister, W.H. and Rotilio, G. 1987. Aspects of the structure, function, and applications of superoxide dismutase. CRC Crit Rev Biochem. 22(2):111-80.

Basaga, H.S. 1990. Biochemical aspects of free radicals. Biochem Cell Biol. 68:989-998.

Bordo, D., Matak, D., Djinovic-Carugo, K., Rosano, C., Pesce, A., Bolognesi, M., Stroppolo, M.E., Falconi, M., Battistoni, A. and Desideri A. 1999. Evolutionary constraints for dimer formation in prokaryotic $\mathrm{Cu}, \mathrm{Zn}$ superoxide dismutase. $J \mathrm{Mol}$ Biol. 285(1):283-96.

Borgstahl, G.E., Parge, H.E., Hickey, M.J., Beyer, W.F., Hallewell, R.A. and Tainer, J.A. 1992. The structure of human mitochondrial manganese superoxide dismutase reveals a novel tetrameric interface of two 4-helix bundles. Cell. 71(1):107-118.

Carugo, K.D., Battistoni, A., Carri, M.T., Polticelli, F., Desideri, A., Rotilio, G., Coda, A., Wilson, K.S. and Bolognesi, M. 1996. Three-dimensional sStructure of Xenopus laevis $\mathrm{Cu}, \mathrm{Zn}$ superoxide dismutase $\mathrm{b}$ determined by $\mathrm{X}$-ray crystallography at 1.5 Å resolution. Acta Cryst. D52:176-188.

Concetti A., Massei P., Rotilio G., Brunori M. and Rachmilewitz E.A. 1976. Superoxide dismutase in red blood cells: method of assay and enzyme content in normal subjects and in patients with B- thalassemia. J Lab Clin Med. 87:1057-1064. 
Cowan, K.J. and Storey, K.B. 2001. Freeze-thaw effects on metabolic enzymes in wood frog organs. Cryobiology 43:32-45.

Das, A. and, Plotkin S.S. 2013. SOD1 exhibits allosteric frustration to facilitate metal binding affinity. Proc Natl Acad Sci U S A. 110(10):3871-3876.

Dawson, N.J., Bell, R.A. and Storey, K.B. 2013. Purification and properties of white muscle lactate dehydrogenase from the anoxia-tTolerant turtle, the red-eared slider, Trachemys scripta elegans. Enz Res. 2013:784973.

De Croos, J.N., McNally, J.D., Palmieri, F. and Storey, K.B. 2004. Upregulation of the mitochondrial phosphate carrier during freezing in the wood frog Rana sylvatica: potential roles of transporters in freeze tolerance. J Bioenerg Biomembr. 36:229239.

Dieni, C.A. and Storey, K.B. 2008. Regulation of 5'-adenosine monophosphate deaminase in the freeze tolerant wood frog, Rana sylvatica. BMC Biochem. 9:12.

Dieni, C.A. and Storey, K.B. 2009. Creatine kinase regulation by reversible phosphorylation in frog muscle. Comp Biochem Physiol B. 152:405-412.

Dieni, C.A. and Storey, K.B. 2010. Regulation of glucose-6-phosphate dehydrogenase by reversible phosphorylation in liver of a freeze tolerant frog. J Comp Physiol .B 180:1133-1142.

Dieni, C.A. and Storey, K.B. 2011. Regulation of hexokinase by reversible phosphorylation in skeletal muscle of a freeze tolerant frog. Comp Biochem Physiol B. 159:236-243.

Duttaroy, A., Paul, A., Kundu, M. and Belton, A. 2003. A Sod2 null mutation confers severely reduced adult life span in Drosophila. Genetics. 165(4):2295-2299.

Famulari, A.L., Marschoff, E.R., Llesuy, S.F., Kohan, S., Serra, J.A., Dominquez, R.O., Repetto, M., Reides, C. and Sacerdote de Lustig, E. 1996. The antioxidant 
enzymatic blood profile in Alzheimer's and vascular diseases. Their association and possible assay to differentiate demented subjects and controls. J Neurol Sci. 141:69-78.

Ferrari, R., Ceconi, C., Curello, S., Cargnoni, A., Pasini, E. and Sioli, O. 1991. The occurrence of oxidative stress during reperfusion in experimental animals and men. Cardiovasc Drugs Ther. 5:277-87.

Fridovich, I. 1975. Superoxide dismutases. Annu Rev Biochem. 44:147-59.

Fridovich, I. 1995. Superoxide radical and superoxide dismutase. Ann Rev Biochem. 64: 97-112.

Gonzales, R., Auclair, C., Voisin, E., Gautero, H., Dhermy, D. and Boivin, P. 1984. Superoxide dismutase, catalase and glutathione peroxidase in red blood cells from patients with malignant disease. Cancer Res. 44:4137-4139.

Greenway, S.C. and Storey, K.B. 1999. Activation of mitogen-activated protein kin ases during natural freezing and thawing in the wood frog. Mol Cell Biochem. 209:2937.

Grundy, J.E. and Storey, K.B. 1998. Antioxidant defenses and lipid peroxidation damage in estivating toads, Scaphiopus couchii. J Comp Physiol B. 168(2):132-142.

Hermes-Lima, M. and Storey, K.B. 1993. Antioxidant defenses in the tolerance of freezing and anoxia by garter snakes. Am J Physiol. 265:R646-R652.

Hermes-Lima, M. and Storey, K.B. 1995. Antioxidant defenses and metabolic depression in a pulmonate land snail. Am J Physiol. 268:R1386-R1393.

Hermes-Lima, M. and Storey, K.B. 1998. Role of antioxidant defenses in the tolerance of severe dehydration in anurans. The case of the leopard frog Rana pipiens. Mol Cell Biochem. 189:79-89. 
Holden, CP and Storey, KB. (1996) Signal transduction, second messenger, and protein kinase responses during freezing exposure in wood frogs. Am J Physiol. 271:R1205-R1211.

Hudson, N.J., Lehnert, S.A., Ingham, A.B., Symonds, B., Franklin, C.E. and Harper, G.S. 2005. Lessons from an estivating frog: sparing muscle protein despite starvation and disuse. Am J Physiol. 290(3):R836-R843.

Iqbal, J., Clerch, L.B., Hass, M.A. Frank, L. and Massaro, D. 1989. Endotoxin increases lung $\mathrm{Cu}, \mathrm{Zn}$ superoxide dismutase mRNA: $\mathrm{O}_{2}$ raises enzyme synthesis. $\mathrm{Am} \mathrm{J}$ Physiol. 257:L61-L64.

Joanisse, D.R. and Storey, K.B. 1996. Oxidative damage and antioxidants in Rana sylvatica, the freeze-tolerant wood frog. Am J Physiol. 271(3):R545-R553.

Katzenback, B.A., Holden, H.A., Falardeau, J., Childers, C., Hadj-Moussa, H., Avis, T.J. and Storey, K.B., 2014. Regulation of the Rana sylvatica brevinin-1SY antimicrobial peptide during development and in dorsal and ventral skin in response to freezing, anoxia, and dehydration. J Exp Biol. 217:1392-1401.

Klein, S.L., Strausberg, R.L., Wagner, L., Pontius, J., Clifton, S.W. and Richardson, P. 2002. Genetic and genomic tools for Xenopus research: The NIH Xenopus initiative. Dev Dyn. 225(4):384-391.

Kokoszka, J.E., Coskun, P., Esposito, L.A. and Wallace, D.C. 2001. Increased mitochondrial oxidative stress in the Sod2 (+/-) mouse results in the age-related decline of mitochondrial function culminating in increased apoptosis. Proc Natl Acad Sci U S A. 98:2278-2283.

Konstantinov, A.A., Peskin, A.V., Popova, E.Y., Khomutov, G.B. and Ruuge, E.K. 1987. Superoxide generation by the respiratory chain of tumor mitochondria. Biochim Biophys Acta. 894:1-10. 
Lah, M.S., Dixon, M.M., Pattridge, K.A., Stallings, W.C., Fee, J.A. and Ludwig, M.L. 1995. Structure-function in Escherichia coli iron superoxide dismutase: comparisons with the manganese enzyme from Thermus thermophilus. Biochemistry. 34(5):1646-1660.

Li, Y., Huang, T.T., Carlson, E.J., Melov, S., Ursell, P.C., Olson, J.L., Noble, L.J., Yoshimura, M.P., Berger, C., Chan, P.H., Wallace, D.C. and Epstein, C.J. 1995. Dilated cardiomyopathy and neonatal lethality in mutant mice lacking manganese superoxide dismutase. Nat Genet. 11(4):376-381.

Lushchak, V.I., Bagnyukova, T.V., Lushchak, O.V., Storey, J.M. and Storey, K.B. 2005. Hypoxia and recovery perturb free radical processes and antioxidant potential in common carp (Cyprinus carpio) tissues. Int J Biochem Cell Biol. 37(6):1319-1330.

MacDonald, J.A., and Storey, K.B. 1999. Protein phosphatase response during freezing and thawing in wood frogs: Control of liver cryoprotectant metabolism. CroyLetters. 20:297-306.

Mao, G.D. and Poznansky, M.J. 1992. Electron spin resonance study on the permeability of superoxide radicals in lipid bilayers and biological membranes FEBS Lett. 305(3):233-236.

Mavelli, I., Ciriolo, M.R., Rossi, L., Meloni, T., Forteleoni, G., De Flora, A., Benatti, U., Morelli, A. and Rotilio, G. 1984. Favism: a hemolytic disease associated with increased superoxide dismutase and decreased glutathione peroxidase activities in red blood cells. Eur J Biochem. 139:13-18.

McCord, J.M. 1995. Superoxide radical, controversies, contradictions and paradoxes. Proc Soc Exp Biol Med. 209:112-117.

Melov, S., Coskun, P., Patel, M., Tuinstra, R., Cottrell, B., Jun, S., Zastawny, T.H., Dizdaroglu, M., Goodman, S.I., Huang, T.T., Miziorko, H., Epstein, C.J. and 
Wallace, C. 1999. Mitochondrial disease in superoxide dismutase 2 mutant mice. Proc Natl Acad Sci USA. 96:846-851.

Mizuno, Y. 1984. Superoxide dismutase activity in early stages of development in normal and dystrophic chickens. Life Sci. 34:909-914.

Muller, F.L., Liu, Y. and Van Remmen, H. 2004. Complex III releases superoxide to both sides of the inner mitochondrial membrane. J Biol Chem. 279:49064-49073.

Noor, R., Mittal, S. and Iqbal, J. 2002. Superoxide dismutase - applications and relevance to human diseases. Med Sci Monit. 8(9):RA210-215.

Panchenko, L.F., Lamchingiin, T., Gerasimov, A.M., Sukhanov, I.S. and Konoplina, L.A. 1979. Superoxide dismutase activity in the blood of children with iron deficiency anemia. Vopr Med Khim. 25(2):181-185.

Pannunzio, T.M. and Storey, K.B. 1998. Antioxidant defenses and lipid peroxidation during anoxia stress and aerobic recovery in the marine gastropod, Littorina littorea. J Exp Mar Biol Ecol. 221:277-292. Paoletti F., Aldinucci D., Mocali A., and Caparrini A. 1986. A sensitive spectrophotometric method for the determination of superoxide dismutase activity in tissue extracts. Anal Biochem. 154(2):536-541.

Park, C. and Marqusee, S. 2005. Pulse proteolysis: A simple method for quantitative determination of protein stability and ligand binding. Nat. Meth. 2:207-212.

Paoletti, F., Aldinucci, D., Mocali, A. and Caparrini, A. 1986. A sensitive spectrophotometric method for the determination of superoxide dismutase activity in tissue extracts. Anal Biochem. 154(2):536-541.

Purrello, M., Di Pietro, C., Ragusa, M., Pulvirenti, A., Giugno, R., Pietro, V.D., Emmanuele, G., Travali, S., Scalia, M., Shasha, D. and Ferro, A. 2005. In vitro and in silico cloning of Xenopus laevis SOD2 cDNA and its phylogenetic analysis. DNA Cell Biol. 24:111-116. 
Ratoviski, A. and Leigh, P.N. 1996. Cu/Zn superoxide dismutase gene mutations in amyotrophic lateral sclerosis: Correlation between genotypes and clinical features. Neural Neurosurg Psychol. 61:565-572.

Ray, G., Kumar, V., Kapoor, A.V., Dutta, A.K. and Batra, S. 1999. Status of antioxidants and other biochemical abnormalities in children with dengue fever. $J$ Trop Pediatr. 45:4-7.

Reiter, R.J. 1995. Oxidative process and antioxidative defense mechanisms in the aging brain. FASEB J. 9:526-533.

Rhodin, J., Thomas, T., Bryant, M. and Sutton, E.T. 2000. Animal model of Alzheimerlike vascular pathology and inflammatory reaction. Ann N Y Acad Sci. 903:345352.

Rider, M.H., Hussain, N., Horman, S., Dilworth, S.M. and Storey, K.B. 2006. Stressinduced activation of the AMP-activated protein kinase in the freeze-tolerant frog Rana sylvatica. Cryobiology 53:297-309.

Rubinsky, B., Lee, C.Y., Bastacky, J. and Onik, J. 1987. The process of freezing and the mechanism of damage during hepatic cryosurgery. Cryobiology 27:85-97.

Rubinsky, B., Wong, S.T.S., Hong, J.-S., Gilbert, J., Roos, M. and Storey, K.B. 1994. ${ }^{1}$ H magnetic resonance imaging of freezing and thawing in freeze-tolerant frogs. Am J Physiol. 266:R1771-R1777.

Ryan K.C., Johnson O.E., Cabelli D.E., Brunold T.C. and Maroney M.J. 2010. Nickel superoxide dismutse: structural and functional roles of Cys2 and Cys6. J Biol Inorg Chem. 15(5):795-807.

Schinina, M.E., Barra, D., Bossa, F., Calabrese, L., Montesano, L., Carri, M.T., Mariottini, P., Amaldi, F. and Rotilio, G. 1989. Primary structure from amino acid and cDNA sequences of two $\mathrm{Cu}, \mathrm{Zn}$ superoxide dismutase variants from Xenopus laevis. Arch Biochem Biophys. 272:507-515. 
Schuyler, A.D., Carlson, H.A. and Feldman, E.L. 2011. Computational methods for identifying a layered allosteric regulatory mechanism for ALS-causing mutations of $\mathrm{Cu}-\mathrm{Zn}$ superoxide dismutase 1. Proteins. 79(2):417-427.

Scott, C.J., Seidler, E.A. and Levin, L.A. 2010. Cell-autonomous generation of mitochondrial superoxide is a signal for cell death in differentiated neuronal precursor cells. Brain Res. 1306:142-148.

Simpson, P.J. and Lucchesi, B.R. 1987. Free radicals and myocardial ischemia and reperfusion injury. J Lab Clin Med. 110(1):13-30.

Sinclair, B.J., Stinziano, J.R., Williams, C.M., MacMillan, H.A., Marshall, K.E. and Storey, K.B. 2013. Real-time measurement of metabolic rate during freezing and thawing of the wood frog, Rana sylvatica: implications for overwinter energy use. J Exp Biol. 216:292-302.

Stieber, A.A., Gonatas, J.O. and Gonatas, N.K. 2000. Aggregation of ubiquitin and a mutant ALS-linked SOD 1 protein correlate with disease progression and fragmentation of Golgi apparatus. J Neurol Sci. 173:53-62.

Storey, J.M. and Storey, K.B. 2004. Cold hardiness and freeze tolerance. In: Storey, K.B. (Ed.), Functional Metabolism: Regulation and Adaptation. Wiley-Liss, Hoboken. pp. 473-503.

Storey, K.B. 1984. Freeze tolerance in the frog, Rana sylvatica. Experientia. 40:12611262.

Storey, K.B. and Storey, J.M. 1984. Freeze tolerant frogs: cryoprotectants and tissue metabolism during freeze-thaw cycles. Can J Zool. 64:49-56.

Storey, K.B. 1990. Life in a frozen state: adaptive strategies for natural freeze tolerance in amphibians and reptiles. Am J Physiol. 258:R559-R568.

Storey, K.B. 2004. Strategies for exploration of freeze responsive gene expression: advances in vertebrate freeze tolerance. Cryobiology 48:134-145.

Thannickal, V. and Fanburg, B. 2000. Reactive oxygen species in cell signalling. Am J Physiol. 279:L1005-L028. 
Tierney, D.L., Fee, J.A., Ludwig, M.L. and Penner-Hahn, J.E. 1995. X-ray absorption spectroscopy of the iron site in Escherichia coli Fe(III) superoxide dismutase. Biochemistry. 34(5):1661-1668.

Turrens, J.F., Freeman, B.A., Levitt, J.G. and Crapo, J.D. 1982. The effect of hyperoxia on superoxide production by lung submitochondrial particles. Arch Biochem Biophys. 217:401-410.

Vucetic, M., Stancic, A., Otasevic, V., Jankovic, A., Korac, A., Markelic, M., Velickovic, K., Golic, I., Buzadzic, B., Storey, K.B. and Korac B. 2013. The impact of cold acclimation and hibernation on antioxidant defenses in the ground squirrel (Spermophilus citellus): an update. Free Radic Biol Med. 65:916-924.

Willmore, W.G. and Storey, K.B. 1997. Antioxidant systems and anoxia tolerance in a freshwater turtle Trachemys scripta elegans. Mol Cell Biochem. 170(1-2):177185.

Yu, B.P. 1994. Cellular defences against damage from reactive oxygen species. Physiol Rev. 74:139-162.

Zemlan, F.P., Thienhaus, O.J. and Bosmann, H.B. 1989. Superoxide dismutase activity in Alzheimer's disease: possible mechanism for paired helical filament formation. Brain Res. 476:160-162.

Zweier, J.L. and Talukder, M.A. 2006. The role of oxidants and free radicals in reperfusion injury. Cardiovasc Res. 70(2):181-190. 
Table 2.1. Typical purification and yield of Rana sylvatica muscle CuZnSOD

\begin{tabular}{cccccc}
\hline $\begin{array}{c}\text { Purification } \\
\text { Step }\end{array}$ & $\begin{array}{c}\text { Total } \\
\text { Protein } \\
(\mathbf{m g})\end{array}$ & $\begin{array}{c}\text { Total } \\
\text { Activity } \\
(\mathbf{U})\end{array}$ & $\begin{array}{c}\text { Specific Activity } \\
\mathbf{( U / m g )}\end{array}$ & $\begin{array}{c}\text { Fold } \\
\text { Purification }\end{array}$ & $\begin{array}{c}\text { Yield } \\
\mathbf{( \% )}\end{array}$ \\
\hline Crude extract & 185.6 & 1230 & 6.63 & - & 100 \\
DEAE $^{+}$ & 9.0 & 837 & 93.08 & 14.0 & 68.1 \\
Copper Chelate & 0.096 & 133 & 1385.4 & 209.0 & 10.8 \\
\hline
\end{tabular}

Table 2.2. Typical purification and yield of Rana sylvatica muscle MnSOD

\begin{tabular}{cccccc}
\hline $\begin{array}{c}\text { Purification } \\
\text { Step }\end{array}$ & $\begin{array}{c}\text { Total } \\
\text { Protein } \\
(\mathbf{m g})\end{array}$ & $\begin{array}{c}\text { Total } \\
\text { Activity } \\
(\mathbf{U})\end{array}$ & $\begin{array}{c}\text { Specific Activity } \\
(\mathbf{U} / \mathbf{m g})\end{array}$ & $\begin{array}{c}\text { Fold } \\
\text { Purification }\end{array}$ & $\begin{array}{c}\text { Yield } \\
\text { (\%) }\end{array}$ \\
\hline Crude extract & 185.6 & 1230 & 6.63 & - & 100 \\
DEAE $^{+}$ & 9.0 & 837 & 93.08 & 14.0 & 68.1 \\
Copper Chelate & 0.159 & 247 & 1550.69 & 234.0 & 20.1 \\
\hline
\end{tabular}


Table 2.3. CuZnSOD and MnSOD kinetic parameters from purified control and frozen $R$. sylvatica muscle. ${ }^{*}$ - indicates a significant difference from the corresponding control value, $\mathrm{p}<0.05$.

\begin{tabular}{lcc}
\hline Enzyme parameters & Control & 24h Frozen \\
\hline CuZnSOD & & \\
$\mathrm{K}_{\mathrm{m}}$ superoxide $(\mathrm{mM})$ & $0.17 \pm 0.019$ & $0.14 \pm 0.011$ \\
$\mathrm{~V}_{\max }(\mathrm{U} / \mathrm{mg})$ & $1390 \pm 10$ & $2100 \pm 17^{*}$ \\
$\mathrm{C}_{\mathrm{m}}$ urea (M) & $0.62 \pm 0.03$ & $0.72 \pm 0.10$ \\
MnSOD & & \\
$\mathrm{K}_{\mathrm{m}}$ superoxide $(\mathrm{mM})$ & $0.20 \pm 0.014$ & $0.13 \pm 0.019^{*}$ \\
$\mathrm{~V}_{\max }(\mathrm{U} / \mathrm{mg})$ & $1550 \pm 85$ & $1570 \pm 79$ \\
$\mathrm{C}_{\mathrm{m}}$ urea $(\mathrm{M})$ & $2.53 \pm 0.34$ & $2.92 \pm 0.22^{*}$ \\
\hline
\end{tabular}



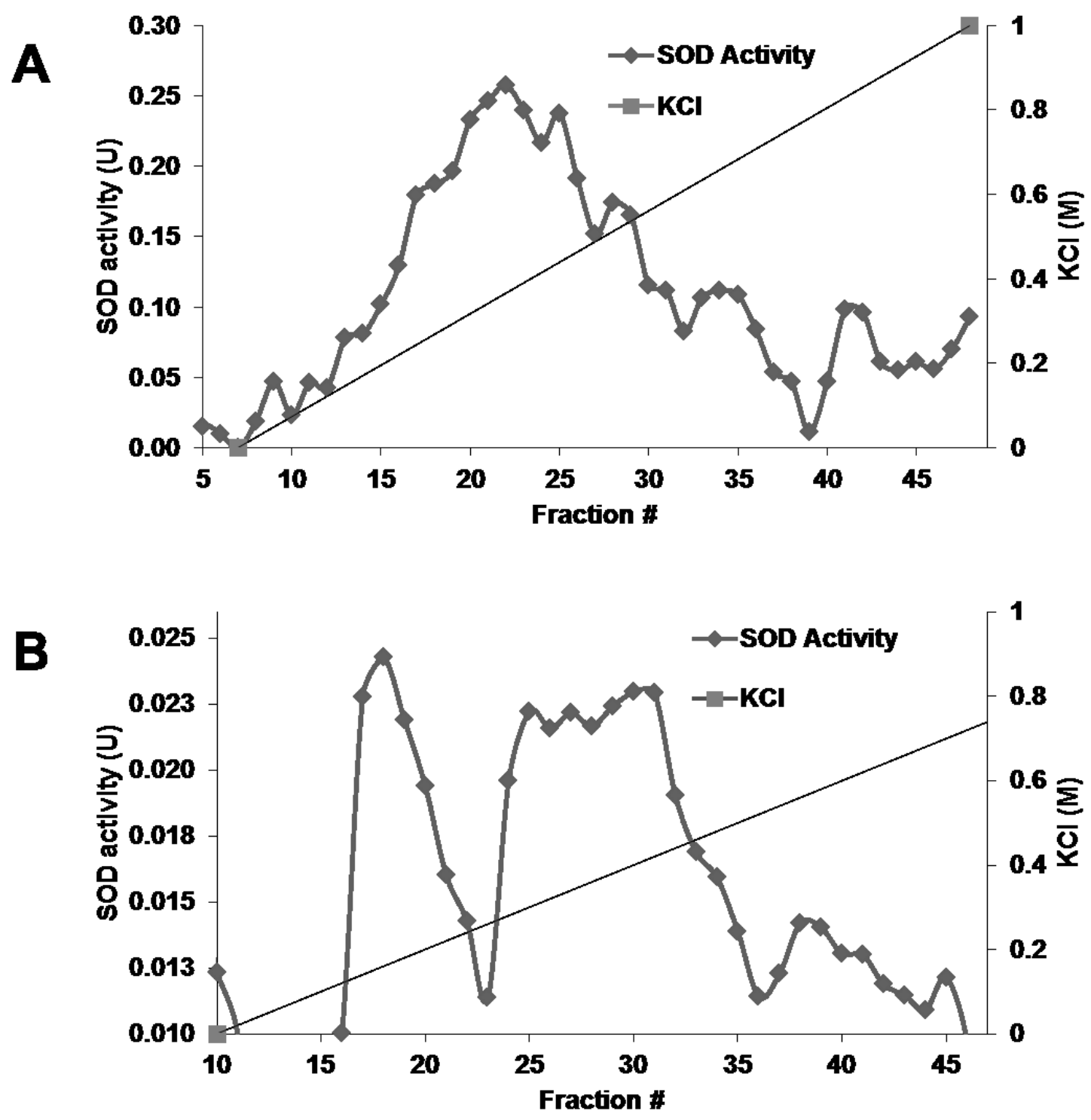

Figure 2.1. (A) Typical elution profile for control SOD on a DEAE+ column. (B) Typical elution profile for control SOD on a copper chelate column. 


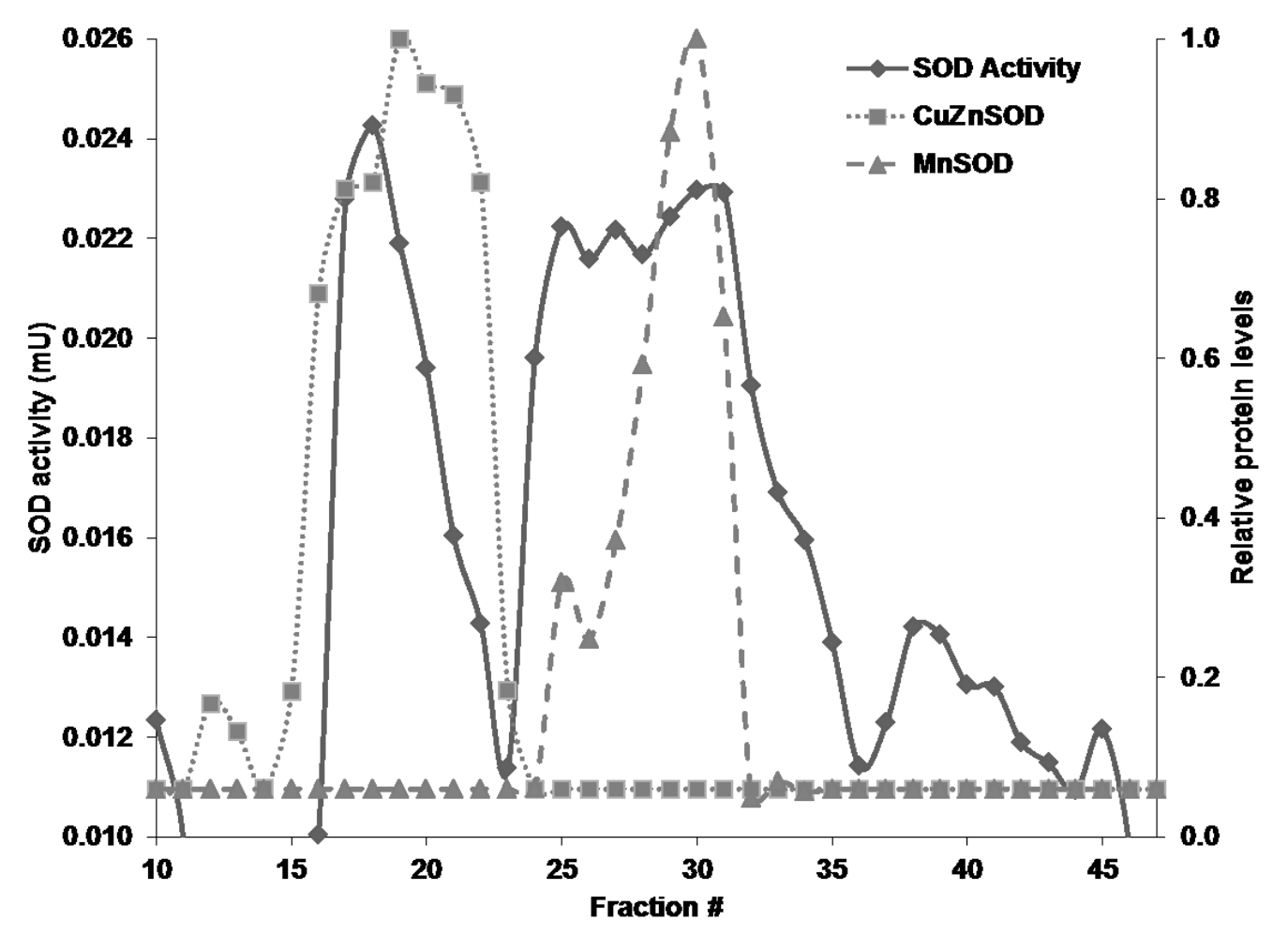

Figure 2.2. Copper chelate column elution profile for SOD superimposed with western blot analysis showing the cross-reactivity of anti-CuZnSOD (dotted line) and antiMnSOD (dashed line) with individual fractions. 


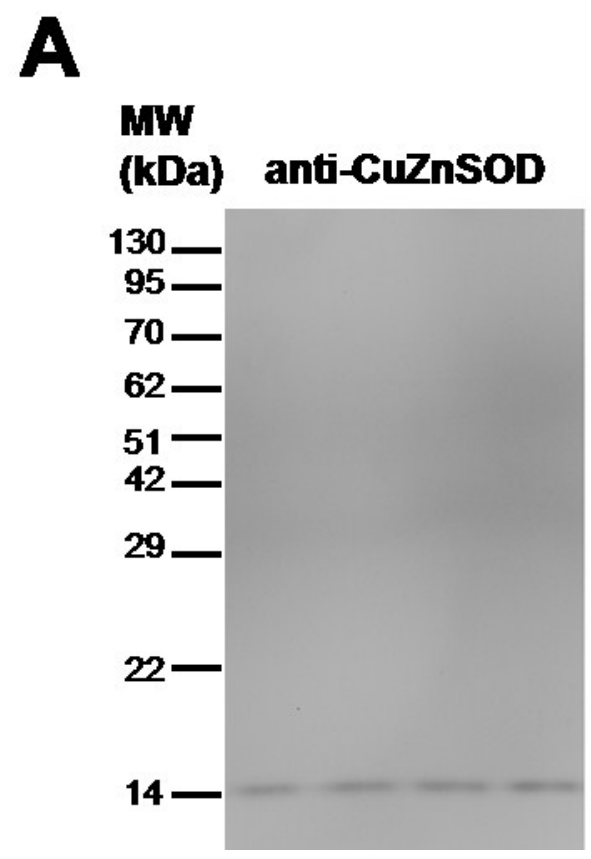

\section{B}

\section{MW \\ (kDa) anti-MnSOD}

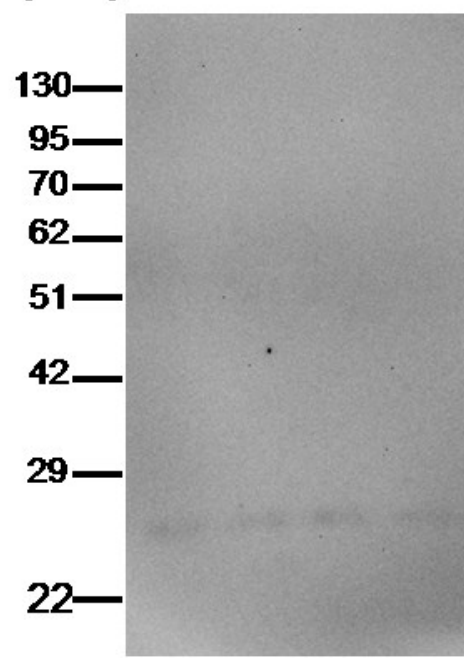

Figure 2.3. Immunoblot analysis of (A) purified CuZnSOD from the muscle of control $R$. sylvatica and (B) purified MnSOD from the muscle of control R. sylvatica. 

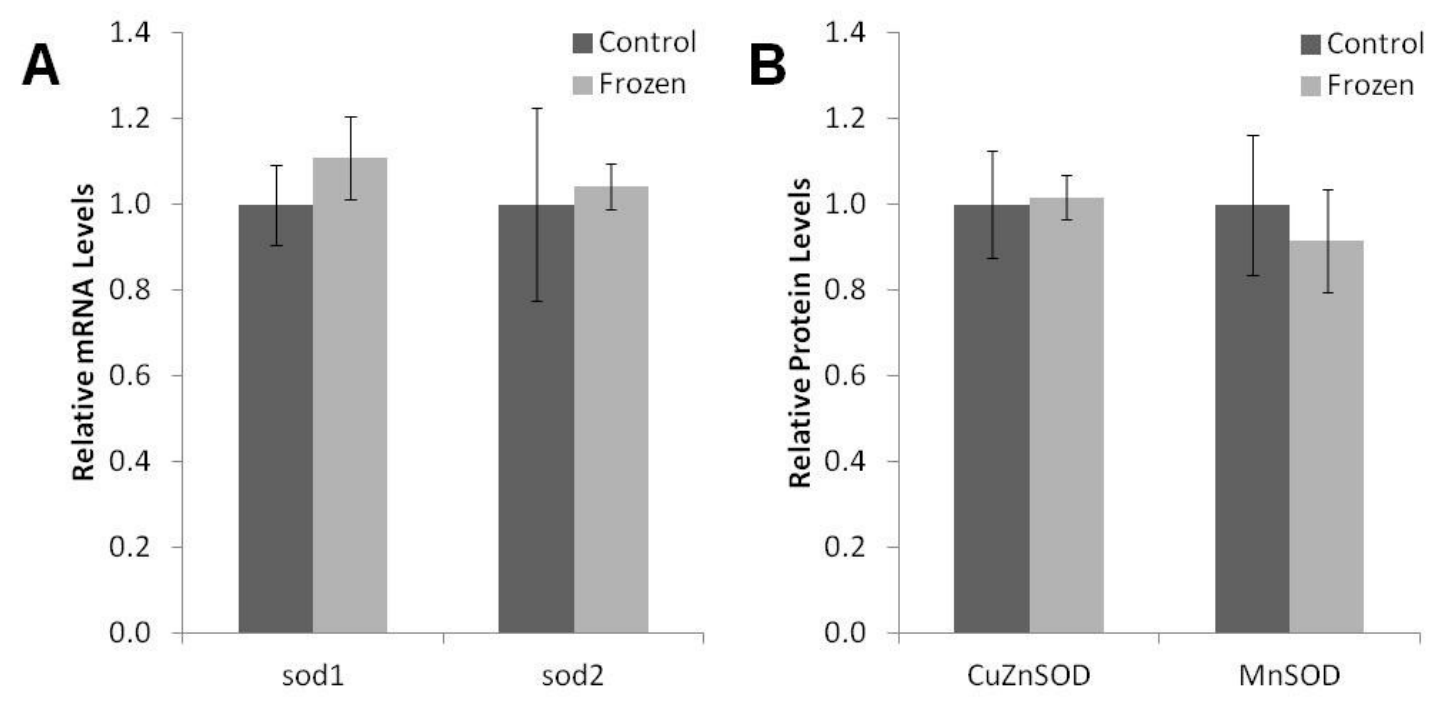

Figure 2.4. (A) RT-PCR analysis of sod transcript levels in frog muscle. (B) Western blotting analysis of the amount of SOD protein in frog muscle. No significant differences were observed using the Student's t-test $(n=4, P<0.05)$. 


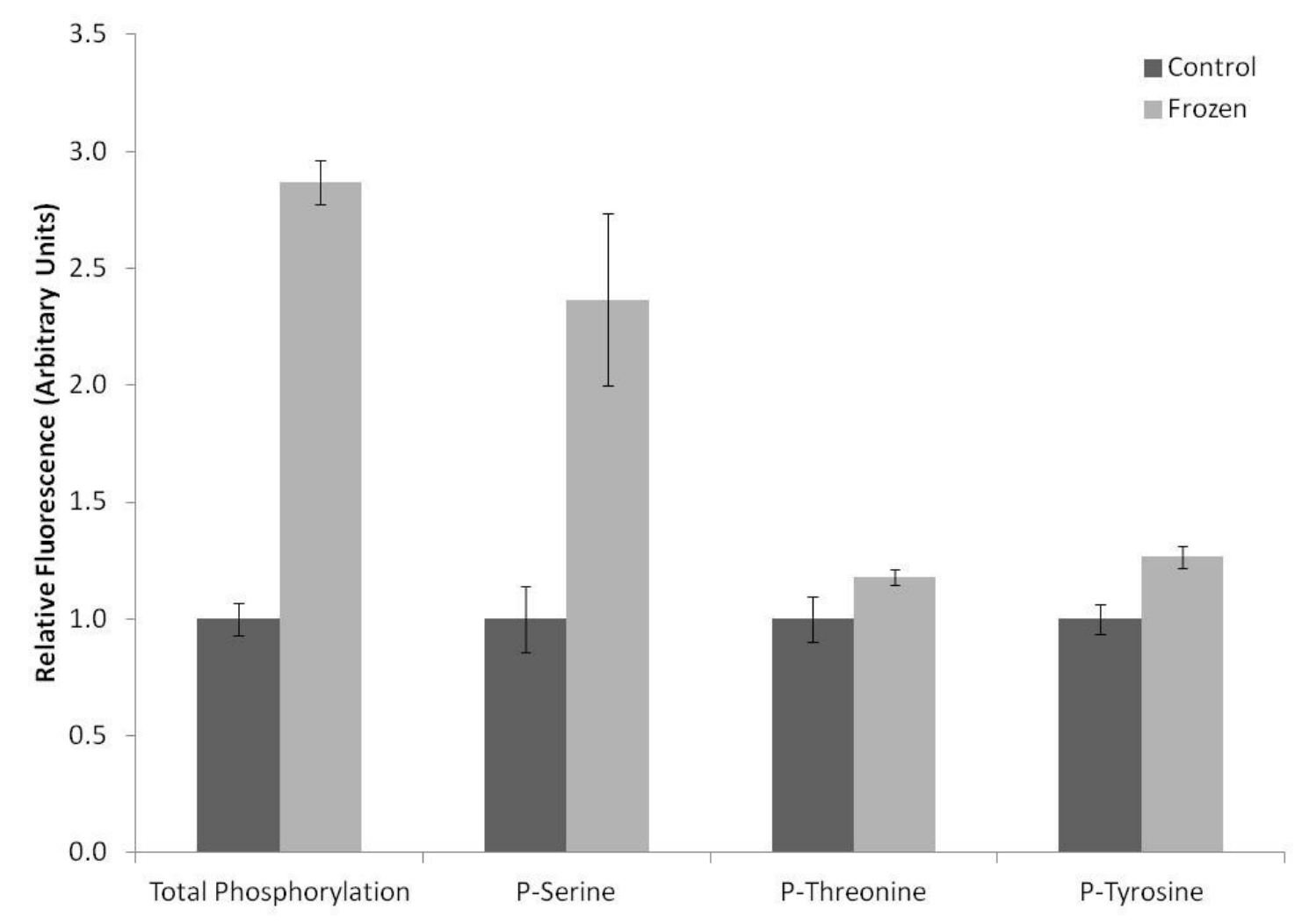

Figure 2.5. Relative phosphorylation levels of MnSOD from muscle of control and $24 \mathrm{~h}$ frozen frogs using Pro-Q diamond phospho-protein staining to analyze relative total phosphorylation of the enzyme, and dot-blot analysis of residue-specific phosphorylation. * - Significantly different from the corresponding control value, $\mathrm{p}<0.05$. 


\section{A CuZnSOD}

KAGCVMKG $\mathbf{S} S E V T G V V R F E Q E E D G P V T$ VTGQITGLTDGKHGFHIHTYGDN TNGCVSAGPHFNPQGKTHGGPDDEVRHVGDLGNITSAAGVADINIKDKLI CLTGEHSIVGRTAVVHEKEDDLGKGGDNES

B $\quad$ - - PKC delta

T - Erk1 Kinase

\section{MnSOD}

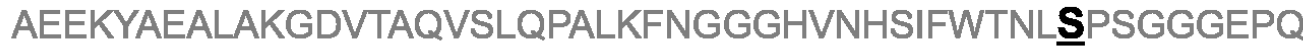 GELLKAIIRDFG FEKFKDKLTTMSVAVQG ANQDPLQGTTGLIPLLGIDWWEHAYYLQYK}

D $\mathbf{S}(\mathbf{1})$ - Erk1 kinase

S(2) - PKC alpha/beta/gamma/zeta, Calmodulin dependent kinase 2

$\mathbf{S ( 3 )}$ - PKC epsilon/delta/mu, Casein kinase 1

$\mathrm{T}(\mathbf{1})$ - PKC mu

T(2) - PKC epsilon/delta

$T(3)$ - Calmodulin dependent kinase 2, Akt kinase

Figure 2.6. Predicted phosphorylation sites for CuZnSOD and MnSOD. (A) Partial amino sequence for $\mathrm{CuZnSOD}$, highlighting predicted phosphorylation sites (bold, underlined). (B) Kinases predicted to phosphorylate CuZnSOD at the amino acid sites highlighted in A. (C) Partial amino sequence for MnSOD, highlighting predicted phosphorylation sites (bold, underlined). (D) Kinases predicted to phosphorylate MnSOD at the amino acid sites highlighted in C. 


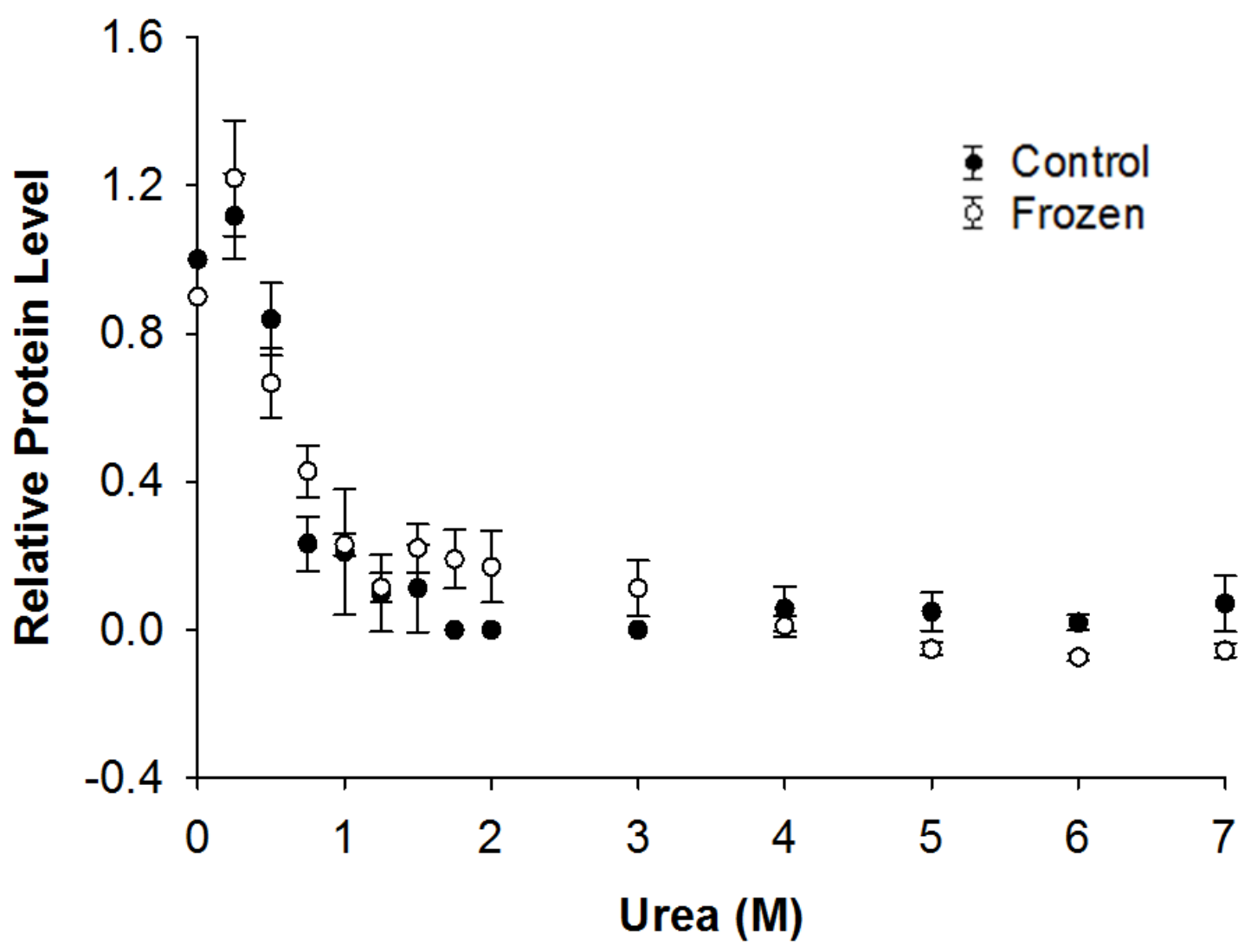

Control

Frozen

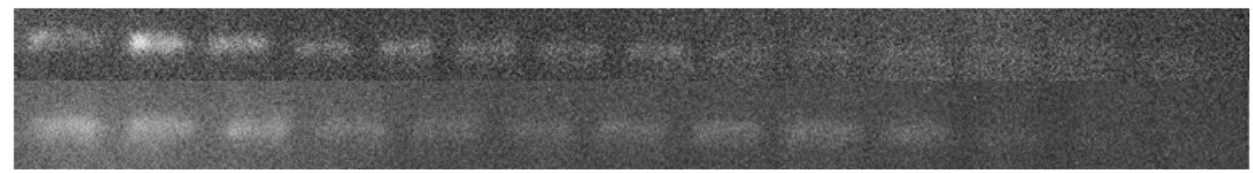

Figure 2.7. Stability of CuZnSOD from crude extracts of frog muscle. Samples were incubated for $24 \mathrm{~h}$ at $4^{\circ} \mathrm{C}$ with varying concentrations of urea then treated with pulse proteolysis to digest denatured CuZnSOD. Samples were then analyzed by western blotting and band densities of urea-treated samples are plotted relative to the initial band densities of untreated enzyme samples. 


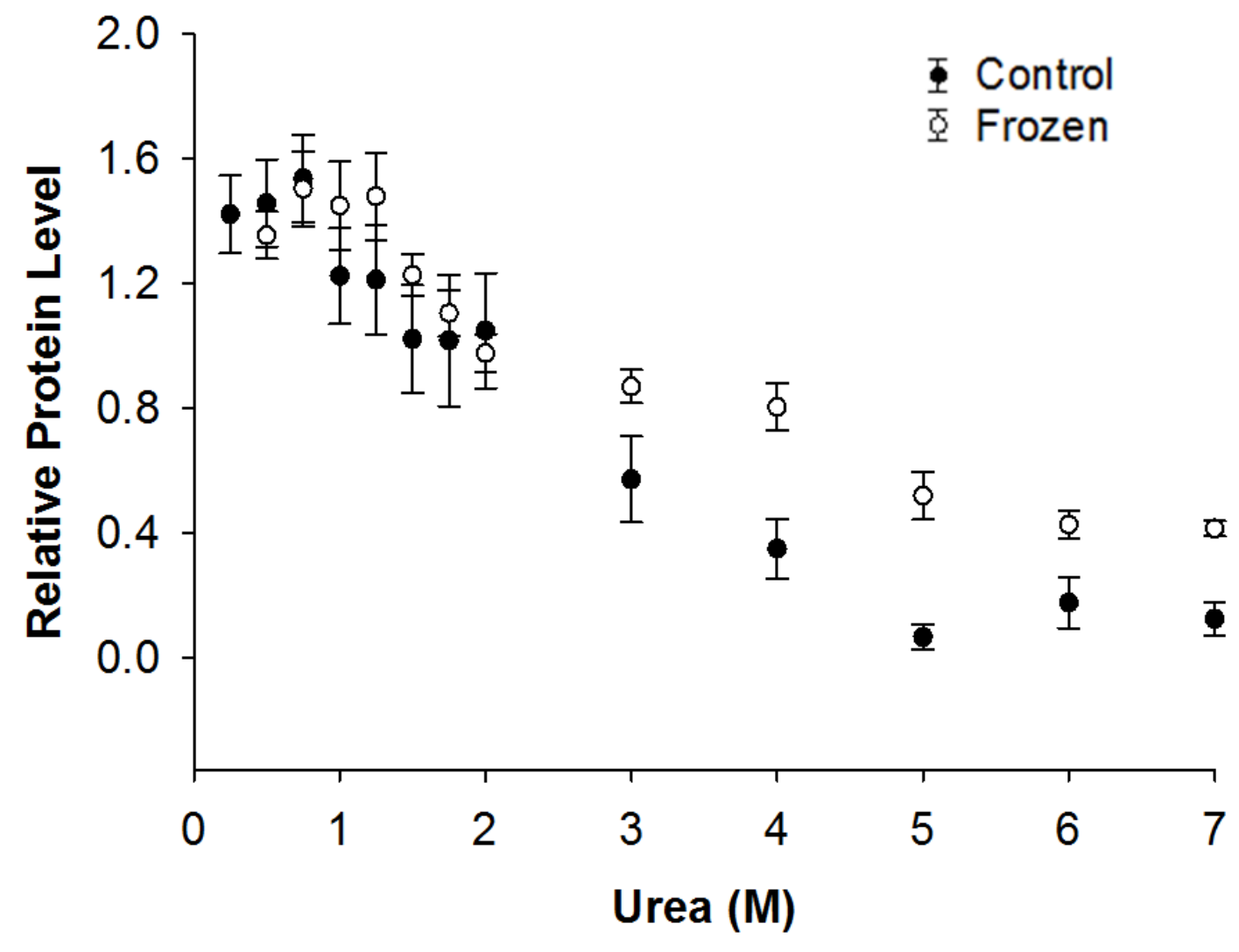

\section{Control} Frozen

Figure 2.8. Stability of MnSOD from crude extracts of frog muscle. Samples were incubated for $24 \mathrm{~h}$ at $4{ }^{\circ} \mathrm{C}$ with varying concentrations of urea then treated with pulse proteolysis to digest denatured MnSOD. Frozen MnSOD showed a significant difference when compared to MnSOD from control frogs as observed using student's t-test ( $\mathrm{n}=4$, $\mathrm{P}<0.05)$. 


\section{Chapter 3:}

Passive regeneration of glutathione: Purification and properties of glutathione reductase regulation from the freeze-tolerant North American wood frog, Rana sylvatica. 


\section{Introduction}

As the frog freezes, the overall reducing environment of cells increases as oxygen is depleted as the final electron acceptor during aerobic metabolism (Storey, 1996). Since oxygen is exhausted in the frozen state, the electron transport chain is fully reduced, essentially priming the cell for reactive oxygen species (ROS) production. In order to combat the increasingly reduced state of the cell, as well as the burst production of free radicals during reperfusion, $R$. sylvatica has markedly higher levels of reduced glutathione (GSH) $(219 \pm 17 \mathrm{nmol} / \mathrm{g}$ wet weight) in skeletal muscle than its non-freezing cousin, R. pipiens $(19.9 \pm 1.8 \mathrm{nmol} / \mathrm{g}$ wet weight)(Joanisse and Storey, 1996). The levels of GSH in the muscle of $R$. sylvatica were also observed to increase significantly during freezing in R. sylvatica to $308 \pm 21 \mathrm{nmol} / \mathrm{g}$ wet weight (Joanisse and Storey, 1996). An increase in total GSH levels could counteract an increase in production of ROS during freeze-induced ischemia or reperfusion during thawing.

GSH is the most abundant non-protein thiol in cells and plays a primary role as an antioxidant in mammalian cells (Meister, 1995). The role of GSH as an antioxidant can be divided into two main functions: direct interaction with ROS or as an electron donor to antioxidant enzymes such as glutathione peroxidase (GPX), glutathione-S-transferase (GST) and glutaredoxin (Meyer et al., 2009). Glutathione exists in two forms, the reduced form (GSH) or the oxidized form (GSSG), the latter arising from the disulfide linkage of two GSH molecules. Synthesis of the tripeptide GSH is catalyzed by two enzymes, $\gamma$-glutamylcysteine synthetase ( $\gamma$-GCS) which synthesizes $\gamma$-glutamylcysteine from glutamate and cysteine, and GSH synthetase (GS) which forms GSH from glycine and $\gamma$-glutamylcysteine (Forman et al., 2008). 
Glutathione reductase (GR)(E.C. 1.8.1.7) (also known as glutathione disulfide reductase or GSR) is a secondary antioxidant enzyme involved in the reduction of glutathione disulfide (GSSG) into two glutathione molecules (GSH). Specifically, GR catalyzes the following reaction:

$$
\mathrm{GSSG}+\mathrm{NADPH}+\mathrm{H}^{+} \rightarrow 2 \mathrm{GSH}+\mathrm{NADP}^{+}
$$

Primary antioxidant enzymes use GSH to detoxify ROS species and glutathione reductase is the primary enzyme tasked with actively recycling oxidized GSSG back to GSH. In vertebrates, GR typically has only one gene, gsr, as in Xenopus and humans. GR from $X$. tropicalis or $X$. laevis has a molecular weight of $51.8 \mathrm{kDa}$ as reported in the UniProtKB database (B1WBJ3_XENTR, Q58E89_XENLA) (Klein et al., 2002). The active site of GR has two key tyrosine residues that stabilize NADPH and GSSG during catalysis (Krauth-Siegel et al., 1988).

GR plays a major role in maintaining the GSH/GSSG ratio in the cell. Maintenance of this ratio is crucial, since GSH deficiencies cause severe oxidative shock to cells and can lead to apoptotic or necrotic cell death (Galluzzi et al., 2007; Circu and Aw, 2008). In fact, keeping GSH levels high has been shown to be beneficial in apoptotic resistant models (Friesen et al., 2004; Armstrong et al., 2002). Although GSH is found in high amounts (mM levels) in the cytoplasm, GSH also exists in many organelles in the cell including the mitochondria, peroxisomes, nuclear matrix, and the ER (Forman et al., 2008). Mitochondria are incapable of de novo synthesis of GSH, which suggests that the importance of GSH is amplified in the mitochondria, the organelle with perhaps the highest continuous generation of ROS in association with running the electron transport system (Galluzzi et al., 2007; Circu and Aw, 2008). This emphasizes the crucial role of 
mitochondrial GR in recycling GSH from GSSG. It has been proposed that both GR and GSH must be actively transported into the mitochondrial matrix (Franco and Cidlowski, 2009). The roles of mitochondrial and cytosolic levels of GSH have been explored independently, and oxidative stress has been linked to both in a similar fashion, suggesting that their roles may in fact not be independent of one another (Lash, 2006; Garcia-Ruiz and Fernandez-Checa, 2006).

Cytosolic and mitochondrial GSH pools seem to be critically important to counteract the production of ROS during reoxygenation of cells, and reactivation of the ETS in the mitochondria following ischemic stress (Muyderman et al., 2007). This may cause certain sites of burst ROS production, such as the mitochondria, to overwhelm the GSH pools at the site of insult during or proceeding ischemic stress. One of the main ROS produced in the mitochondria is superoxide $\left(\mathrm{O}_{2}^{-}\right) \cdot \mathrm{O}_{2}^{-}$cannot cross the mitochondrial membrane, and either reacts with GSH or other antioxidants or is converted into $\mathrm{H}_{2} \mathrm{O}_{2}$ by MnSOD. GR plays a pivotal role in maintaining the redox state of the cell, specifically the GSSG/GSH ratio, and maintenance of the mitochondrial ratio of GSSG/GSH has also been linked to the suppression of apoptosis (Marchetti et al., 1997; Muydermann et al., 2007).

GR has been widely studied and characterized from humans and traditional animal models, however, less is known about its role in disease states, or its role in aiding survival in the freezing frog. This chapter presents the first investigation of the potential method of regulation of GR in the leg muscle of $R$. sylvatica, comparing control and frozen states, and provides evidence of possible regulation by glucose levels as well as a 
general characterization of the enzyme, including the propensity to become phosphorylated in vitro.

\section{Materials and Methods}

\subsection{Chemicals}

All biochemicals were from BioShop (Burlington, ON, Canada) with a few exceptions; oxidized glutathione (GSSG) was from Sigma (St. Louis, MO), Cibacron blue column was from Affiland (Ans, Belgium), hydroxyapatite Bio-Gel ${ }^{\circledR}$ HTP Gel column was from Bio-Rad (Hercules, CA) and potassium phosphate, monobasic was from J.T. Baker Chemical Company (London, UK).

\subsection{Animals}

Male wood frogs were cared for and sampled as in Chapter 2 section 2.2.

\subsection{Preparation of muscle tissue lysates for protein purification}

For protein purification, samples of frozen muscle tissue were homogenized 1:5 w:v in ice-cold homogenizing buffer A [50 mM potassium phosphate (KPi) buffer, $\mathrm{pH}$ 7.2, containing $30 \mathrm{mM} \beta$-glycerophosphate, $1 \mathrm{mM}$ EGTA, $1 \mathrm{mM}$ EDTA, $15 \mathrm{mM} \beta$ mercaptoethanol, 10\% glycerol and $1 \mathrm{mM}$ phenylmethylsulfonyl fluoride (PMSF)]. Homogenates were then centrifuged at $13,500 \times g$ at $4{ }^{\circ} \mathrm{C}$ and the supernatant was collected for use in protein purification. 


\subsection{Purification of $G R$}

A $5 \mathrm{~cm}$ column of Sephadex G-50 in a syringe barrel was equilibrated in buffer A and centrifuged at $500 \mathrm{~g}$ in a bench-top centrifuge for $2 \mathrm{~min}$ to remove excess buffer. An aliquot of $2 \mathrm{~mL}$ of frog muscle tissue supernatant was applied to the column and centrifuged again. The resulting eluant was collected. A hydroxyapatite column $(1.5 \mathrm{~cm} \times$ $2 \mathrm{~cm}$ ) was then washed with $20 \mathrm{~mL}$ of buffer A to equilibrate the column. The eluant collected from the Sephadex G50 column was applied to the hydroxyapatite column and washed with $20 \mathrm{~mL}$ buffer A to remove unbound proteins. GR was eluted from the hydroxyapatite column with a linear gradient of $0-3.5 \mathrm{M} \mathrm{KCl}$ in buffer $\mathrm{A}$. The 4 fractions (with highest activity) of $900 \mu \mathrm{L}$ were collected and $10 \mu \mathrm{L}$ from each fraction was assayed to detect GR activity (see kinetic assays section below for methodology). The fractions of peak GR activity were pooled and diluted 10-fold with buffer A. The diluted fractions were applied to a Cibacron blue column $(1.5 \mathrm{~cm} \times 10 \mathrm{~cm})$ pre-washed with 50 $\mathrm{mL}$ of buffer $\mathrm{A}$. The column was washed with a further $50 \mathrm{~mL}$ of buffer $\mathrm{A}$ to remove unbound protein and then bound protein was eluted with a linear gradient of $0-2 \mathrm{M} \mathrm{KCl}$ in homogenization buffer A. The top 4 fractions (with highest activity) of $450 \mathrm{~mL}$ were collected and $20 \mu \mathrm{L}$ from each fraction was assayed to detect GR activity. To assess enzyme purity, aliquots of GR from different stages of the purification procedure were first assayed for protein concentration as described in chapter 2 section 2.7, then combined with an equal volume of $2 \times$ SDS loading buffer (100 mM Tris buffer, $\mathrm{pH} 6.8$, $4 \% \mathrm{w} / \mathrm{v}$ SDS, $20 \% \mathrm{v} / \mathrm{v}$ glycerol, $0.2 \% \mathrm{w} / \mathrm{v}$ bromophenol blue, $10 \% \mathrm{v} / \mathrm{v} 2-$ mercapotethanol), boiled for $5 \mathrm{~min}$, and then $20 \mu \mathrm{L}$ samples were run of on SDS-PAGE as described in chapter 2 section 2.7 . 


\subsection{Kinetic assays}

GR was assayed using a modified version of the method of Di Ilio (1983). Assay conditions will were: $50 \mathrm{mM}$ KPi buffer (pH 7.2), 2 mM GSSG, $0.25 \mathrm{mM}$ NADPH, and $10 \mu \mathrm{L}$ tissue extract. One unit of enzyme activity is the amount that oxidizes $1 \mu \mathrm{mol}$ of NADPH per minute at $25^{\circ} \mathrm{C}$. The amount of NADPH was measured at $340 \mathrm{~nm}$ in a Thermo Labsystems Multiskan spectrophotometer (Thermo Scientific, Waltham, MA, USA). Enzyme affinity for GSSG was determined in the presence versus absence of 75 mM urea or $300 \mathrm{mM}$ glucose. Activation of GR by adenosine triphosphate (ATP), adenosine diphosphate (ADP), adenosine monophosphate (AMP), magnesium $\left(\mathrm{Mg}^{2+}\right)$, manganese $\left(\mathrm{Mn}^{2+}\right)$, potassium $\left(\mathrm{K}^{+}\right)$, calcium $\left(\mathrm{Ca}^{2+}\right)$, or zinc $\left(\mathrm{Zn}^{2+}\right)$ was also tested. Data were analyzed using the Kinetics v.3.5.1 program (Brooks 1992).

\subsection{ProQ Diamond Phosphoprotein Staining}

Muscle GR from control and frozen frogs was purified as described in section 2.4. The top four fractions based on activity were pooled, and protein levels in the pooled fractions were quantified using the Coomassie blue dye-binding method. Aliquots of the pooled fractions were then mixed 1:1 v:v with SDS loading buffer (100 mM Tris buffer, $\mathrm{pH} 6.8,4 \% \mathrm{w} / \mathrm{v}$ SDS, $20 \% \mathrm{v} / \mathrm{v}$ glycerol, $0.2 \% \mathrm{w} / \mathrm{v}$ bromophenol blue, $10 \% \mathrm{v} / \mathrm{v} 2-$ mercapotethanol), subsequently boiled for 5 minutes and stored at $-20^{\circ} \mathrm{C}$ until used.

Equal volumes of each sample were loaded on a 10\% SDS-PAGE gel. The gel was run at $180 \mathrm{~V}$ for $55 \mathrm{~min}$ in running buffer (0.5 M Tris, $5 \mathrm{M}$ glycine, $0.5 \% \mathrm{w} / \mathrm{v} \mathrm{SDS})$. The gel was removed and washed in fixing solution $(50 \% \mathrm{v} / \mathrm{v}$ methanol, $10 \% \mathrm{v} / \mathrm{v}$ acetic 
acid) twice for $10 \mathrm{~min}$, then left in fixing solution overnight at $4^{\circ} \mathrm{C}$ followed by 3 washes with $\mathrm{ddH}_{2} \mathrm{O}$ for $10 \mathrm{~min}$. The gel was then stained with ProQ Diamond Phosphoprotein stain (Invitrogen, Eugene, OR) for 90 min and washed 3 times with $\mathrm{ddH}_{2} \mathrm{O}$ for $10 \mathrm{~min}$. The gel was covered during staining (and for the remainder of the protocol) with aluminum foil to prevent the photosensitive stain from interacting with light. To minimize non-specific background, the gel was washed in ProQ Diamond destaining solution ( $20 \% \mathrm{v} / \mathrm{v}$ acetonitrile, $50 \mathrm{mM}$ sodium acetate, $\mathrm{pH}$ 4) for 45 minutes, and then washed 3 times in $\mathrm{ddH}_{2} 0$ for 10 minutes. The bands on the gel were visualized using the ChemiGenius Bioimaging System (Syngene, Frederick, MD) to assess the relative intensities of the fluorescent bands. The fluorescence of the bands was quantified using the accompanying GeneTools software.

\subsection{In vitro Incubation to Stimulate Protein Kinases}

Frog muscle tissue extracts, prepared as previously described in section 2.2 , were filtered through a G50 spun column equilibrated in incubation buffer $(50 \mathrm{mM} \mathrm{KPi}, 10 \%$ v:v glycerol, $30 \mathrm{mM} \beta$-mercaptoethanol, $\mathrm{pH}$ 7.2). Aliquots of the filtered supernatants were incubated for 12 hours at $4^{\circ} \mathrm{C}$ with specific inhibitors and stimulators of protein kinases, as described in Macdonald and Storey (1999). Each aliquot was mixed 2:1 v:v with the appropriate solutions to stimulate protein kinases. Each solution was prepared in incubation buffer and the following incubation conditions were used:

(a) STOP conditions: $2.5 \mathrm{mM}$ EGTA, $2.5 \mathrm{mM}$ EDTA and $30 \mathrm{mM} \beta$ glycerophosphate (designed to inhibit both kinases and phosphatases). 
(b) Stimulation of endogenous kinases: $5 \mathrm{mM} \mathrm{Mg-ATP,} 30 \mathrm{mM} \beta$ glycerophosphate,1 mM cAMP (to stimulate PKA), $1 \mathrm{mM}$ cGMP (for PKG), $1.3 \mathrm{mM}$ $\mathrm{CaCl}_{2}+7 \mu \mathrm{g} / \mathrm{mL}$ PMA (for PKC), $1 \mathrm{mM}$ AMP (for AMPK), and $1 \mathrm{U}$ of calf intestine calmodulin $+1.3 \mathrm{mM} \mathrm{CaCl}_{2}$ (for $\left.\mathrm{CaMK}\right)$.

GR was then purified as previously described in section 2.4 and samples were analyzed using Pro-Q diamond phosphoprotein stain as described in section 2.6. Figure 3.2 shows the elution profile for control and frozen preparations from a $\mathrm{DEAE}^{+}$column. There was no significant difference in the elution profiles. Western blotting was carried out as described in chapter 1 section 2.7 , with the following primary antibodies: (1) rabbit anti-phosphoserine (Cat \#618100, Invitrogen, Carlsbad, CA, USA); (2) rabbit antiphosphothreonine (Cat. \# 718200, Invitrogen, Carlsbad, CA, USA); or (3) rabbit antiphosphotyrosine (Cat \# 615800, Invitrogen, Carlsbad, CA, USA).

\subsection{Arrhenius Plots}

Maximal GR activity was determined at $5^{\circ} \mathrm{C}$ increments starting from $5^{\circ} \mathrm{C}$ and ending at $45^{\circ} \mathrm{C}$. The reaction temperature was altered by placing the Thermo Labsystems Multiskan spectrophotometer into a VWR International BOD 2020 Incubator (Sheldon Manufacturing Inc., Oregon USA) set to the desired temperature. Microplates filled with assay mixture (but without enzyme) were equilibrated in the same incubator for several minutes until the desired temperature was reached (as measured by a telethermometer). Plates were then placed into the spectrophotometer and reactions were initiated by the 
addition of enzyme. Arrhenius plots were constructed from these experiments and the activation energy $\left(\mathrm{E}_{\mathrm{a}}\right)$ was calculated.

\subsection{Determination of protein stability}

Differential scanning fluorimetry (DSF) is a high throughput method that monitors the thermal unfolding of proteins in the presence of a fluorescent dye (Niesen et al., 2007). Purified control and $24 \mathrm{~h}$ frozen GR were aliquoted to a concentration of approximately $0.1 \mu \mathrm{g} / \mu \mathrm{L} /$ well into the wells of a 96-well, thin-walled PCR plate along with the dye SYPRO Orange (40X final concentration, Invitrogen) to a total volume of $20 \mu \mathrm{L}$. PCR plates were then sealed with sealing tape and placed into a BioRad iCycler5 PCR instrument. SYPRO Orange fluorescence was monitored as described by Biggar et al. (2012). Briefly, SYPRO Orange was excited through the transmission of light through the FAM filter ( $485 \pm 30 \mathrm{~nm}$ ), with the subsequent emission of light through the ROX filter $(625 \pm 30 \mathrm{~nm})$. Measurements were taken every $30 \mathrm{~s}$ at $1{ }^{\circ} \mathrm{C}$ increments from $25^{\circ} \mathrm{C}$ to $97^{\circ} \mathrm{C}$. Subsequent analysis of the fluorescent data using OriginPro 8.5 and the Boltzmann distribution curve yielded the midpoint temperature of the protein unfolding transition, known as the protein melting temperature $\left(\mathrm{T}_{\mathrm{m}}\right)$, for control and frozen frog muscle GR. 


\subsection{Statistical analysis}

Comparison of enzyme kinetics, relative protein phosphorylation and protein stability were performed using a Student's t test, two-tailed, assuming unequal variances. A probability of $\mathrm{P}<0.05$ was considered significant.

\section{Results}

\subsection{Purification of GR from the muscle of control and frozen frogs}

The purification scheme used for wood frog muscle GR is shown in Table 3.1. The procedure used ion exchange chromatography on a Bio-Gel ${ }^{\circledR}$ HTP Gel hydroxyapatite column (Figure 3.1A), and Cibacron blue chromatography (Figure 3.1B). GR eluted from the Cibacron blue column at approximately $1 \mathrm{M} \mathrm{KCl}$. Frog muscle GR was purified 134.9 fold with an overall yield of activity of $34.2 \%$ (Table 3.1). The final specific activity of GR was $124.73 \mathrm{mU} / \mathrm{mg}$ of protein (Table 3.1). The success of the purification process was assessed using SDS-PAGE with Coomassie blue staining of the gel (Figure 3.3). This showed that GR was purified to near homogeneity as there was one band corresponding to correct molecular weight of $\sim 50 \mathrm{kDa}$ for GR (Figure 3.3).

\subsection{Kinetic characterization of $\mathrm{GR}$}

Kinetic parameters of purified muscle GR were assessed to search for differences between control and frozen animals. The $\mathrm{K}_{\mathrm{m}}$ for GSSG and the $\mathrm{V}_{\max }$ of GR from the muscle of R. sylvatica did not change significantly between control and frozen animals 
$(p>0.05)$ (Table 3.2). However, when assayed in the presence of different additives, the $\mathrm{K}_{\mathrm{m}}$ value for GSSG changed. In the presence of $75 \mathrm{mM}$ urea, the $\mathrm{K}_{\mathrm{m}}$ for GSSG increased significantly $(1.57$ fold, $\mathrm{p}<0.05)$ in comparison to the $\mathrm{K}_{\mathrm{m}}$ of GSSG in untreated samples (Table 3.2). Oppositely, in the presence of $300 \mathrm{mM}$ glucose, the $\mathrm{K}_{\mathrm{m}}$ for GSSG decreased significantly to $50 \%$ of the measured $\mathrm{K}_{\mathrm{m}}$ of GSSG in untreated samples. In the presence

of both $75 \mathrm{mM}$ urea and $300 \mathrm{mM}$ glucose, $\mathrm{K}_{\mathrm{m}}$ for GSSG was significantly different from the $\mathrm{K}_{\mathrm{m}}$ of GSSG in both urea treated and untreated samples but not different from the $\mathrm{K}_{\mathrm{m}}$ in the presence of glucose.

The control form of GR was activated when assayed in the presence of ATP (1.42 fold), ADP (1.37 fold) and AMP (1.35 fold) (Table 3.2). $\mathrm{K}_{\mathrm{a}}$ values for ATP or ADP $\mathrm{K}_{\mathrm{a}}$ were similar at 0.076 and $0.071 \mathrm{mM}$, respectively. AMP had a $\mathrm{K}_{\mathrm{a}}(0.16 \mathrm{mM})$ of more than 2 fold greater that of either ATP or ADP (Table 3.2).

$\mathrm{Mn}^{2+}$ inhibited GR activity, showing an $\mathrm{I}_{50}$ value (inhibitor concentration that reduced activity by $50 \%$ ) of $4.44 \mathrm{mM}$ (Table 3.3 ). $\mathrm{Ca}^{2+}$ inhibited GR activity, with an $\mathrm{I}_{50}$ of $5.12 \mathrm{mM}$ (Table 3.2). $\mathrm{Mg}^{2+}$ and $\mathrm{K}^{+}$did not inhibit GR activity up to $10 \mathrm{mM}$.

\subsection{Post-translational modification of GR}

To test whether GR was susceptible to reversible phosphorylation the purified GR from muscle of both control and frozen frogs was run on an SDS-PAGE gel and stained with ProQ Diamond phosphoprotein stain. GR did not react with the ProQ Diamond phosphoprotein stain, resulting in no apparent banding (Figure 3.3). 
Crude extracts of skeletal muscle from control and frozen frogs were incubated to stimulate the activity of endogenously present kinases and GR was then purified as described in section 2.7. The enzyme showed a clear band at $\sim 50 \mathrm{kDa}$ when stained for total phosphorylation (Figure 3.5). However, there was no significant difference in band intensities between GR purified from control and frozen incubated samples.

Immunoblotting was used to assess residue-specific phosphorylation of muscle GR. Purified GR reacted with antibodies testing for phosphorylation on serine residues threonine residues and tyrosine residues (Figure 3.6). However, relative phosphorylation levels of serine, threonine or tyrosine residues did not change between control and frozen states $(\mathrm{P}>0.05)$.

\subsection{Scansite Prediction of Phosphosites}

The Scansite application from the Massachusetts Institute of Technology (http:// scansite.mit.edu/) was used to analyze GR sequences from two other frogs, Xenopus laevis and $X$. tropicalis to search the proteins for putative phosphorylation sites (Figure 3.7). GR protein sequences showed $94.75 \%$ identity between $X$. tropicalis and $X$. laevis. Multiple putative phosphorylation sites were predicted to occur on GR based on the presence of consensus sequence motifs for different protein kinases. Only those kinases predicted to phosphorylate GR from both $X$. laevis and X. tropicalis are reported. Putative consensus sequences for phosphorylation sites of Akt kinase (threonine), AMP kinase (serine, threonine), calmodulin dependent kinase 2 (serine, threonine), casein kinase 1 (serine, threonine), casein kinase 2 (serine, threonine), EGFR kinase (tyrosine), Fgr 
kinase (tyrosine), PKA (serine, threonine), PKC alpha (serine, threonine), PKC beta (serine, threonine), PKC delta (serine), PKC epsilon (serine), PKC gamma (serine, threonine), and PKC mu (serine) were predicted for GR.

Human GR shows $81.75 \%$ identity when compared to $X$. laevis and X. tropicalis. Human GR was analyzed for comparison using Scansite, resulting in the following putative consensus sequences for phosphorylation sites: Akt kinase (serine, threonine), AMP kinase (serine, threonine), calmodulin dependent kinase 2 (serine), casein kinase 1 (threonine), casein kinase 2 (threonine), EGFR Kinase (tyrosine), Erk1 Kinase (serine, threonine), Fgr Kinase (tyrosine), GSK3 kinase (serine, threonine), PKA (threonine), PKC alpha (serine, threonine), PKC beta (serine, threonine), PKC delta (serine, threonine), PKC epsilon (threonine), PKC gamma (serine, threonine), PKC mu (serine, threonine) and PKC zeta (serine) were predicted for GR (Figure 3.7).

\subsection{Arrhenius Plots}

Maximum GR activity was measured at $5^{\circ} \mathrm{C}$ increments starting from $5^{\circ} \mathrm{C}$ and ending at $45^{\circ} \mathrm{C}$ using purified GR from the leg muscle of $R$. sylvatica. Purified GR demonstrated a positive correlation between temperature and activity (Figure 3.8). Arrhenius plots were created by plotting $\ln \left(\mathrm{V}_{\max }\right)$ versus $1 /$ temperature in Kelvin. The $\mathrm{E}_{\mathrm{a}}$ was then calculated as $40.7 \pm 0.9 \mathrm{~kJ} / \mathrm{mol}$ (Table 3.2; Figure 3.8). 


\subsection{Stability of GR}

The structural stability of GR was evaluated by testing enzyme sensitivity to thermal denaturation using differential scanning fluorimetry as described in section 2.8. There was no significant difference in the pattern of thermal denaturation of purified GR between control and frozen frogs (Figure 3.9). GR purified from the muscle of $R$. sylvatica showed a peak at $68^{\circ} \mathrm{C}$ for both control and frozen frogs. The calculated $\mathrm{T}_{\mathrm{m}}$ value (temperature that results in a $50 \%$ loss of folded enzyme) was $64.7^{\circ} \mathrm{C}$ for GR from control frog muscle extracts, which was not significantly different than the value of $63.8^{\circ} \mathrm{C}$ for GR from frozen muscle extracts (Table 3.2; Figure 3.9).

\section{Discussion}

Abnormalities in GR activity have been linked to disease states including Parkinson's disease and Alzheimer's disease, in which an increase in GSSG concentration was linked with greater apoptotic cell death (Diaz-Hernandez et al., 2005; Merad-Boudia et al., 1998; Aksenov and Markesbery, 2001). An increase in the activity of GR has been observed in rheumatoid arthritis (Mulherin et al., 1996) and in cancer, changes in the expression level and activity of GR have also been found (Mullineaux and Creissen, 1997). Although the exact role of GR in disease is still being explored, knockout and knockdown experiments with GR have proven to be lethal (Pretsch, 1999; Rogers et al., 2004; Rogers et al., 2006). Specifically, elevated levels of GSSG due to oxidative stress have been directly linked to apoptotic signaling events in these experiments. Since, the function of GR seems paramount for the continued survival and 
quality of life in humans, exploration of GR function in organisms than can endure long periods of time under conditions that mimic disease-like states is of great interest to understanding the role of GR in disease. A common theme observed for the diseases mentioned above is an increase in oxidative stress imposed on both the whole cell and at the mitochondrial level due to fluctuations in blood flow and oxygen deprivation. Organisms experiencing changes in GR regulation under oxygen deprived states include: the red eared slider turtle (Trachemys scripta elegans) which shows fluctuations in GR activity as well as decreased GSH levels in the liver, heart and muscle during anoxia (Willmore and Storey, 1997), the leopard frog (Rana pipiens) which shows a reduction in GR activity in muscle tissue during severe dehydration (Hermes-Lima and Storey, 1998), the common carp (Cyprinus carpio) which shows increases in GR activity in the brain during hypoxia (Lushchak et al., 2005), the spadefoot toad (Scaphiopus couchii) where GR activity in the liver, heart and kidney was significantly lower during estivation (Grundy and Storey, 1998), and the marine periwinkle (Littorina littorea) where GR activity decreased in the hepatopancreas during anoxia as well as foot muscle upon exit from anoxia (Pannunzio and Storey, 1998).

In line with the animals discussed above, the freeze-tolerant frog also experiences low oxygen, specifically in the form of ischemia, which has been repeatedly demonstrated to include oxidative stress and a burst production of ROS in the reperfusion recovery episode (Ferrari et al., 1991; Simpson and Lucchesi, 1987; Zweier and Talukder, 2006). Studies involving the overexpression or increased activity of GR in the mitochondria have shown increased resistance to oxidative stress (Foyer 1995; Mockett 1999). Therefore, through exploration of the role of GR in maintaining GSH pools during 
freezing in $R$. sylvatica, with particular importance in the mitochondria, the regulation of GR in the frozen frog presented in this chapter can provide important information for both the survival of the animal and insight into disease states by staving off signaling of apoptosis upon reoxygenation.

\subsection{Kinetic changes of GR in the face of increasing glucose}

The kinetic properties of wood frog skeletal muscle GR did not change significantly when comparing GR purified from control and frozen animals (Table 3.2). Since GR is an abundant enzyme in muscle cells, and found in several subcellular locations, it may be less energetically costly to modify the entire GR pool in order to deal with the stress imposed by freezing. However, covalent modification of proteins is only one of many methods to change enzyme activity or function. $R$. sylvatica increases the levels of select osmolytes to extreme levels during freezing such as glucose $(>200 \mathrm{mM}$ levels) which seem to affect the enzymatic function of GR (Storey and Storey, 2004).

GR purified from the muscle of $R$. sylvatica demonstrated significant changes in affinity for GSSG when tested in the presence of the physiological concentrations of glucose or urea that are encountered during freezing (Table 3.2). GR showed a significant decrease in affinity for GSSG when subjected to physiological levels of urea (75 mM) that can be preseent during freezing (Table 3.2). This phenomenon was overwhelmed by the effects of high glucose, since purified GR showed a significant increase in affinity for GSSG when subjected to physiological levels of glucose alone or glucose + urea (Table 3.2). As previously mentioned, $R$. sylvatica elevates glucose levels in order to prevent the 
osmotic loss of water from cells due to freezing of extracellular water. The frog may be benefitting from a preexisting hyperglycemic response to augment the function of GR. Ischemia stress must be removed in order to return glucose levels to normal, therefore, the positive effects of glucose on GR activity would likely remain throughout the burst production of ROS during reperfusion. Once the initial oxidative stress imposed on the cells due to prolonged ischemia has been surmounted, freezing, and subsequently the glucose levels will gradually return to normal levels, and the glucose-induced increase in GR affinity for GSSG will also return to normal. This is of note, since the GSSG/GSH ratios are involved in many signaling pathways, and could be disrupted by maintaining elevated GR affinity beyond the necessary time to overcome reperfusion induced ROS production.

In humans, high glucose has been suggested to increase the production of free radicals, and ultimately cell death and reduced proliferation, in diabetic and glucose treated human cell lines (Curcio and Ceriello, 1992; Durante et al., 1988; Ceriello et al., 1993; Tesfamaiam and Cohen, 1992). However, the effect of elevated or added GSH has demonstrated protective effects on glucose-treated human cell lines (Marfella et al., 1995). Previous studies on the effects of elevated glucose levels on antioxidant enzymes have demonstrated up-regulation in the presence of high glucose, suggesting that glucose can stimulate the activity of antioxidant enzymes (Ceriello et al., 1996). It is clear from these studies, as well as the evidence of glucose-activated GR in this chapter, that the relationship between glucose levels, free radicals and antioxidant enzyme activity is linked. 


\subsection{Kinetic changes of GR due to common metabolites}

The effect of $\mathrm{Ca}^{2+}$ on GR is likely linked to damage of the mitochondrial membrane, which would lead to an increase in the cytoplasmic $\mathrm{Ca}^{2+}$ concentration (Halliwell, 1992). Leakage of $\mathrm{Ca}^{2+}$ has been widely characterized in the mitochondrial signaling of apoptosis (Pinton et al., 2008). It has also been suggested that freeze-thaw cycles can disrupt $\mathrm{Ca}^{2+}$ transport in muscle, suggesting that as $\mathrm{Ca}^{2+}$ levels return to normal, GR activity could be influenced by the change in $\mathrm{Ca}^{2+}$ levels (Storey and Storey 2004; Halliwell, 1992).

Cellular $\mathrm{Mn}^{2+}$ exists mainly in complexes with proteins and a rise in free metals is usually due to damage of proteins, and subsequent release of the bound metals from the protein structure (Valko et al., 2005). It would appear that the inhibition of GR could be linked to cellular damage and subsequent release of $\mathrm{Mn}^{2+}$ when proteins are damaged; however, it is unclear at this time what the role of $\mathrm{Mn}^{2+}$ is in inhibiting GR activity in $R$. sylvatica.

R. sylvatica ATP levels have been shown to drop during freezing (Storey and Storey, 1985). ATP, ADP and AMP were observed to activate GR similarly (Table 3.2) suggesting that any activation of GR by changes in adenylate ratios during freezing, is unlikely. 


\subsection{Phosphorylation of GR during freezing and induced phosphorylation of GR by} endogenous kinases

Reversible protein phosphorylation has been demonstrated as an important method of modifying key enzymes involved in the success of $R$. sylvatica during freezing (Dieni and Storey, 2008; Dieni and Storey, 2009; Dieni and Storey, 2010; Dieni and Storey, 2011; Abboud and Storey, 2013; Chapter 2 and 4). The potential phosphorylation of GR during freezing was therefore explored in order to determine if this same method of regulation was used to aid GSSG/GSH homeostasis during freezing. There was, however, no evidence of changes in the phosphorylation state of GR between control or frozen states as assessed by ProQ diamond staining (Figure 3.4). This lack of phosphorylation suggested that any differences in GR activity are not due to a freezeinduced phosphorylation event.

The phosphorylation state of GR was nonetheless explored as a potential method of further regulating the protein and to discover if different phosphorylation profiles are possible between the control and frozen states. The activities of endogenous kinases were stimulated in frog muscle homogenates as described in section 2.7 , resulting in the phosphorylation of frog muscle GR (Figure 3.5). Figure 3.2 shows the elution profile for control and frozen preparations from a $\mathrm{DEAE}^{+}$column. There was no significant difference in the elution profiles, seemingly suggesting that no frozen state-specific phosphorylation site exists. Further analysis of the induced phosphorylation of GR suggested that phosphorylation was achieved on serine, threonine and tyrosine residues (Figure 3.6). This is the first study to show phosphorylation of GR in vitro. 
However, phosphorylation of GR does not seem to play a role in freeze tolerance of $R$. sylvatica, but, it highlights the propensity of GR for phosphorylation, which may play other roles in the regulation of GR in the frog. Investigation into the putative phosphorylation sites on GR, based on sequences from $X$. laevis and $X$. tropicalis, showed the presence of putative sites for serine, threonine and tyrosine kinases supporting the notion that endogenous kinases in $R$. sylvatica muscle can phosphorylate GR (Figure 3.7). Several of the kinases stimulated in the endogenous incubation study were among those predicted to phosphorylate GR, including AMPK, CamK, PKA and PKC. This suggests that although altered phosphorylation of GR is not part of freezetolerance in $R$. sylvatica, it could play a role in other cellular functions. Interestingly, human GR also shows potential serine, threonine and tyrosine predicted phosphorylation sites, suggesting the possibility for GR phosphorylation in humans. Although GR shows the propensity for phosphorylation, more work must be conducted to elucidate the physiological role of phosphorylation of this enzyme. It is clear, however, that the phosphorylation of GR during freezing in $R$. sylvatica is unlikely to have a role in maintenance of the GSH/GSSG levels.

\subsection{Thermal stability and temperature dependent activity of GR}

GR purified from both control and frozen frogs was explored via DSF, and showed no significant differences in enzyme structural stability between states (Figure 3.9). This provides further proof that GR from control and frozen animals is not functionally different. Past studies of GR have demonstrated the thermodynamic stability 
of GR activity, and have similarly shown that GR remains active across a broad range of temperatures (Ohtsuka et al., 1994; Lopez-Barea and Chi-Yu, 1979; Rescigno and Perham 1994). The $\mathrm{T}_{\mathrm{m}}$ determined for frog GR shows that denaturation takes place at a relatively high temperature of approximately $64^{\circ} \mathrm{C}$, suggesting the GR is a very stable enzyme (Table 3.2, Figure 3.9). The calculated $E_{a}$ was $40.7 \mathrm{~kJ} / \mathrm{mol}$ which suggests that the reaction catalyzed by GR is endothermic in nature, and that the reaction may be hindered at low temperatures.

\subsection{Conclusion}

This study of the regulation of GR in the freeze tolerant frog, $R$. sylvatica provides useful insights into the maintenance of the cellular redox states as well as the GSSG/GSH ratios involved in apoptotic cell signaling. GR from the muscle of $R$. sylvatica does not seem to be covalently modified during freezing, although it does show the propensity to be phosphorylated through activation of endogenous kinases. The regulation of GR activity during freezing seems to be related to the changing cellular environment, specifically increases in glucose concentrations. GR from $R$. sylvatica seems to have coupled an increase in affinity for GSSG with a natural increase in the concentration of glucose during freezing. Although cytosolic concentrations of GSH are significantly higher in $R$. sylvatica in comparison to other closely related frog species, an increase in GR activity may be vital to maintaining GSH/GSSG levels, specifically in the mitochondria. The mitochondrial production of ROS has been linked to apoptotic signaling, and GR activity may be augmented in order to combat the mitochondrial 
production of ROS during thaw-induced reperfusion. GR, along with many antioxidantrelated proteins, has a high degree of similarity across species. The similarity observed in mitochondrial proteins could allow for researchers to explore possible roles for GR in a controlled ischemic state, such as freezing in $R$. sylvatica. It is clear from this study and others, that the role of GSH and GR maintenance of the mitochondrial redox environment during freezing in R. sylvatica should be explored in greater detail, as it could provide valuable insight into disease pathology by offering a unique observation of the role of GR during ischemia. 


\section{References}

Abboud, J. and Storey, K.B. 2013. Novel control of lactate dehydrogenase from the freeze tolerant wood frog: role of posttranslational modifications. Peer J. 1:e12

Aksenov, M.Y. and Markesbery, W.R. 2001. Changes in thiol content and expression of glutathione redox system genes in the hippocampus and cerebellum in Alzheimer's disease. Neurosci Lett. 302:141-145.

Armstrong, J.S. Steinauer, K.K., Hornung, B., Irish, J.M., Lecane, P., Birrell, G.W., Peehl, D.M., and Knox, S.J. 2002. Role of glutathione depletion and reactive oxygen species generation in apoptotic signaling in a human B lymphoma cell line. Cell Death Differ. 9:252-263.

Ceriello, A., dello Russo, P., Amstad, P., and Cerutti, P. 1996. High glucose induces antioxidant enzymes in human endothelial cells in culture: Evidence linking hyperglycemia and oxidative stress. Diabetes. 45:471-477.

Circu, M.L. and Aw, T.Y. Glutathione and apoptosis. 2008. Free Radic Res. 42:689-706.

Cowan, K.J. and Storey ,K.B. 2001. Freeze-thaw effects on metabolic enzymes in wood frog organs. Cryobiology. 43:32-45.

Curcio, F. and Ceriello, A. 1992. Decreased cultured endothelial cell proliferation in high glucose medium is reversed by antioxidants: new insights on the pathophysiological mechanism of diabetic vascular complications. In Vitro Cell Dev Biol. 28A:787-790.

Dawson, N.J., Bell, R.A., Storey, K.B., 2013. Purification and properties of white muscle lactate dehydrogenase from the anoxia-tolerant turtle, the red-eared slider, Trachemys scripta elegans. Enz Res. 2013:784973.

De Croos, J.N., McNally, J.D., Palmieri, F., and Storey, K.B. 2004. Upregulation of the mitochondrial phosphate carrier during freezing in the wood frog Rana sylvatica: potential roles of transporters in freeze tolerance. J Bioenerg Biomembr. 36:229239. 
Diaz-Hernandez, J.I., Almeida, A., Delgado-Esteban, M., Fernandez, E., and Bolanos, J.P. 2005. Knockdown of glutamate-cysteine ligase by small hairpin RNA reveals that both catalytic and modulatory subunits are essential for the survival of primary neurons. J Biol Chem. 280:38992-39001.

Dieni, C.A. and Storey, K.B. 2008. Regulation of 5'-adenosine monophosphate deaminase in the freeze tolerant wood frog, Rana sylvatica. BMC Biochem. 9:12.

Dieni, C.A. and Storey, K.B. 2009. Creatine kinase regulation by reversible phosphorylation in frog muscle. J Comp Biochem Physiol B. 152:405-412.

Dieni, C.A. and Storey, K.B. 2010. Regulation of glucose-6-phosphate dehydrogenase by reversible phosphorylation in liver of a freeze tolerant frog. J Comp Physiol B. 180:1133-1142.

Dieni, C.A. and Storey, K.B. 2011. Regulation of hexokinase by reversible phosphorylation in skeletal muscle of a freeze tolerant frog. Comp Biochem Physiol B. 159:236-243.

Durante, W., Sen, A.K., and Sunahara, F.A. 1988. Impairment of endothelium-dependent relaxation in aortae from spontaneously diabetic rats. Br J Pharmacol. 94:463-468.

Famulari, A.L., Marschoff, E.R., Llesuy, S.F., Kohan, S., Serra, J.A., Dominquez, R.O., Repetto, M., Reides, C., and Sacerdote de Lustig, E. 1996. The antioxidant enzymatic blood profile in Alzheimer's and vascular diseases. Their association and possible assay to differentiate demented subjects and controls. J Neurol Sci. 141:69-78.

Franco, R., Schoneveld, O.J., Pappa, A., and Panayiotidis, M.I. 2007. The central role of glutathione in the pathophysiology of human diseases. Arch Physiol Biochem. 113:234-258.

Franco, R. and Cidlowski, J.A. 2009. Apoptosis and glutathione: beyond an antioxidant. Cell Death Differ. 16: 1303-1314.

Forman, H.J., Zhang, H., Rinna, A. 2008. Glutathione: overview of its protective roles, measurement, and biosynthesis. Mol Aspects Med. 30:1-12. 
Friesen, C., Kiess, Y., and Debatin, K.M. 2004. A critical role of glutathione in determining apoptosis sensitivity and resistance in leukemia cells. Cell Death Differ. 11(1):S73-S85.

Galluzzi, L., Maiuri, M.C., Vitale, I., Zischka, H., Castedo, M., Zitvogel, L., and Kroemer, G. 2007. Cell death modalities: classification and pathophysiological implications. Cell Death Differ. 14:1237-1243.

Garcia-Ruiz, C. and Fernandez-Checa, J.C. 2006. Mitochondrial glutathione: hepatocellular survival death switch. J Gastroenterol Hepatol. 21(3): S3-S6.

Grundy, J.E. and Storey, K.B. Antioxidant defenses and lipid peroxidation damage in estivating toads, Scaphiopus couchii. 1998. J Comp Physiol B. 168(2):132-42.

Halliwell, B. 1992. Reactive oxygen species and the central nervous system. $J$ Neurochem. 59:1609-1623.

Hermes-Lima, M. and Storey, K.B. 1993. Antioxidant defenses in the tolerance of freezing and anoxia by garter snakes. Am J Physiol. 265:R646-R652.

Hermes-Lima, M. and Storey, K.B. 1995. Antioxidant defenses and metabolic depression in a pulmonate land snail. Am J Physiol. 268:R1386-R1393.

Hermes-Lima, M. and Storey, K.B. 1998. Role of antioxidant defenses in the tolerance of severe dehydration in anurans. The case of the leopard frog Rana pipiens. Mol Cell Biochem. 189:79-89.

Holden, C.P. and Storey, K.B. 1996. Signal transduction, second messenger, and protein kinase responses during freezing exposure in wood frogs. Am J Physiol. 271:R1205-R1211.

Hudson, N.J., Lehnert, S.A., Ingham, A.B., Symonds, B., Franklin, C.E. and Harper, G.S. 2005. Lessons from an estivating frog: sparing muscle protein despite starvation and disuse. Am J Physiol. 290(3):R836-R843.

Joanisse, D.R. and Storey, K.B. 1996. Oxidative damage and antioxidants in Rana sylvatica, the freeze-tolerant wood frog. Am J Physiol. 271(3):R545-R553. 
Klein, S.L., Strausberg, R.L., Wagner, L., Pontius, J., Clifton, S.W. and Richardson, P. 2002. Genetic and genomic tools for Xenopus research: The NIH Xenopus initiative. Dev Dyn. 225(4):384-91.

Krauth-Siegel, R.L., Arscott, L.D., Schönleben-Janas, A., Schirmer, R.H. and Williams, C.H. 1998. Role of active site tyrosine residues in catalysis by human glutathione reductase. Biochemistry. 37(40):13968-13977.

Lash, L.H. 2006. Mitochondrial glutathione transport: physiological, pathological and toxicological implications. Chem Biol Interact. 163:54-67.

Lopez-Barea, J. and Lee, C.Y. 1979. Mouse-liver glutathione reductase. Eur J Biochem. 98:487-499.

Lushchak, V.I., Bagnyukova, T.V., Lushchak, O.V., Storey, J.M. and Storey, K.B. 2005. Hypoxia and recovery perturb free radical processes and antioxidant potential in common carp (Cyprinus carpio) tissues. Int J Biochem Cell Biol. 37(6):1319-1330.

Marchetti, P., Decaudin, D., Macho, A., Zamzami, N., Hirsch, T., Susin, S.A. and Kroemer, G. 1997. Redox regulation of apoptosis: impact of thiol oxidation status on mitochondrial function. Eur J Immunol. 27:289-296.

Marfella, R., Verrazo, G., Acampora, R., La Marca, C., Giunta, R., Lucarelli, C., Paolisso, G., Ceriello, A. and Giugliano, D. 1995. Glutathione reverses systemic hemodynamic changes induced by acute hyperglycemia in healthy subjects. Am $J$ Physiol. 268:E1167-E1173.

Mao, G.D. and Poznansky, M.J. 1992. Electron spin resonance study on the permeability of superoxide radicals in lipid bilayers and biological membranes FEBS Lett. 305(3):233-236.

McCord, J.M. 1995. Superoxide radical, controversies, contradictions and paradoxes. Proc Soc Exp Biol Med. 209:112-117.

Meister, A. 1995. Glutathione biosynthesis and its inhibition. Methods Enzymol. 252:2630. 
Merad-Boudia, M., Nicole, A., Santiard-Baron, D., Saille, C. and Ceballos-Picot, I. 1998. Mitochondrial impairment as an early event in the process of apoptosis induced by glutathione depletion in neuronal cells: relevance to Parkinson's disease. Biochem Pharmacol. 56:645-655.

Meyer, Y., Buchanan, B.B., Vignols, F. and Reichheld, J.P. 2009. Thioredoxins and glutaredoxins: unifying elements in redox biology. Annu Rev Genet. 43:335-367.

Mockett, R.J., Sohal, R.S. and Orr, W.C. 1999. Overexpression of glutathione reductase extends survival in transgenic Drosophila melanogaster under hyperoxia but not normoxia. FASEB J. 13:1733-42.

Mulherin, D.M., Thurnham, D.I. and Situnayake, R.D. 1996. Glutathione reductase activity, riboflavin status, and disease activity in rheumatoid arthritis. Ann Rheum Dis. 55:837-914.

Mullineaux, P. and Creissen, G.P. 1997.Glutathione reductase: regulation and role in oxidative stress. In: Oxidative stress and the molecular biology of antioxidant defences. (Scandalios , J.G., ed.) Cold Spring Harbor Monograph. Vol. 34. pp. $667-713$.

Muyderman, H., Wadey, A.L., Nilsson, M. and Sims, N.R. 2007. Mitochondrial glutathione protects against cell death induced by oxidative and nitrative stress in astrocytes. J Neurochem. 102:1369-1382.

Ohtsuka, Y., Yabunaka, N., Fujisawa, H., Watanabe, I. and Agishi, Y. 1994. Effect of thermal stress on glutathione metabolism in human erythrocytes. Eur J Appl Physiol Occup hysiol. 68(1):87-91.

Pannunzio, T.M. and Storey, K.B. 1998. Antioxidant defenses and lipid peroxidation during anoxia stress and aerobic recovery in the marine gastropod, Littorina littorea. J Exp Mar Biol Ecol. 221:277-292.

Pinton, P., Giorgi C., Siviero, R., Zecchini, E. and Rizzuto, R. 2008. Calcium and apoptosis: ER-mitochondria $\mathrm{Ca}^{2+}$ transfer in the control of apoptosis. Oncogene. 27:6407-6418. 
Pretsch, W. 1999. Glutathione reductase activity deficiency in homozygous Gr1a1Neu mice does not cause haemolytic anaemia. Genet Res. 73:1-5.

Reiter, R.J. (1995) Oxidative process and antioxidative defense mechanisms in the aging brain. FASEB J. 9:526-533.

Rescigno, M. and Perham, R.N. 1994. Structure of the NADPH-Binding motif of glutathione reductase: efficiency determined by evolution. Biochemistry. 33(19):5721-5727.

Rider, M.H., Hussain, N., Horman, S., Dilworth, S.M. and Storey, K.B. 2006. Stressinduced activation of the AMP-activated protein kinase in the freeze-tolerant frog Rana sylvatica. Cryobiology 53:297-309.

Rogers, L.K., Tamura, T., Rogers, B.J., Welty, S.E., Hansen, T.N. and Smith, C.V. 2004. Analyses of glutathione reductase hypomorphic mice indicate a genetic knockout. Toxicol Sci. 82:367-373.

Rogers, L.K., Bates, C.M., Welty, S.E. and Smith, C.V. 2006. Diquat induces renal proximal tubule injury in glutathione reductase-deficient mice. Toxicol Appl Pharmacol. 217:289-298.

Rubinsky, B., Lee, C.Y., Bastacky, J. and Onik, J. 1987. The process of freezing and the mechanism of damage during hepatic cryosurgery. Cryobiology 27:85-97.

Rubinsky, B., Wong, S.T.S., Hong, J.-S., Gilbert, J., Roos, M. and Storey, K.B. 1994. ${ }^{1}$ H magnetic resonance imaging of freezing and thawing in freeze-tolerant frogs. Am J Physiol. 266:R1771-R1777.

Scott, E.M., Duncan, I.W. and, Ekstrand V. 1963. Purification and properties of glutathione reductase of human erythrocytes. J Biol Chem. 238:3928-3933.

Storey, K.B. 1984. Freeze tolerance in the frog, Rana sylvatica. Experientia. 40:12611262.

Storey, K.B. 1990. Life in a frozen state: adaptive strategies for natural freeze tolerance in amphibians and reptiles. Am J Physiol. 258:R559-R568. 
Storey, K.B. and Storey, J.M. 2004. Physiology, biochemistry and molecular biology of vertebrate freeze tolerance: the wood frog. In: Life in the Frozen State (Benson, E., Fuller, B., and Lane, N., eds.) CRC Press, Boca Raton, pp. 243-274.

Sinclair, B.J., Stinziano, J.R., Williams, C.M., MacMillan, H.A., Marshall, K.E. and Storey, K.B. 2013. Real-time measurement of metabolic rate during freezing and thawing of the wood frog, Rana sylvatica: implications for overwinter energy use. J Exp Biol. 216:292-302.

Tesfamariam, B. and Cohen, R.A. 1992. Free radicals mediate endothelial dysfunction caused by elevated glucose. Am J Physiol. 264:H859-H864.

Thannickal, V. and Fanburg, B. 2000. Reactive oxygen species in cell signalling. Am J Physiol. 279:L1005-L1028.

Valko, M., Morris, H. and Cronin, M.T. 2005. Metals, toxicity and oxidative stress. Curr Med Chem. 12:1161-1208.

Vucetic, M., Stancic, A., Otasevic, V., Jankovic, A., Korac, A., Markelic, M., Velickovic, K., Golic, I., Buzadzic, B., Storey, K.B., and Korac, B. 2013. The impact of cold acclimation and hibernation on antioxidant defenses in the ground squirrel (Spermophilus citellus): an update. Free Radic Biol Med. 65:916-924.

Willmore, W.G. and Storey, K.B. 1997. Antioxidant systems and anoxia tolerance in a freshwater turtle Trachemys scripta elegans. Mol Cell Biochem. 170(1-2):177185. 
Table 3.1. Typical purification and yield of Rana sylvatica muscle GR

\begin{tabular}{lccccc}
\hline Purification Step & $\begin{array}{c}\text { Total } \\
\text { Protein } \\
(\mathbf{m g})\end{array}$ & $\begin{array}{c}\text { Total } \\
\text { Activity } \\
(\mathbf{m U})\end{array}$ & $\begin{array}{c}\text { Specific } \\
\text { Activity } \\
(\mathbf{m U} / \mathbf{m g})\end{array}$ & $\begin{array}{c}\text { Fold } \\
\text { Purification }\end{array}$ & $\begin{array}{c}\text { Yield } \\
(\%)\end{array}$ \\
\hline Crude extract & 73.6 & 69.3 & 0.94 & - & 100 \\
Sephadex G50 & 63.6 & 63.0 & 0.99 & 1.1 & 91.0 \\
Hydroxylapatite & 0.55 & 25.8 & 46.91 & 49.9 & 37.2 \\
Cibacron Blue & 0.19 & 23.7 & 124.73 & 134.9 & 34.2 \\
\hline
\end{tabular}


Table 3.2. Kinetic parameters of GR purified from muscle of control and frozen $R$. sylvatica

\begin{tabular}{|c|c|c|}
\hline Enzyme parameters & Control & 24h Frozen \\
\hline $\mathrm{K}_{\mathrm{m}} \mathrm{GSSG}(\mathrm{mM})$ & $0.054 \pm 0.006$ & $0.048 \pm 0.003$ \\
\hline $\mathrm{V}_{\max }(\mathrm{mU} / \mathrm{gww})$ & $125 \pm 6.1$ & $121 \pm 5.3$ \\
\hline $\mathrm{T}_{\mathrm{m}}$ & $63.8 \pm 0.4$ & $64.7 \pm 0.4$ \\
\hline $\mathrm{K}_{\mathrm{m}} \mathrm{GSSG}+$ Urea $(\mathrm{mM})$ & $0.085 \pm 0.009 *$ & \\
\hline $\mathrm{K}_{\mathrm{m}} \mathrm{GSSG}+\mathrm{Glucose}(\mathrm{mM})$ & $0.027 \pm 0.002 *$ & \\
\hline $\mathrm{K}_{\mathrm{m}}$ GSSG+Glucose+Urea (mM) & $0.031 \pm 0.002 *$ & \\
\hline $\mathrm{K}_{\mathrm{a}} \mathrm{ATP}(\mathrm{mM})$ & $0.076 \pm 0.02$ & \\
\hline Fold activation ATP & 1.42 & \\
\hline $\mathrm{K}_{\mathrm{a}} \mathrm{ADP}(\mathrm{mM})$ & $0.071 \pm 0.01$ & \\
\hline Fold activation ADP & 1.37 & \\
\hline $\mathrm{K}_{\mathrm{a}} \mathrm{AMP}(\mathrm{mM})$ & $0.16 \pm 0.03$ & \\
\hline Fold activation AMP & 1.35 & \\
\hline $\mathrm{I}_{50} \mathrm{Mn}^{2+}(\mathrm{mM})$ & $4.44 \pm 0.33$ & \\
\hline $\mathrm{I}_{50} \mathrm{Mg}^{2+}(\mathrm{mM})$ & No inhibition $\leq 10 \mathrm{mM}$ & \\
\hline $\mathrm{I}_{50} \mathrm{~K}^{+}(\mathrm{mM})$ & No inhibition $\leq 10 \mathrm{mM}$ & \\
\hline $\mathrm{I}_{50} \mathrm{Ca}^{2+}(\mathrm{mM})$ & $5.12 \pm 0.99$ & \\
\hline $\mathrm{E}_{\mathrm{a}}(\mathrm{kJ} / \mathrm{mol})$ & $40.7 \pm 0.9$ & \\
\hline
\end{tabular}

To test the effects of additives on $\mathrm{K}_{\mathrm{m}}$, assays were run with the addition of $75 \mathrm{mM}$ urea or $300 \mathrm{mM}$ glucose. $\mathrm{K}_{\mathrm{a}}$ and $\mathrm{I}_{50}$ values were determined at $\mathrm{K}_{\mathrm{m}}$ values for GSSG. Means \pm $\mathrm{SEM}, \mathrm{n}=8$. * - Signigficantly different from control value without additives. 

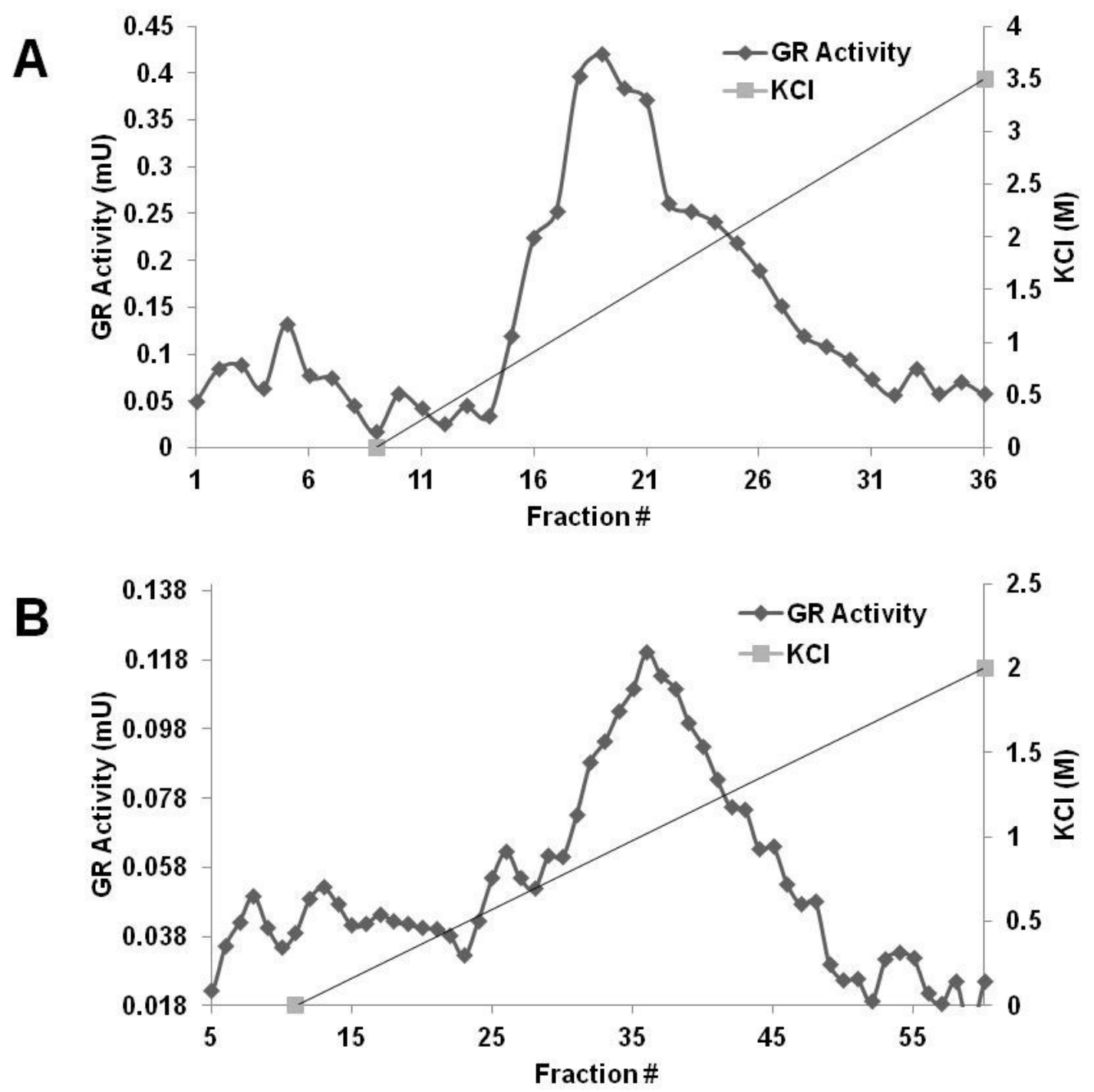

Figure 3.1. (A) Typical elution profile for GR on a hydroxyapatite column. (B) Typical elution profile for GR on a Cibacron blue column. 


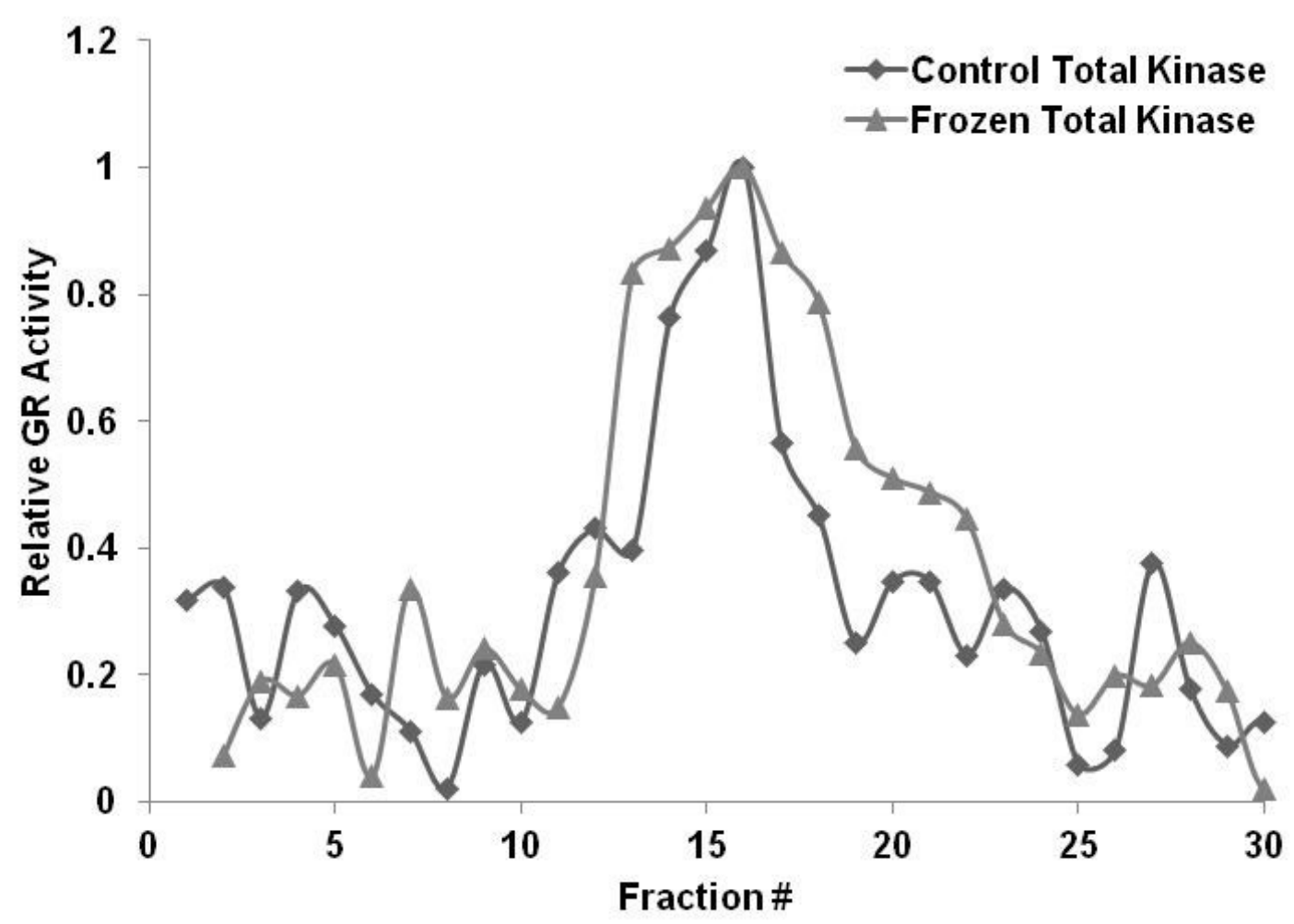

Figure 3.2. $\mathrm{DEAE}^{+}$elution profiles for purified GR from control and $24 \mathrm{~h}$ frozen muscle after incubation to stimulate protein kinases. 


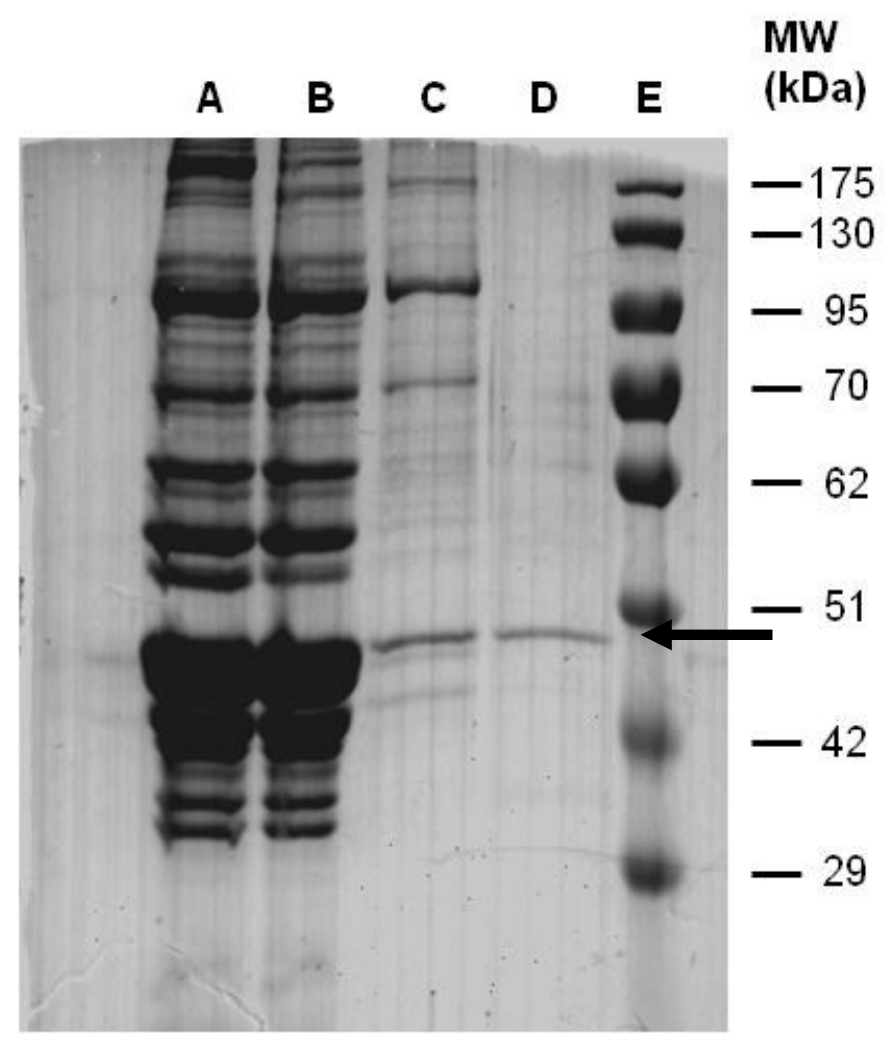

Figure 3.3. Purified GR from the muscle of control R. sylvatica. (A) crude muscle homgogenate, (B) GR-containing eluant after Sephadex G50 chromatography, (C) GRcontaining eluant after hydroxylapetite chromatography, (D) purified GR from Cibacron blue chromatography, and (E) molecule weight standards. GR protein is the prominent band at $\sim 50 \mathrm{kDa}$ indicated by the arrow. 


\section{MW}

(kDa)

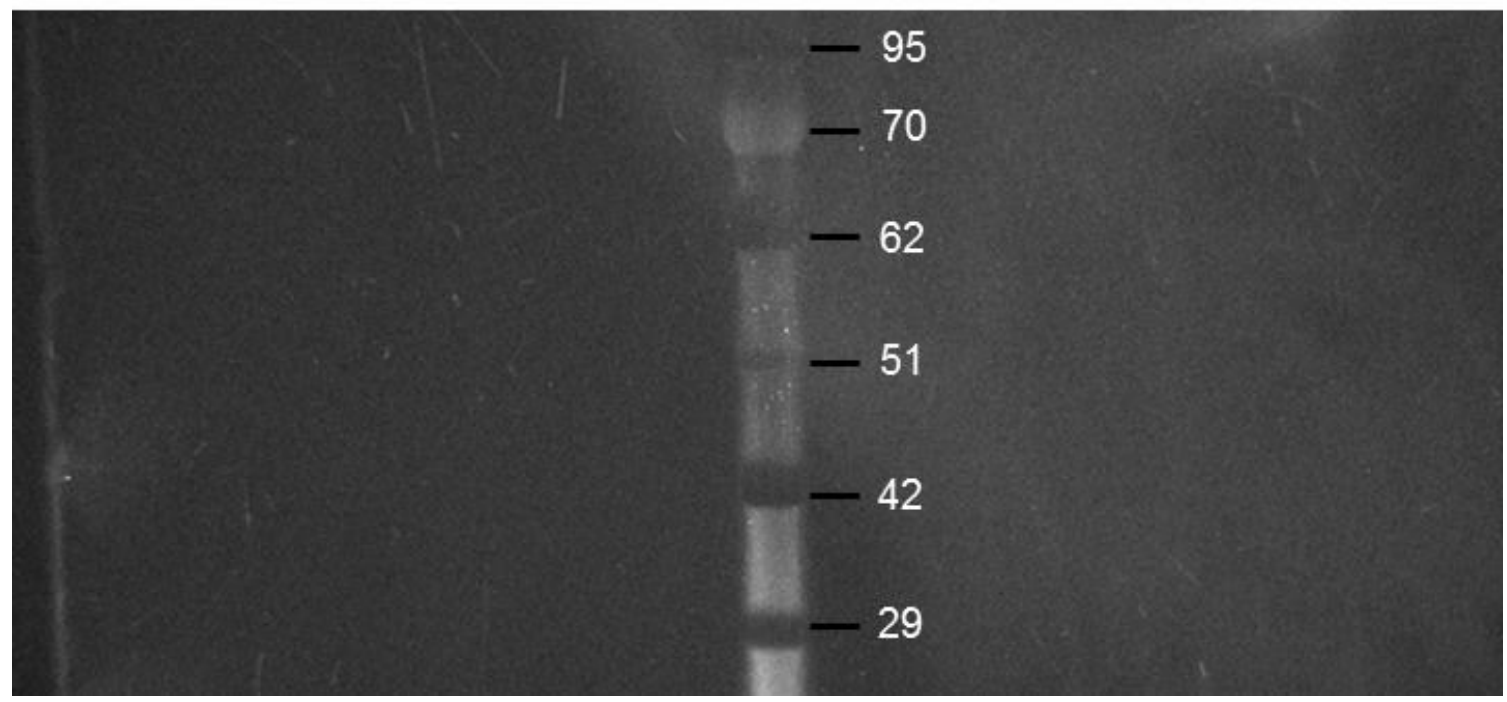

Figure 3.4. Absence of bands indicates no apparent phosphorylation of muscle GR from either control or $24 \mathrm{~h}$ frozen frogs as assessed by Pro-Q diamond phosphoprotein staining.

\section{MW}

(kDa)

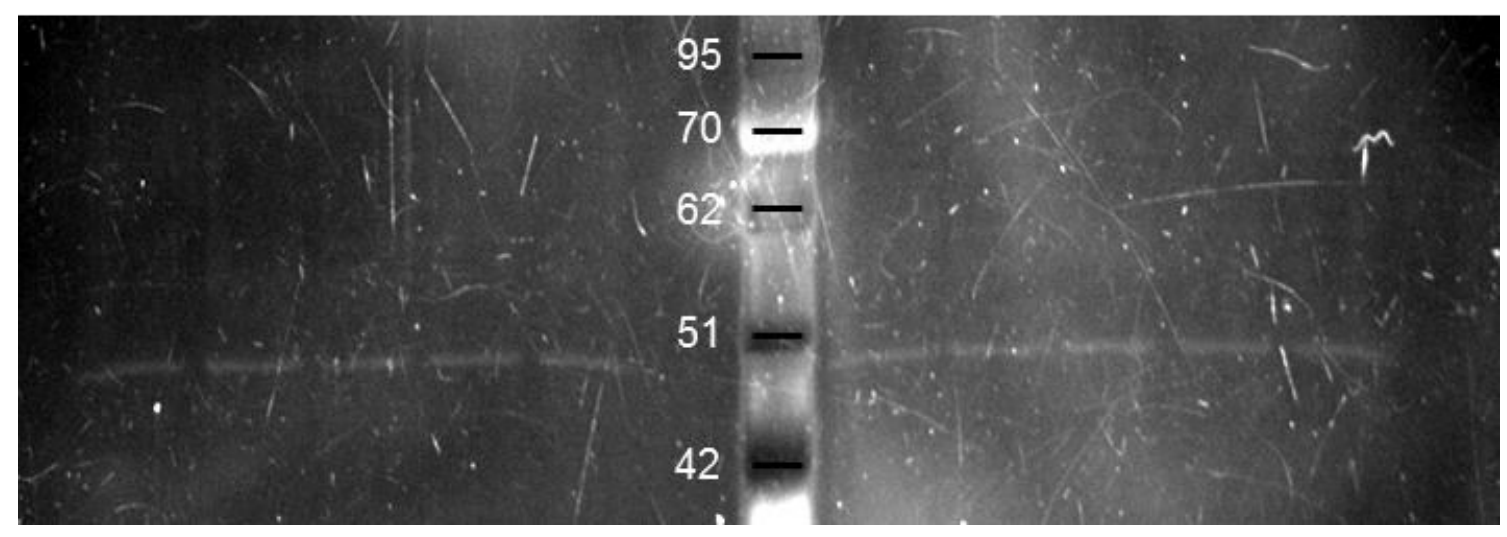

Figure 3.5. Relative phosphorylation levels of GR from control and $24 \mathrm{~h}$ frozen frog muscle after total kinase incubations as assessed by Pro-Q diamond phosphoprotein staining. Bands on the left are for GR from control muscle; on the right are $24 \mathrm{~h}$ frozen. 


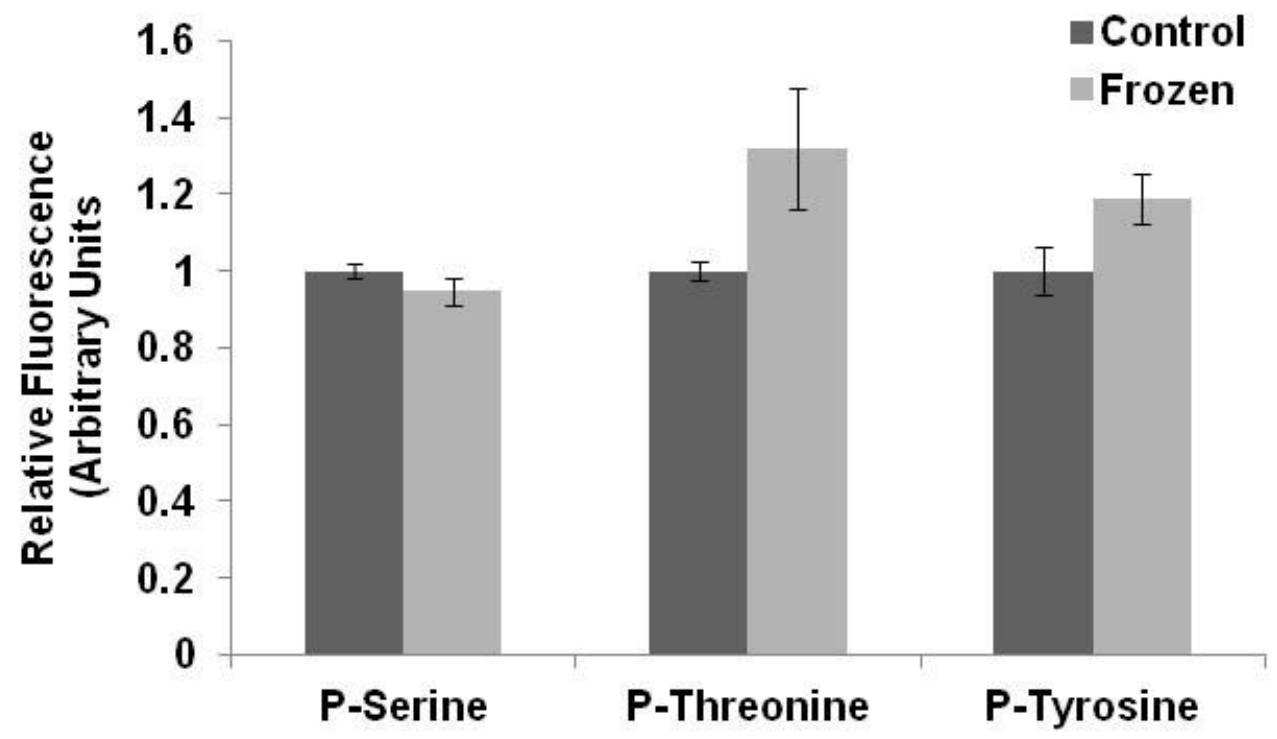

Figure 3.6. Relative phosphorylation levels of wood frog muscle GR after incubations to stimulate total kinases; control and $24 \mathrm{~h}$ frozen conditions are compared using Westernblot analysis of site-specific phosphorylation. Data are means \pm SEM, $n=4$ There were no significant differences between control and frozen values, $\mathrm{p}<0.05$. 


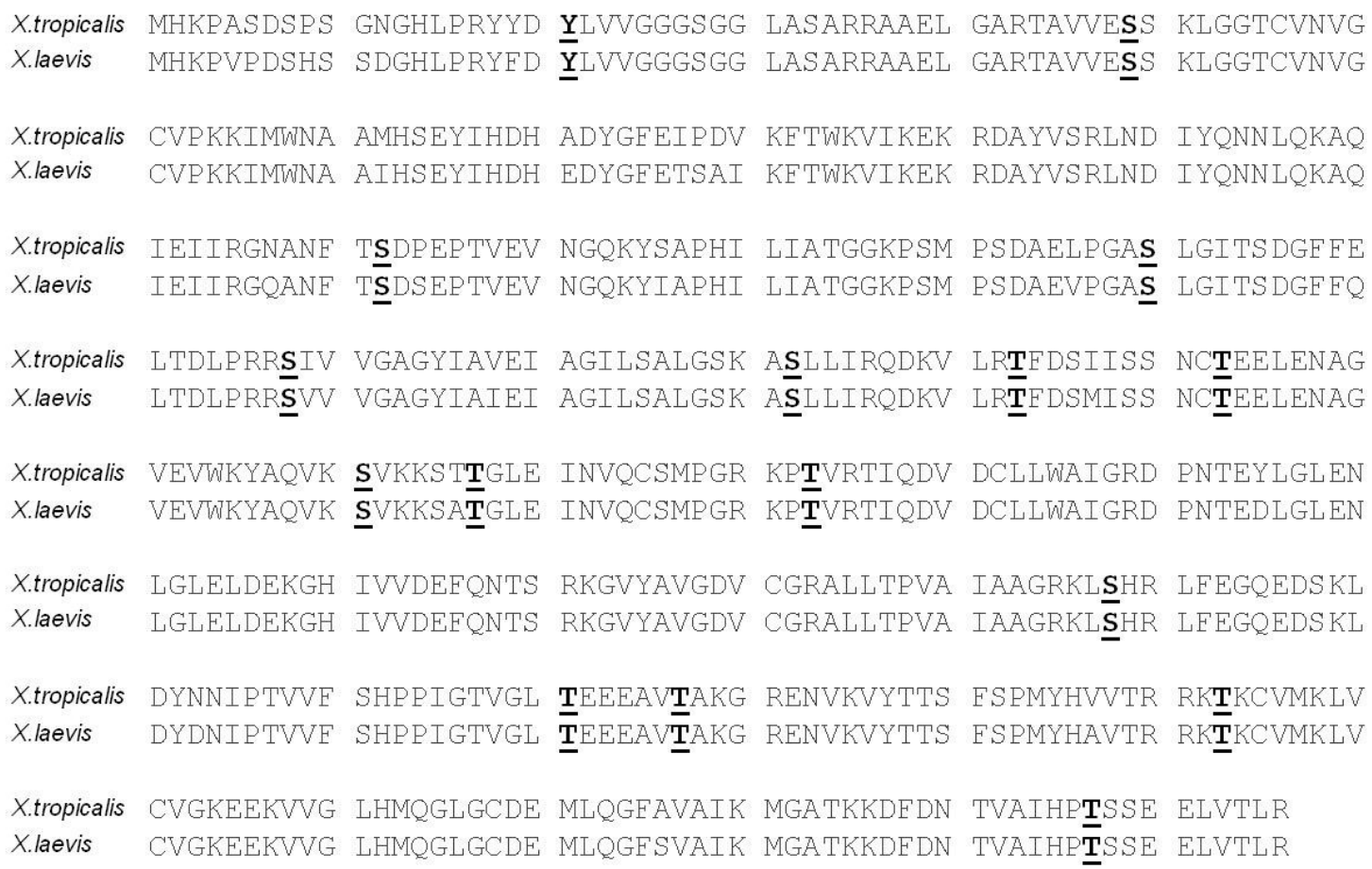

Figure 3.7. A comparison of the predicted serine (S), threonine (T) and tyrosine (Y) phosphorylation sites on GR that are shared between $X$. tropicalis and X. laevis. Predicted phosphorylation sites are shown in bold and underlined. 


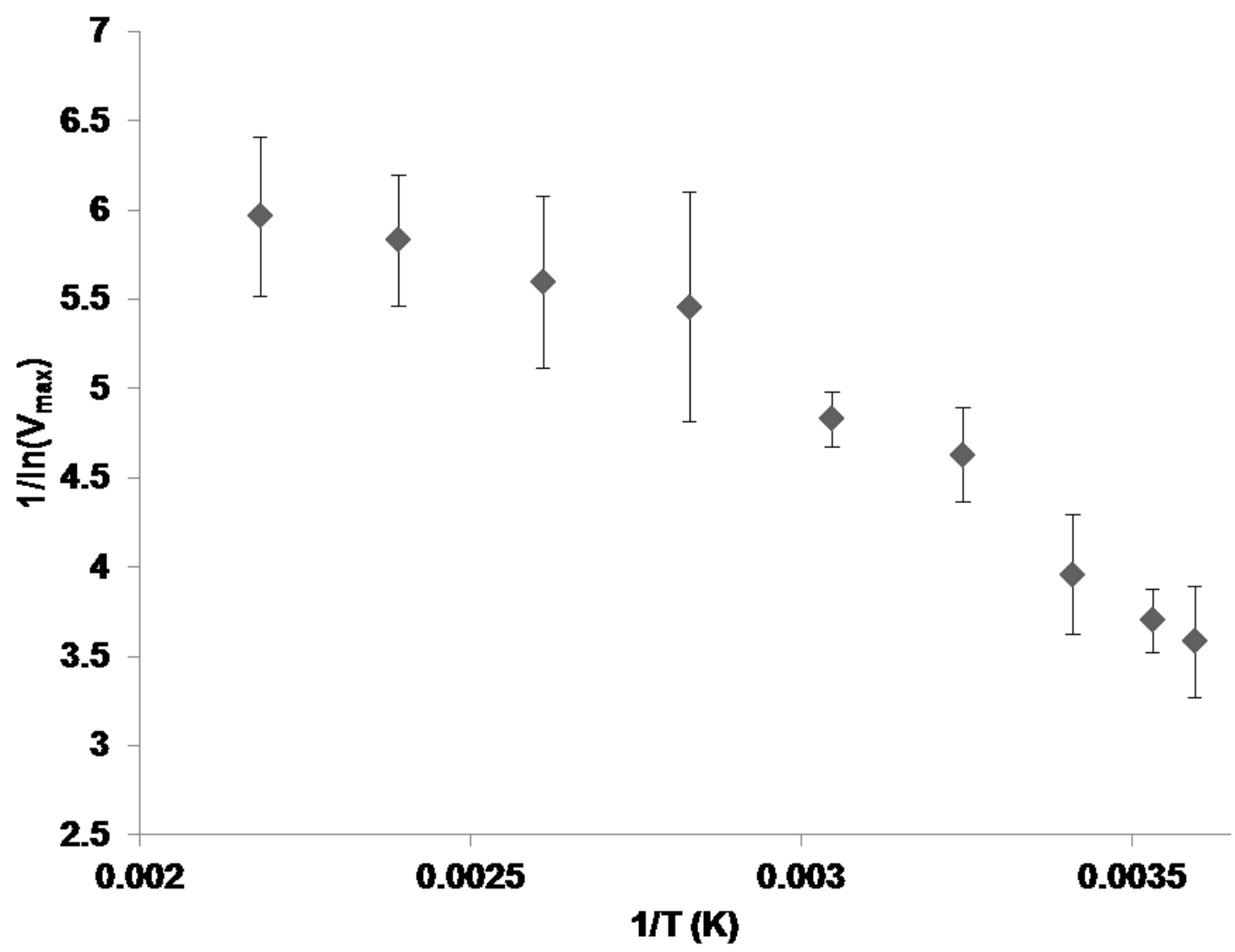

Figure 3.8. Arrhenius plot for purified GR from the muscle of control R. sylvatica. Data are means \pm SEM, $n=4$. 


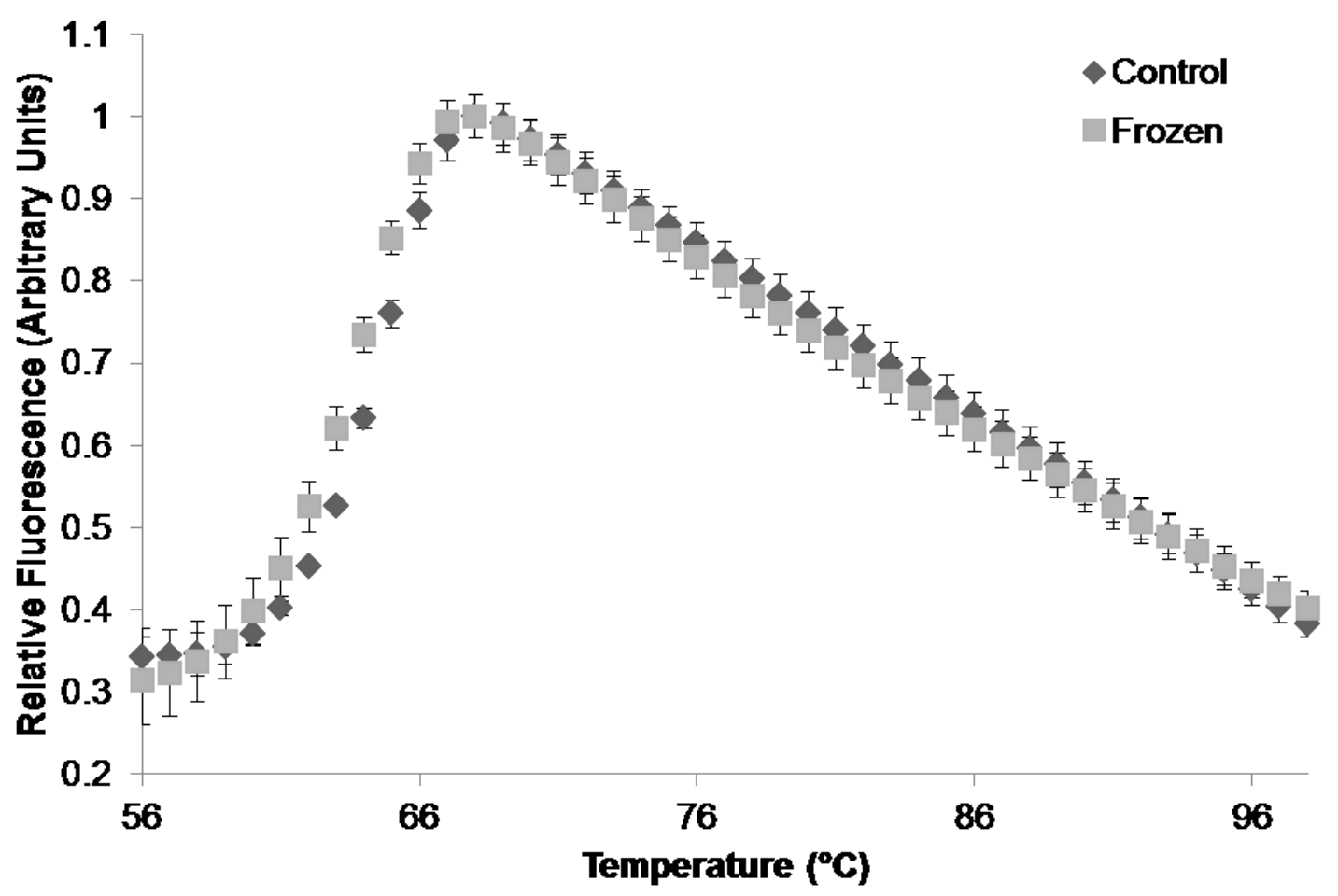

Figure 3.9. Differential scanning fluorimetry analysis of the thermal stability of purified GR from control and $24 \mathrm{~h}$ frozen frog muscle. Frozen GR showed no significant difference when compared to GR from control frogs, $\mathrm{n}=8$ independent trials. 


\section{Chapter 4:}

A hydrogen peroxide safety valve: The reversible phosphorylation of catalase from the freeze tolerant North American wood frog, Rana sylvatica. 


\section{Introduction}

Formation of $\mathrm{H}_{2} \mathrm{O}_{2}$ in animal tissues can arise directly from enzymatic sources, specifically a number of different oxidases including xanthine oxidase, monoamine oxidase, and amino acid oxidase (Sies, 1974). However, $\mathrm{H}_{2} \mathrm{O}_{2}$ formation due to superoxide dismutase activity is considered to be the major cellular source (Boveris et al., 1972). Although $\mathrm{O}_{2}{ }^{-}$can spontaneously dismutate, superoxide dismutase catalyzes this reaction at much higher rates. Superoxide radicals have been linked to the mitochondrial formation of $\mathrm{H}_{2} \mathrm{O}_{2}$ via the respiratory chain (Loschen et al., 1971; Loschen et al., 1974). The mitochondria are a major site of $\mathrm{H}_{2} \mathrm{O}_{2}$ formation, due in large part to the superoxide formed via complexes I and III of the electron transport system (Drose and Brandt, 2008). Specifically, complex III releases $\mathrm{O}_{2}^{-}$into the intermembrane space, while complex I releases $\mathrm{O}_{2}{ }^{-}$into the inner mitochondrial matrix space where $\mathrm{MnSOD}$ produces $\mathrm{H}_{2} \mathrm{O}_{2}$ (Boveris et al., 1972; Loschen et al., 1971; Loschen et al., 1974). R. sylvatica muscle superoxide dismutase activity seems to be boosted in the mitochondria (chapter 2), which could lead to the increased formation of $\mathrm{H}_{2} \mathrm{O}_{2}$.

$\mathrm{H}_{2} \mathrm{O}_{2}$ is generated in a site specific manner and the local concentration of $\mathrm{H}_{2} \mathrm{O}_{2}$ is modulated by its generation and subsequent removal. The diffusion of $\mathrm{H}_{2} \mathrm{O}_{2}$ away from the site of production and across membranes creates a $\mathrm{H}_{2} \mathrm{O}_{2}$ gradient (Antunes and Cadenas, 2000). Furthermore, the sites of $\mathrm{H}_{2} \mathrm{O}_{2}$ removal, via catalase in the peroxisomes, glutathione peroxidase and peroxiredoxins in the cytosol and other organelles further drives this diffusion gradient from the site of production to the site of removal (Antunes and Cadenas, 2000; Mueller et al., 2009; Sobatta et al., 2013). Under normal cellular 
concentrations, peroxidases seem to play a much larger role in catalyzing the reduction of $\mathrm{H}_{2} \mathrm{O}_{2}$ in comparison to other enzymatically driven reduction reactions. This is in large part due to the significantly higher affinity for $\mathrm{H}_{2} \mathrm{O}_{2}$ by the peroxiredoxins (Kim et al., 1988). Peroxiredoxins are estimated to be responsible for the reduction of greater than $90 \%$ of the mitochondrial and cytosolic $\mathrm{H}_{2} \mathrm{O}_{2}$ under normal cellular conditions (Cox et al., 2010; Winterbourn, 2008). However, peroxiredoxins, like most peroxidase driven reactions, have limited flux and are inactivated via $\mathrm{H}_{2} \mathrm{O}_{2}$ reaction with cysteine thiolate in peroxiredoxins in the face of elevated levels of $\mathrm{H}_{2} \mathrm{O}_{2}$ (Flohe, 2010; Winterbourn, 2013; Hall et al., 2011). This means that under conditions such as ischemia/reperfusion, peroxiredoxins would likely be inactive.

Catalase (CAT) (E.C. 1.11.1.6) is a primary antioxidant enzyme responsible for catalyzing the decomposition of hydrogen peroxide into water and oxygen. There are three known types of CAT studied to date, however, only the mammalian model will be discussed herein. Mammalian CAT is a tetrameric protein containing four identical hemecontaining subunits (Young and Woodside, 2001). The exact mechanism by which CAT decomposes $\mathrm{H}_{2} \mathrm{O}_{2}$ is very complex; however, it can be simplified as follows:

$$
\begin{gathered}
\mathrm{H}_{2} \mathrm{O}_{2}+\mathrm{Fe}(\mathrm{III})-\mathrm{CAT} \rightarrow \mathrm{H}_{2} \mathrm{O}+\mathrm{O}=\mathrm{Fe}(\mathrm{IV})-\mathrm{CAT}^{+} \\
\mathrm{H}_{2} \mathrm{O}_{2}+\mathrm{H}_{2} \mathrm{O}+\mathrm{O}=\mathrm{Fe}(\mathrm{IV})-\mathrm{CAT}^{+} \rightarrow \mathrm{H}_{2} \mathrm{O}+\mathrm{Fe}(\mathrm{III})-\mathrm{CAT}+\mathrm{O}_{2}
\end{gathered}
$$

In this proposed mechanism, CAT reacts with $\mathrm{H}_{2} \mathrm{O}_{2}$ to form an intermediate called compound I which reacts with a second $\mathrm{H}_{2} \mathrm{O}_{2}$ molecule to return CAT to the native state (Andersson et al., 1991). It has been suggested that a key histidine residue in the active site is involved in the proton transfer (Andersson et al., 1991). 
Interestingly, CAT is a major NADPH binding enzyme, showing significantly high specificity for NADPH over NADH or the corresponding oxidized forms (Fita and Rossman, 1985; Kirkman et al., 1984). The function of NADPH is not fully understood, however, several proposed roles have recently emerged. The first role proposed for NADPH has been a protective one, in which NADPH may hinder the inactivation of CAT by $\mathrm{H}_{2} \mathrm{O}_{2}$ by oxidizing bound NADPH (Kirkman et al., 1999). The second is as an alternative reduction pathway for $\mathrm{CAT}$ at low $\mathrm{H}_{2} \mathrm{O}_{2}$ concentrations (Olson and Bruice, 1995; Ivancich et al., 1996; Hoffschir et al., 1998; Putnam et al., 2000). The last, and most interesting with respect to this thesis, is as a regulatory protein, releasing NADPH when the cell is under peroxidative stress (Kirkman et al., 1984). The release of NADPH from CAT could augment the activities of glutathione reductase in conjunction with glutathione peroxidase to help remove excess $\mathrm{H}_{2} \mathrm{O}_{2}$ (Kirkman et al., 1984).

Although there are several primary antioxidant enzymes involved in the detoxification of ROS species, CAT is the primary enzyme tasked with actively decomposing high levels of $\mathrm{H}_{2} \mathrm{O}_{2}$ and some other cytotoxic oxygen derivatives (Gaetani et al., 1996; Mueller et al., 1997). CAT is encoded by a similar gene, cat, in both frogs ( Xenopus tropicalis, X. laevis) and humans. CAT from X. tropicalis and X. laevis has a molecular weight of $60 \mathrm{kDa}$ as reported in the UniProtKB database (F6PYM8_XENTR, Q4FZM6_XENLA) (Klein et al., 2002). CAT has a significantly lower affinity for $\mathrm{H}_{2} \mathrm{O}_{2}$, than the peroxidase family of enzymes, and is often thought to carry out the reduction of $\mathrm{H}_{2} \mathrm{O}_{2}$ under extreme or toxic conditions (Kim et al., 1888).

Increases in mitochondrial $\mathrm{H}_{2} \mathrm{O}_{2}$ concentrations and loss of the enzymatic ability to reduce $\mathrm{H}_{2} \mathrm{O}_{2}$, has been shown to play a role in signaling during hypoxia, inflammation, 
and apoptosis (Finkel, 2012). Elevated $\mathrm{H}_{2} \mathrm{O}_{2}$ during ischemia / reperfusion has been demonstrated to overwhelm delicate balances in cellular $\mathrm{H}_{2} \mathrm{O}_{2}$ distribution, maintained by compartmentalized peroxidases, often triggering apoptosis under oxidative stress (Clement et al., 1998). Although it is unclear how $\mathrm{H}_{2} \mathrm{O}_{2}$ stimulates apoptosis, it is clear that CAT is important in humans and traditional animal models, however, less is known about its role in disease states, or its role aiding survival in the freezing frog. This chapter presents the first investigation of the potential method of regulation of CAT in the leg muscle of $R$. sylvatica, comparing control and frozen states, and provides evidence of CAT regulation by reversible protein phosphorylation during freezing, including the possibility of multiple phosphorylation states in vitro.

\section{Materials and Methods}

\subsection{Chemicals}

All biochemicals were from BioShop (Burlington, ON, Canada) with a few exceptions; hydrogen peroxide $\left(\mathrm{H}_{2} \mathrm{O}_{2}\right)$ was from Caledon Labs (Ontario, Canada), the

Cibacron blue column was from Affiland (Ans, Belgium), hydroxyapatite Bio-Gel ${ }^{\circledR}$ HTP Gel column was from Bio-Rad (Hercules, CA) and potassium phosphate, monobasic was from J.T. Baker Chemical Company (London, UK).

\subsection{Animals}

Wood frogs were cared for and sampled as described in chapter 2 section 2.2. 


\subsection{Preparation of muscle tissue lysates for protein purification}

For protein purification, samples of frozen muscle tissue were homogenized 1:5 w:v in ice-cold homogenizing buffer A [20 mM potassium phosphate (KPi) buffer, $\mathrm{pH}$ 7.2, containing $15 \mathrm{mM} \beta$-glycerophosphate, 1 mM EGTA, 1 mM EDTA, $10 \mathrm{mM} \beta$ mercaptoethanol, $5 \% \mathrm{v} / \mathrm{v}$ glycerol and $1 \mathrm{mM}$ phenylmethylsulfonyl fluoride (PMSF)]. Homogenates were then centrifuged at $13,500 \times g$ at $4{ }^{\circ} \mathrm{C}$ and the supernatant collected for use in protein purification.

\subsection{Purification of CAT}

A hydroxyapatite column was equilibrated in homogenization buffer A. A $3 \mathrm{~mL}$ aliquot of frog muscle extract was the applied to the column $(1.5 \mathrm{~cm} \times 2 \mathrm{~cm})$ and washed with $20 \mathrm{~mL}$ of buffer A to remove unbound proteins. CAT was eluted from the hydroxyapatite column with a linear gradient of 0-3.5 M KCl in buffer A. Fractions of $900 \mu \mathrm{L}$ were collected and $10 \mu \mathrm{L}$ from each fraction was assayed to detect CAT activity (see kinetic assays section for methodology). The top 7 fractions of peak CAT activity were pooled and diluted 10-fold with buffer A. The diluted fractions were applied to a Cibacron blue column $(1.5 \mathrm{~cm} \times 10 \mathrm{~cm})$ pre-washed with $30 \mathrm{~mL}$ of buffer $\mathrm{A}$. The Cibacron blue column was then washed with $30 \mathrm{~mL}$ of buffer A to remove unbound protein. Bound proteins were eluted with a linear gradient of $0-2 \mathrm{M} \mathrm{KCl}$ in buffer $\mathrm{A}$. Fractions of $450 \mathrm{~mL}$ were collected and $10 \mu \mathrm{L}$ from each fraction was assayed to detect CAT activity. The top 14 fractions of peak CAT activity were pooled and diluted 10-fold with buffer A. The diluted fractions were applied to a $\operatorname{DEAE}^{+}$column $(1.5 \mathrm{~cm} \times 20 \mathrm{~cm})$ 
pre-washed with $50 \mathrm{~mL}$ of buffer A. The DEAE ${ }^{+}$column was then washed with $50 \mathrm{~mL}$ of buffer A to remove unbound protein. Bound proteins were eluted with a linear gradient of 0-1 $\mathrm{M} \mathrm{KCl}$ in buffer A. Fractions of $900 \mathrm{~mL}$ were collected and $10 \mu \mathrm{L}$ from each fraction was assayed to detect CAT activity, the top 12 fractions were pooled for control CAT, while the top 9 fractions were pooled for frozen CAT. The purity of CAT was determined by combining aliquots of samples $2: 1 \mathrm{v}: \mathrm{v}$ with $2 \times$ SDS loading buffer $(100 \mathrm{mM}$ Tris buffer, pH 6.8, 4\% w/v SDS, 20\% v/v glycerol, $0.2 \% \mathrm{w} / \mathrm{v}$ bromophenol blue, $10 \% \mathrm{v} / \mathrm{v} 2-$ mercapotethanol), boiling for $5 \mathrm{~min}$, and then running $30 \mu \mathrm{L}$ samples purified from each successive purification on SDS-PAGE, as described in section 2.6.

\subsection{Kinetic assays}

CAT was assayed using a modified version of the method of Aebi (1984). Assay conditions were: $50 \mathrm{mM} \mathrm{KPi}$ buffer ( $\mathrm{pH}$ 7.2), $40 \mathrm{mM} \mathrm{H}_{2} \mathrm{O}_{2}$, and $10 \mu \mathrm{L}$ enzyme preparation. One unit of enzyme activity is the amount that reduces $1 \mu$ mol of $\mathrm{H}_{2} \mathrm{O}_{2}$ per minute at $25^{\circ} \mathrm{C}$. The amount of $\mathrm{H}_{2} \mathrm{O}_{2}$ was measured at $240 \mathrm{~nm}$ in a Thermo Labsystems Multiskan spectrophotometer (Thermo Scientific, Waltham, MA, USA). Data were analyzed using the Kinetics v.3.5.1 program, developed by Brooks (1992).

\subsection{Gel electrophoresis}

CAT was purified as described in section 2.4. Protein separation was achieved by running $30 \mu \mathrm{L}$ of CAT samples on 10\% SDS-PAGE gels. Sample aliquots were loaded onto polyacrylamide gels together with PageRuler ${ }^{\circledR}$ pre-stained molecular weight 
standards (Thermo Scientific; Cat\# 26616) and separated using a discontinuous buffer system. Electrophoresis was carried out at $180 \mathrm{~V}$ for 65 min using the BioRad MiniProtean 3 system with $1 \mathrm{x}$ Tris-glycine running buffer ( $0.05 \mathrm{M}$ Tris, $0.5 \mathrm{M}$ glycine, $0.05 \%$ w/v SDS). Protein banding was visualized with Coomassie blue.

\subsection{ProQ Diamond phosphoprotein staining}

Enzyme extracts from muscle of both control and frozen frogs were purified as described in section 2.4. The top fractions based on activity were pooled, and protein levels in the pooled fractions were quantified using the Coomassie blue dye-binding method. Aliquots of the pooled fractions were then mixed 2:1 v:v with SDS loading buffer (100 mM Tris buffer, $\mathrm{pH} 6.8,4 \% \mathrm{w} / \mathrm{v}$ SDS, $20 \% \mathrm{v} / \mathrm{v}$ glycerol, $0.2 \% \mathrm{w} / \mathrm{v}$ bromophenol blue, $10 \% \mathrm{v} / \mathrm{v}$ 2-mercapotethanol) and subsequently boiled for 5 minutes and stored at $-20^{\circ} \mathrm{C}$ until used. The gel was then run as in section 2.6 above and then subjected to ProQ diamond staining as described in chapter 3 section 2.7.

\subsection{Western blotting analysis of post-translational modifications of CAT}

Electrophoresis was carried out as described in section 2.6. Proteins on the gel were then electroblotted onto polyvinylidene difluoride (PVDF) membrane (Millipore, Bedford, MA) using a BioRad mini Trans-Blot cell. The transfer was carried out at 160 $\mathrm{mA}$ for $1.5 \mathrm{~h}$. Following the transfer, membranes were washed in TBST (10 mM Tris, $\mathrm{pH}$ $7.5,150 \mathrm{mM} \mathrm{NaCl}, 0.05 \% \mathrm{v} / \mathrm{v}$ Tween-20) for $3 \times 5 \mathrm{~min}$. The membranes were blocked using $0.1 \%$ polyvinyl alcohol in TBST for $30 \mathrm{~min}$. After blocking, the membranes were 
probed with primary antibody diluted 1:500 v:v in TBST for $3 \mathrm{~h}$ at room temperature (RT) with the following primary antibodies: (1) rabbit anti-phosphoserine (Cat \#618100, Invitrogen, Carlsbad, CA, USA); (2) rabbit anti-phosphothreonine (Cat. \# 718200, Invitrogen, Carlsbad, CA, USA); or (3) rabbit anti-phosphotyrosine (Cat \# 615800, Invitrogen, Carlsbad, CA, USA). The membranes were washed $3 \times 5$ min with TBST at RT and probed with goat anti-rabbit-peroxidase secondary antibody for $20 \mathrm{~min}$. Membranes were washed again $3 \times 5 \mathrm{~min}$ in TBST at RT. Blots were developed with enhanced chemiluminescence reagents. Images were captured using a ChemiGenius BioImaging system with GeneSnap software and densitometry analysis performed using GeneTools software (Syngene, Frederick, MD). The intensity of the immunoreactive bands were standardized against corresponding Coomassie blue stained bands. The intensity of the immunoreactive bands from control muscle tissue was set to a reference value of 1 whereas the intensity of standardized immunoreactive bands from frozen muscle tissue was expressed as a fold change.

\subsection{In vitro incubation to stimulate protein kinases and phosphatases}

Frog muscle extracts from control animals, prepared as described in section 2.2, were filtered through a G50 spun column equilibrated in incubation buffer (50 mM KPi, $10 \% \mathrm{v} / \mathrm{v}$ glycerol, $30 \mathrm{mM} \beta$-mercaptoethanol, $\mathrm{pH}$ 7.2). Aliquots of the filtered supernatants were incubated for 12 hours at $4^{\circ} \mathrm{C}$ with specific inhibitors and stimulators of protein kinases, as described in Macdonald and Storey (1999). Each aliquot was mixed 
2:1 v:v with the appropriate solutions to stimulate protein kinases. Each solution was prepared in incubation buffer and the following incubation conditions were used:

(a) STOP conditions: $2.5 \mathrm{mM}$ EGTA, $2.5 \mathrm{mM}$ EDTA and $30 \mathrm{mM} \beta$ glycerophosphate.

(b) Stimulation of total endogenous kinases: $30 \mathrm{mM} \beta$-glycerophosphate, $2 \mathrm{mM}$ AMP, 2 mM cAMP, 10 mM ATP, 2 mM cGMP, $2.6 \mathrm{mM} \mathrm{CaCl}_{2}, 14 \mu \mathrm{g} / \mathrm{mL}$ phorbol myristate acetate, $20 \mathrm{mM} \mathrm{MgCl}_{2}$ and $10 \mathrm{mM} \mathrm{Na}_{3} \mathrm{VO}_{4}$.

(c) Stimulation of total endogenous kinases: $10 \mathrm{mM} \mathrm{MgCl}_{2}$ and $10 \mathrm{mM} \mathrm{CaCl}_{2}$.

(d) Stimulation of endogenous AMP-activated kinase (AMPK): $1 \mathrm{mM}$ AMP, 5 mM ATP, $10 \mathrm{mM} \mathrm{MgCl} 2,30 \mathrm{mM} \beta$-glycerophosphate, $5 \mathrm{mM} \mathrm{Na}_{3} \mathrm{VO}_{4}$.

(e) Stimulation of endogenous calcium-calmodulin dependent kinase (CaMK): 1 $\mathrm{U}$ of calf intestine calmodulin $+1.3 \mathrm{mM} \mathrm{CaCl}_{2}, 5 \mathrm{mM}$ ATP, $10 \mathrm{mM} \mathrm{MgCl}, 30 \mathrm{mM} \beta$ glycerophosphate, $5 \mathrm{mM} \mathrm{Na}_{3} \mathrm{VO}_{4}$.

(f) Stimulation of endogenous cyclic-AMP dependent protein kinase (PKA): 1 mM cAMP, $5 \mathrm{mM}$ ATP, $10 \mathrm{mM} \mathrm{MgCl} 2,30 \mathrm{mM} \beta$-glycerophosphate, $5 \mathrm{mM} \mathrm{Na}_{3} \mathrm{VO}_{4}$.

(g) Stimulation of endogenous cyclic-GMP dependent protein kinase G (PKG): 1 mM cGMP, 5 mM ATP, 10 mM MgCl $2,30 \mathrm{mM} \beta$-glycerophosphate, $5 \mathrm{mM} \mathrm{Na}_{3} \mathrm{VO}_{4}$.

(h) Stimulation of endogenous protein phosphatases 1+2A (PP1+PP2A): $2 \mathrm{mM}$ EDTA, 2 mM EGTA, $30 \mathrm{mM} \mathrm{Na}_{3} \mathrm{VO}_{4}$.

(i) Stimulation of endogenous protein phosphatase 2B (PP2B): 2 mM EDTA, 1 $\mu \mathrm{M}$ okadaic acid, $5 \mathrm{mM} \mathrm{Na}_{3} \mathrm{VO}_{4}$.

(j) Stimulation of endogenous protein phosphatase 2C (PP2C): 2 mM EGTA, 1 nM cypermethrin, $1 \mu \mathrm{M}$ okadaic acid, $5 \mathrm{mM} \mathrm{Na}_{3} \mathrm{VO}_{4}$. 
CAT from control and frozen muscle was then purified as previously described in section 2.4. Samples were then analyzed as described in section 2.5 and the $\mathrm{K}_{\mathrm{m}}$ for $\mathrm{H}_{2} \mathrm{O}_{2}$ was compared for each condition.

\subsection{Determination of protein stability}

Stability parameters of purified CAT from control and $24 \mathrm{~h}$ frozen frogs were analyzed using differential scanning fluorometry as described in chapter 3 section 2.10 and the $\mathrm{T}_{\mathrm{m}}$ for each was recorded.

\subsection{Statistical analysis}

Comparison of enzyme kinetics, relative protein phosphorylation and protein stability were performed using a Student's t test, two-tailed, assuming unequal variances. A probability of $\mathrm{P}<0.05$ was considered significant. Comparison of the $\mathrm{K}_{\mathrm{m}}$ for $\mathrm{H}_{2} \mathrm{O}_{2}$ after incubations stimulating endogenous kinases and phosphatases were performed using analysis of variance followed by the Tukey post hoc test, assuming unequal variances. A probability of $\mathrm{p}<0.05$ was considered significant.

\section{Results}

\subsection{Purification of CAT from the muscle of control and frozen frogs}

The purification scheme used for wood frog muscle CAT is shown in Table 4.1. The procedure used chromatography on a Bio-Gel ${ }^{\circledR}$ HTP Gel hydroxyapatite column 
(Figure 4.1A), Cibacron blue chromatography (Figure 4.1B), and DEAE ${ }^{+}$ion exchange column (Figure 4.1C, 4.1D). Control CAT eluted from the $\mathrm{DEAE}^{+}$ion exchange column yielding a first peak at approximately $200 \mathrm{mM} \mathrm{KCl}$ and a second peak at approximately $300 \mathrm{mM} \mathrm{KCl}$ (Figure 4.1C). Frozen CAT eluted from the DEAE+ ion exchange column in one peak at $300 \mathrm{mM} \mathrm{KCl}$ (Figure 4.1D). Frog muscle CAT was purified 105.4 fold with an overall yield of activity of $11.4 \%$ (Table 4.1 ). The final specific activity of CAT was $2308 \mathrm{mU} / \mathrm{mg}$ of protein. The success of the purification process was assessed using SDS-PAGE with Coomassie blue staining of the gel (Figure 4.2). This showed that CAT was purified to near homogeneity as there was one strong band corresponding to the correct molecular weight of $\sim 60 \mathrm{kDa}$ for CAT (Figure 4.2).

\subsection{Kinetic characterization of CAT}

Kinetic parameters of purified muscle CAT were assessed to determine the differences between the enzyme isolated from control and frozen frogs. The $\mathrm{K}_{\mathrm{m}}$ for $\mathrm{H}_{2} \mathrm{O}_{2}$ and the $\mathrm{V}_{\max }$ of CAT from the muscle of $R$. sylvatica were both demonstrated to change between control and frozen animals $(\mathrm{p}<0.05)$ (Table 4.2). The $\mathrm{K}_{\mathrm{m}}$ for $\mathrm{H}_{2} \mathrm{O}_{2}$ decreased significantly (by $36.4 \%$ ) in frozen frogs in comparison to the $\mathrm{K}_{\mathrm{m}}$ of $\mathrm{H}_{2} \mathrm{O}_{2}$ in control animals (Table 4.2). The $\mathrm{V}_{\max }$ of CAT from frozen frogs increased significantly (1.48 fold) over the measured $\mathrm{V}_{\max }$ of CAT in control animals (Table 4.2). To properly assess frog muscle enzyme kinetics, all recoverable peaks of pure enzyme were combined for each condition prior to kinetic analysis. 


\subsection{Post-translational modification of endogenous CAT}

To test whether or not purified frog muscle CAT was modified by reversible phosphorylation, the peak fractions (based on activity) from the purification profiles for control and frozen frogs were combined and run on SDS-PAGE gels, and stained with ProQ Diamond phosphoprotein stain. When band densities were quantified, they showed a 1.73 fold higher band intensity $(\mathrm{p}<0.05)$ for CAT from muscle of frozen frogs as compared to the enzyme from control frogs (Figure 4.3).

Immunoblotting was then used to further assess residue-specific phosphorylation of muscle CAT. Purified CAT reacted with antibodies specific for phosphorylation at serine residues, threonine residues or tyrosine residues (Figure 4.3). The relative phosphorylation levels of serine and tyrosine residues increased significantly for frozen CAT as compared with control $(\mathrm{p}<0.05$, Figure 4.3$)$.

CAT from muscle of control frogs was purified as described in section 2.4 and the two resulting peaks from the final DEAE chromatography step were assessed independently. Both produced clear band at $\sim 60 \mathrm{kDa}$ but showed differential levels of total phosphorylation when subjected to ProQ diamond phosphoprotein staining. When band densities were quantified, Peak II showed a 3.33 fold higher band intensity $(\mathrm{p}<0.05)$ as compared to Peak I from control frogs (Figure 4.4).

\subsection{In vitro posttranslational modification of CAT}

To test whether or not reversible phosphorylation of CAT could account for the observed changes in $\mathrm{K}_{\mathrm{m}}$ for $\mathrm{H}_{2} \mathrm{O}_{2}$ that were seen in vivo between control and frozen 
states, incubations were set up in which crude extracts of muscle were stimulated by endogenous kinases and phosphatases. CAT was purified as previously described in section 2.4., and subsequent effects on $\mathrm{CAT} \mathrm{K}_{\mathrm{m}} \mathrm{H}_{2} \mathrm{O}_{2}$ were measured. Incubations which stimulated endogenous phosphatases yielded multiple peaks of CAT activity. The first major peak was observed at $\sim 200 \mathrm{mM} \mathrm{KCl}$ with an obvious cleft at $\sim 325 \mathrm{mM} \mathrm{KCl}$, followed by the second major peak at $\sim 400 \mathrm{mM} \mathrm{KCl}$ (Figure $4.5 \mathrm{~A}$ ). Incubations which stimulated total endogenous kinases resulted in a single sharp peak on DEAE + at $\sim 400$ $\mathrm{mM} \mathrm{KCl}$ (Figure 4.5B).

The $\mathrm{K}_{\mathrm{m}}$ of $\mathrm{H}_{2} \mathrm{O}_{2}$ was measured after incubation with the specific endogenous kinases and phosphates as described in section 2.9 (Figure 4.6). Stimulation of AMPK resulted in a significant decrease in the $\mathrm{K}_{\mathrm{m}}$ for $\mathrm{H}_{2} \mathrm{O}_{2}$ for CAT from control frogs, but not frozen frogs $(p<0.05)$. Stimulation of CAMK had no significant effect on the $\mathrm{K}_{\mathrm{m}}$ for $\mathrm{H}_{2} \mathrm{O}_{2}$ for CAT from either control or frozen frogs $(\mathrm{p}<0.05)$. Stimulation of PKA resulted in a significant decrease in the $\mathrm{K}_{\mathrm{m}}$ for $\mathrm{H}_{2} \mathrm{O}_{2}$ for CAT in control frogs, but not for the enzyme from frozen frogs $(\mathrm{p}<0.05)$. Stimulation of PKG had no significant effect on the $\mathrm{K}_{\mathrm{m}}$ for $\mathrm{H}_{2} \mathrm{O}_{2}$ for CAT in control or frozen frogs $(\mathrm{p}<0.05)$. Stimulation of PP1 resulted in no significant changes in the $\mathrm{K}_{\mathrm{m}}$ for $\mathrm{H}_{2} \mathrm{O}_{2}$ for CAT from either control or frozen frogs $(p<0.05)$. However, stimulation of PP2B resulted in a significant increase in the $K_{m}$ for $\mathrm{H}_{2} \mathrm{O}_{2}$ for CAT in frozen frogs, but not in control frogs $(\mathrm{p}<0.05)$. Stimulation of PP2C resulted in a significant increases in the $\mathrm{K}_{\mathrm{m}}$ for $\mathrm{H}_{2} \mathrm{O}_{2}$ for CAT from both control and frozen frogs $(\mathrm{p}<0.05)$. 


\subsection{Scansite Prediction of Phosphosites}

The Scansite application from the Massachusetts Institute of Technology (http:// scansite.mit.edu/) was used to analyze the CAT sequences from two frog species, $X$. laevis and Xtropicalis, in a search for putative phosphorylation sites. These two CAT protein sequences showed $93.18 \%$ identity. Only those kinases predicted to phosphorylate CAT from both X. laevis and X. tropicalis are reported. Putative consensus sequences for phosphorylation sites of Akt kinase (serine, threonine), AMP-activated kinase (serine, threonine), calcium-calmodulin dependent kinase 2 (threonine), Cdc2 kinase (serine, threonine), Cdk5 kinase (serine, threonine), EGFR Kinase (tyrosine), Erk1 (threonine), GSK3 (serine), Lck kinase (tyrosine), PDGFR kinase (tyrosine), PKA (serine, threonine), PKC alpha (serine), PKC beta (serine), PKC delta (serine), PKC epsilon (serine), PKC gamma (serine), PKC mu (serine, threonine), PKC zeta (serine), and Src kinase (tyrosine) were predicted for CAT (Figure 4.7).

Human CAT shows $89.96 \%$ identity when compared to $X$. laevis and $X$. tropicalis. Human CAT was analyzed for comparison using Scansite, resulting in the following putative consensus sequences for phosphorylation sites: Akt kinase (serine, threonine), AMP-activated kinase (threonine), calmodulin dependent kinase 2 (serine), casein kinase 1 (threonine), casein kinase 2 (serine), Cdc2 kinase (serine, threonine), Cdk5 kinase (serine, threonine), EGFR Kinase (tyrosine), Erk1 Kinase (threonine), Lck kinase (tyrosine), PDGFR kinase (tyrosine), PKA (serine, threonine), PKC alpha (serine), PKC beta (serine), PKC delta (serine), PKC epsilon (serine), PKC gamma (serine), PKC $\mathrm{mu}$ (serine, threonine) and PKC zeta (serine), and Src kinase (tyrosine) were predicted for CAT. 


\subsection{Stability of CAT}

The structural stability of CAT was evaluated by testing enzyme sensitivity to thermal denaturation measured using differential scanning fluorimetry as described in section 2.10. There was no significant difference in the thermal denaturation properties of purified CAT between control and frozen frogs (Figure 4.8). CAT purified from the muscle of $R$. sylvatica showed a peak at $60^{\circ} \mathrm{C}$ for control frogs and $61^{\circ} \mathrm{C}$ for frozen frogs. The calculated $\mathrm{T}_{\mathrm{m}}$ value (temperature that results in a 50\% loss of folded structure) was $56.25^{\circ} \mathrm{C}$ for purified CAT from muscle of control frogs, which was not significantly different from the value of $56.67^{\circ} \mathrm{C}$ for purified CAT from muscle of frozen frogs (Table 4.2; Figure 4.8).

\section{Discussion}

The role of CAT in disease is in unclear. Knockout and knockdown experiments of CAT have proven to be non-lethal, however, deleterious effects have been reported including increases incidence of diabetes (Sies, 1986; Mo et al., 1995; Hamilton et al., 2012). Disruption in CAT activity and expression has been observed in many disease states including diabetes, in which decreases in catalase expression contribute to disease development (Goth, 2000; Goth and Eaton, 2000). A complete loss of catalase is the phenotype expressed in Acatalasia or Takahara's disease (Ogata, 1991). Reduced CAT activity has been reported in patients suffering from Parkinson's disease, schizophrenia as well as atherosclerosis (Goth and Vitai, 1996). CAT gene mutations, leading to a dysfunctional enzyme, have been observed in diabetes, hypertension and vitiligo (Goth et 
al., 2004). Functional, endogenous CAT seems to be important for the quality of life, and exploration of CAT function in the wood frog, which can endure long periods of time under conditions that mimic disease-like states, could yield a greater understanding the role of CAT in disease.

Many of the aforementioned disease states include disruption in blood flow or oxygen deprivation, often accompanied by an increase in the oxidative stress imposed on the organism and individual cells. Previous studies exploring organisms experiencing changes in CAT regulation under oxygen deprived states or reduced blood flow include: the ground squirrel (Spermophilus citellus) which shows increased CAT expression during hibernation (Vucetic et al., 2013), the African clawed frog (Xenopus laevis) which exhibits increased CAT expression in both the muscle and liver in response to whole body dehydration (Malik and Storey, 2011), the common carp (Cyprinus carpio) which shows increased CAT activity in the brain and kidneys during hypoxia (Lushchak et al., 2005), the land snail (Otala lactea) in which CAT activity decreases in foot muscle during estivation (Hermes-Lima et al., 1998), the leopard frog (Rana pipiens) which shows an increase in CAT activity in muscle tissue during severe dehydration and anoxic conditions (Hermes-Lima and Storey, 1998), the spadefoot toad (Scaphiopus couchii) where CAT activity in the liver and heart were significantly higher, while being lower in the kidney during estivation (Grundy and Storey, 1998), and the marine periwinkle (Littorina littorea) where CAT activity increased in the hepatopancreas during anoxia as well as in hepatopancreas and foot muscle upon exit from anoxia (Pannunzio and Storey, 1998), and the red eared slider turtle (Trachemys scripta elegans) which shows decreased CAT activity in the heart kidney and brain during anoxia (Willmore and Storey, 1997). 
In addition to oxygen deprivation, the freeze tolerant frog also experiences ischemia which has been repeatedly demonstrated to imposed oxidative stress on the animal during the ischemic period, and a burst production of ROS following the ischemic episode (Ferrari et al., 1991; Simpson and Lucchesi, 1987; Zweier and Talukder, 2006). The wood frog likely experiences similar increases in $\mathrm{H}_{2} \mathrm{O}_{2}$, attributed to the ischemic nature of freezing. Interestingly, introduction of exogenous CAT has been shown to attenuate apoptosis (Sancho et al., 2003). Therefore, through exploration of the role of CAT as a key enzyme involved in the reduction of $\mathrm{H}_{2} \mathrm{O}_{2}$ at high levels, the regulation of $\mathrm{CAT}$ in the frozen frog presented in this chapter can provide important information for both the survival of the animal and insight into disease states by staving off signaling of apoptosis upon reoxygenation.

\subsection{Kinetic changes of CAT during freezing}

The apparent $\mathrm{K}_{\mathrm{m}}$ for $\mathrm{H}_{2} \mathrm{O}_{2}$ of CAT significantly decreased in the frozen state compared to the control state (Table 4.2). This reduction in the apparent $\mathrm{K}_{\mathrm{m}}$ of $\mathrm{H}_{2} \mathrm{O}_{2}$ would suggest that CAT has a higher affinity for $\mathrm{H}_{2} \mathrm{O}_{2}$ during freezing. An increase in affinity for $\mathrm{H}_{2} \mathrm{O}_{2}$ would increase the reducing ability of CAT, and increase protection against the formation of very high levels of $\mathrm{H}_{2} \mathrm{O}_{2}$. As previously mentioned, CAT has a significantly lower affinity for $\mathrm{H}_{2} \mathrm{O}_{2}$ than peroxidases, suggesting that the role of CAT may be a panic switch of sorts (Kim et al., 1988). Although CAT is absent in the organelle that is the major source of $\mathrm{H}_{2} \mathrm{O}_{2}$ production, the mitochondria, $\mathrm{H}_{2} \mathrm{O}_{2}$ is membrane permeable and in large concentrations will follow a concentration gradient 
from sources of production to sources of reduction such as the peroxisome (Sies, 1974). This is of special importance due to the fact that peroxidases are known to be inhibited at high concentrations of $\mathrm{H}_{2} \mathrm{O}_{2}$, possibly shifting the role of the main $\mathrm{H}_{2} \mathrm{O}_{2}$ reducer from the peroxidases to CAT (Flohe, 2010; Winterbourn, 2013; Hall et al., 2011; Wood et al., 2003). Therefore, an increase in production of $\mathrm{H}_{2} \mathrm{O}_{2}$ could lead to a disruption of $\mathrm{H}_{2} \mathrm{O}_{2}$ mediated apoptosis signaling, typically held in check by peroxidase activities, and ultimately lead to the destruction of the cell due to oxidative stress induced signaling of apoptosis. CAT has been proposed to take a more central role in $\mathrm{H}_{2} \mathrm{O}_{2}$ reduction under such circumstances (Wood et al., 2003).

\subsection{Phosphorylation of CAT}

Investigation into the relative phosphorylation state of CAT identified a significant difference in global phosphorylation levels (a 1.73 fold increase) in the frozen state as compared with the control, as well as significant increases in the relative phosphorylation of serine (1.60 fold) and tyrosine (1.27 fold) residues (Figure 4.3). Interestingly, control CAT demonstrated multiple peaks of CAT activity during elution off a DEAE ${ }^{+}$column (Figure 4.1C). Previously, shifts to the right in elution profiles for proteins bound to a positively charged ion exchange column have been attributed to phosphorylation events, since the addition of phosphate groups adds a large negative charge to a protein (Dawson and Storey, 2012; Lant and Storey, 2011; Dawson and Storey, 2011; Holden and Storey, 2011; Bell and Storey, 2010; Dieni and Storey, 2009; Abnous and Storey, 2008). Hence, it is probable that the CAT peaks eluting at lower 
versus higher salt concentrations represent low versus high phosphorylation states of the enzyme. To investigate this experimentally, the phosphorylation state of each peak was directly analyzed for CAT from control frogs. A significantly higher level of phosphorylation (3.33 fold higher) was observed for CAT in the second peak, as determined by ProQ diamond phospho-protein staining (Figure 4.4). This difference in phospho-staining, in conjunction with the two peak elution profile, provides evidence for multiple phosphorylation forms of CAT from the muscle of $R$. sylvatica.

To further analyze CAT posttranslational modification, enzyme preparations were incubated under conditions that stimulated endogenous protein phosphatase or protein kinase activities. After subsequent purification, the protein phosphatase treated enzyme showed the same two peak elution profile as was observed in control frogs (Figure 4.5A) whereas after stimulation of endogenous kinases and subsequent purification, only one sharp peak was discovered in the elution profile, similar to the situation in frozen frogs (Figure 4.5B). This adds strong support for the proposal that the two peaks of CAT activity found in control frogs represent low versus high phosphate forms of the enzyme and that freezing stimulates the conversion of CAT into the high phosphate form.

The phosphorylation phenomenon observed for CAT from $R$. sylvatica was explored further in an attempt to elucidate which kinases and phosphatases are responsible for the reversible phosphorylation of CAT during freezing, and to explore possible functional consequences of phosphorylation. After incubation under conditions which stimulated AMPK and PKA action, CAT from control frogs showed a decrease in the $\mathrm{K}_{\mathrm{m}}$ for $\mathrm{H}_{2} \mathrm{O}_{2}$ to values similar to (for AMPK) or about $50 \%$ lower than (for PKA) that seen for CAT purified from frozen frogs (Figure 4.6). Conversely, under conditions 
which stimulated PP2B or PP2C, CAT from frozen frogs showed an increase in the $\mathrm{K}_{\mathrm{m}}$ of $\mathrm{H}_{2} \mathrm{O}_{2}$ to values similar to CAT purified from control frogs (Figure 4.6). This suggests that the phosphorylation of CAT is a strong candidate for eliciting the apparent increase in affinity for $\mathrm{H}_{2} \mathrm{O}_{2}$ observed during freezing. These data would suggest that the more phosphorylated from of CAT (with the lower $\mathrm{K}_{\mathrm{m}}$ value) is the more active form. Increased affinity for $\mathrm{H}_{2} \mathrm{O}_{2}$ would likely enhance the ability of CAT in the muscle of frozen frogs to minimize/prevent freeze-induced oxidative stress, as well as prepare for the eventual burst production of free radicals during thawing reperfusion.

Previous studies have shown that AMPK activity increases (4.5 fold) during freezing and the percentage of free catalytic subunit of PKA (PKAc) in the muscle of frozen frogs is elevated (3.62 fold) within 2 minutes after freezing begins (Rider and Storey, 2006; Holden and Storey, 1996). The level of PKAc remains significantly high through the duration of freezing, and $24 \mathrm{~h}$ after thawing, and the activity of AMPK remains elevated after thawing $24 \mathrm{~h}$. Hence, this provides further support for the idea that CAT is modified by protein phosphorylation during freezing, and that phosphorylation may be mediated by either AMPK or PKA in frozen frogs. This would suggest that CAT may become more active as freezing begins and remain active throughout the freeze-thaw cycle, suggesting that phosphorylation of CAT by AMPK or PKA would benefit the frog both during freezing and as a preparatory mechanism to deal with reperfusion during thawing.

To further explore the viability of phosphorylation as a mechanism of CAT control in the freezing frog, an investigation into the putative phosphorylation sites present on CAT was undertaken by analyzing the sequences of two genome-sequenced 
frog species (Figure 4.7). This analysis showed the presence of putative AMPK and PKA phosphorylation sites on frog CAT, supporting the idea that AMPK and/or PKA are candidates to phosphorylate CAT during freezing. Interestingly, human CAT also showed the predicted AMPK and PKA phosphorylation sites, suggesting the possibility for AMPK or PKA mediated phosphorylation regulation of the enzyme in humans.

\subsection{Thermal stability of CAT}

CAT purified from both control and frozen frogs was explored via DSF to determine whether the enzymes showed differences in thermal stability which would be indicative of substantive conformational changes in the enzyme between the two states. However, no significant differences in CAT thermal stability were found between the two states (Figure 4.8). This does not exclude to possibility of improved stabilization of CAT in the face of $\mathrm{H}_{2} \mathrm{O}_{2}$ insult. The stability of CAT has been extensively studied, demonstrating the thermodynamic stability of CAT activity, and has shown that CAT remains active across a broad range of temperatures, $\mathrm{pH}$, and $\mathrm{H}_{2} \mathrm{O}_{2}$ concentrations (Nadler et al., 1986; Yumoto et al., 1990; Brown-Peterson and Salin, 1993;

Maricinkeviciene et al., 1995; Fraaije et al., 1996). The $\mathrm{T}_{\mathrm{m}}$ values found in the present study showed that denaturation of frog muscle CAT takes place at a relatively high temperature of approximately $56^{\circ} \mathrm{C}$, suggesting that CAT is a very stable enzyme and unlikely to be denatured under environmentally encountered temperatures (Table 4.2, Figure 4.8). 


\subsection{Conclusion}

The regulation of CAT from muscle of the freeze tolerant frog, $R$. sylvatica, can provide useful insights into the effects of ischemia on free radical mediation. CAT from frozen frogs showed significant modifications compared with the control enzyme including a lower $\mathrm{K}_{\mathrm{m}}$ for $\mathrm{H}_{2} \mathrm{O}_{2}$ a higher $\mathrm{V}_{\max }$, and increased phosphorylation at serine and tyrosine residues. Specifically, phosphorylation of CAT by AMPK and PKAc was suggested. The evidence presented in this chapter suggests that phosphorylation may activate CAT during freezing. Augmented CAT activity may increase the ability of $R$. sylvatica to overcome oxidative stress associated with ischemia or reperfusion. This study can also provide valuable insight into disease pathology by offering a unique observation of the role of CAT during ischemia. CAT has a high degree of similarity across species. The discovery of phosphorylation events for CAT is of interest for human application since CAT from frogs was found to have $90 \%$ amino acid identity when compared to human CAT, as well as similar predicted phosphorylation sites. This striking similarity suggests that researchers should explore possible phosphorylation and subsequent activation of CAT in human disease states since increased CAT activity has been previously attributed to amelioration of disease symptoms. 


\section{References}

Aebi, H. 1984. Catalase In Vitro. Meth Enzymol. 105:121-126.

Abnous, K. and Storey, K.B. 2008. Skeletal muscle hexokinase: regulation in mammalian hibernation. Mol Cell Biochem. 319:41-50.

Andersson, L.A. and Dawson, L.A. 1991. EXAFS spectroscopy of heme containing oxygenases and peroxidases. Structure and Bonding. 64:1-40.

Antunes, F. and Cadenas, E. 2000. Estimation of $\mathrm{H}_{2} \mathrm{O}_{2}$ gradients across biomembranes. FEBS Lett. 475:121-126.

Bell, R.A.V. and Storey, K.B. 2010. Regulation of liver glutamate dehydrogenase by reversible phosphorylation in a hibernating mammal. Comp Biochem Physiol B. 157:310-316.

Boveris, A., Oshino, N. and Chance, B. 1972. The cellular production of hydrogen peroxide. Biochem J. 128:617-630.

Brown-Peterson, N.J. and Salin, M.L. 1993. Purification of a catalase-peroxidase from Halobacterium halobium: characterization of some unique properties of the halophilic enzyme. J Bacteriol. 175:4197-4202.

Cox, A.G., Winterbourn, C.C. and Hampton, M.B. 2010. Mitochondrial peroxiredoxin involvement in antioxidant defence and redox signalling. Biochem J. 425:313-325

Dawson, N.J. and Storey, K.B. 2011. Regulation of tail muscle arginine kinase by reversible phosphorylation in an anoxia tolerant crayfish. J Comp Physiol B. 181:851-859.

Dawson, N.J. and Storey, K.B. 2012. Regulation of tail muscle hexokinase in the anoxiatolerant freshwater crayfish, Orconectes virilis. HOAJ Biology. 1:1.

Dieni, C.A. and Storey, K.B. 2009. Creatine kinase regulation by reversible phosphorylation in frog muscle. J Comp Biochem Physiol B. 152:405-412. 
Dröse, S. and Brandt, U. 2008. The mechanism of mitochondrial superoxide production by the cytochrome bc1 complex. J Biol Chem. 283:21649-21654.

Finkel, T. 2012. Signal transduction by mitochondrial oxidants. J Biol Chem. 287:44344440.

Fita, I. and Rossmann, M.G. 1985. The NADPH binding site on beef liver catalase. Proc Natl Acad Sci USA. 82:1604-1608.

Flohé, L. 2010. Changing paradigms in thiology: from antioxidant defense toward redox regulation. Meth Enzymol. 473:1-39

Fraaije, M.W., Roubroeks, H.P., Hagen, W.R. and Van Berkel, W.J.H. 1996. Purification and characterization of an intracellular catalase-peroxidase from Penicillium simplicissimum. Eur J Biochem. 235:192-198.

Famulari, A.L., Marschoff, E.R., Llesuy, S.F., Kohan, S., Serra, J.A., Dominquez, R.O., Repetto, M., Reides, C. and Sacerdote de Lustig, E. 1996. The antioxidant enzymatic blood profile in Alzheimer's and vascular diseases. Their association and possible assay to differentiate demented subjects and controls. J Neurol Sci. 141:69-78.

Gaetani, G.F., Ferraris, A.M., Rolfo, M., Mangerini, R., Arena, S. and Kirkman, H.N. (1996). Predominant role of catalase in the disposal of hydrogen peroxide within human erythrocytes. Blood. 87:1595-1599.

Góth, L. 2000. Lipid and carbohydrate metabolism in acatalasemia. Clin Chem. 46:564566.

Góth, L. and Eaton, J.W. 2000. Hereditary catalase deficiencies and increased risk of diabetes. Lancet. 356:1820-1821.

Góth, L., Rass, P. and Páy, A. 2004. Catalase enzyme mutations and their association with diseases. Mol Diagn. 8:141-149.

Góth, L. and Vitai, M. 1996. Hypocatalasemia in hospital patients. Clin Chem. 42:341342. 
Grundy, J.E. and Storey, K.B. Antioxidant defenses and lipid peroxidation damage in estivating toads, Scaphiopus couchii. 1998. J Comp Physiol B. 168(2):132-42.

Hall, A., Nelson, K., Poole, L.B. and Karplus, P.A. 2011. Structure-based insights into the catalytic power and conformational dexterity of peroxiredoxins. Antioxid Redox Signal. 15:795-815

Hamilton, R.T., Walsh, M.E. and Remmen, H.V. 2012. Mouse models of oxidative stress indicate a role for modulating healthy aging. J Clin Exp Pathol. S4:1-14.

Hermes-Lima, M. and Storey, K.B. 1998. Role of antioxidant defenses in the tolerance of severe dehydration in anurans. The case of the leopard frog Rana pipiens. Mol Cell Biochem. 189:79-89.

Hermes-Lima, M., Storey, J.M. and Storey, K.B. 1998. Antioxidant defenses and metabolic depression. The hypothesis of preparation for oxidative stress in land snails. Comp Biochem Physiol B. 120:437-448.

Hoffschir, F., Daya-Grosjean, L., Petit, P.X., Nocentini, S., Dutrillaux, B., Sarasin, A. and Vuillaume, M. 1998. Low catalase activity in xeroderma pigmentosum fibroblasts and SV40-transformed human cell lines is directly related to decreased intracellular levels of the cofactor, NADPH. Free Radic Biol Med. 24:809-816.

Holden, C.P. and Storey, K.B. 1996. Signal transduction, second messenger, and protein kinase responses during freezing exposure in wood frogs. Am J Physiol. 271:R1205-R1211.

Holden, H.A and Storey, K.B. 2011. Reversible phosphorylation regulation of NADPHlinked polyol dehydrogenase in the freeze-avoiding gall moth, Epiblema scudderiana: Role in glycerol metabolism. Arch Insect Biochem Physiol. 77:32-44.

Ivancich, A., Jouve, H.M. and Gaillard, J. 1996. EPR evidence for a tyrosyl radical intermediate in bovine liver catalase. J Am Chem Soc. 118:12852-12853.

Joanisse, D.R. and Storey, K.B. 1996. Oxidative damage and antioxidants in Rana sylvatica, the freeze tolerant wood frog. Am J Physiol. 271(3):R545-53. 
Kim, K., Kim, I.H., Lee, K.Y., Rhee, S.G. and Stadtman, E.R. 1988. The isolation and purification of a specific "protector" protein which inhibits enzyme inactivation by a thiol/Fe(III)/O2 mixed-function oxidation system. J Biol Chem. 263:4704-4711.

Kirkman, H.N. and Gaetani, G.F. 1984. Catalase: a tetrameric enzyme with four tightly bound molecules of NADPH. Proc Natl Acad Sci USA. 81:4343-4347.

Kirkman, H.N., Rolfo, M., Ferraris, A.M. and Gaetani, G.F. 1999. Mechanisms of protection of catalase by NADPH. Kinetics and stoichiometry. J Biol Chem. 274:13908-13914.

Klein, S.L., Strausberg, R.L., Wagner, L., Pontius, J., Clifton, S.W. and Richardson, P. 2002. Genetic and genomic tools for Xenopus research: The NIH Xenopus initiative. Dev Dyn. 225(4):384-91.

Lant, B. and Storey, K.B. 2011. Glucose-6-phosphate dehydrogenase regulation in anoxia tolerance of the freshwater crayfish Orconectes virilis. Enzyme Res. Article ID $524906,8 \mathrm{pp}$.

Loschen, G., Flohé, L. and Chance, B. 1971. Respiratory chain linked H2O2 production in pigeon heart mitochondria. FEBS Lett. 18:261-264.

Loschen, G., Azzi, A., Richter, C. and Flohé, L. 1974. Superoxide radicals as precursors of mitochondrial hydrogen peroxide. FEBS Lett. 42:68-72.

Lushchak, V.I., Bagnyukova, T.V., Lushchak, O.V., Storey, J.M. and Storey, K.B. 2005. Hypoxia and recovery perturb free radical processes and antioxidant potential in common carp (Cyprinus carpio) tissues. Int J Biochem Cell Biol. 37(6):1319-30.

Marcinkeviciene, J.A., Magliozzo, R.S. and Blanchard, J.S. (1995). Purification and characterization of the Mycobacterium smegmatis catalase-peroxidase involved in isoniazid activation. J Biol Chem. 270:22290-22295.

Mo, J.Q., Hom, D.G. and Andersen, J.K. 1995. Decreases in protective enzymes correlates with increased oxidative damage in the aging mouse brain. Mech Ageing Dev. 81:73-82. 
Mueller, S., Riedel, H.D. and Stremmel, W. 1997. Direct evidence for catalase as the predominant $\mathrm{H}_{2} \mathrm{O}_{2}$-removing enzyme in human erythrocytes. Blood. 90:49734978.

Mueller, S., Millonig, G. and Waite, G.N. 2009. The GOX/CAT system: a novel enzymatic method to independently control hydrogen peroxide and hypoxia in cell culture. Adv Med Sci. 54:121-135

Nadler, V., Goldberg, I. and Hochman, A. 1986. Comparative study of bacterial catalase. Biochim Biophys Acta. 882:234-241.

Ogata, M. 1991. Acatalasemia. Hum Genet. 86:331-340.

Olson, L.P. and Bruice, T.C. 1995. Electron tunneling and ab initio calculations related to the one-electron oxidation of $\mathrm{NAD}(\mathrm{P}) \mathrm{H}$ bound to catalase. Biochemistry. 34:73357347 .

Pannunzio, T.M. and Storey, K.B. 1998. Antioxidant defenses and lipid peroxidation during anoxia stress and aerobic recovery in the marine gastropod, Littorina littorea. J Exp Mar Biol Ecol. 221:277-292.

Putnam, C.D., Arvai, A.S., Bourne, Y. and Tainer, J.A. 2000. Active and inhibited human catalase structures: ligand and NADPH binding and catalytic mechanism. $J$ Mol Biol. 296:295-309.

Rider, M.H., Hussain, N., Horman, S., Dilworth, S.M. and Storey, K.B. 2006. Stressinduced activation of the AMP-activated protein kinase in the freeze tolerant frog Rana sylvatica. Cryobiol. 53:297-309.

Rubinsky, B., Wong, S.T.S., Hong, J.-S., Gilbert, J., Roos, M. and Storey, K.B. 1994. 1H magnetic resonance imaging of freezing and thawing in freeze tolerant frogs. Am J Physiol. 266:R1771-R1777.

Sancho, P., Troyano, A., Fernández, C., De Blas, E. and Aller, P. 2003. Differential effects of catalase on apoptosis induction in human promonocytic cells.

Relationships with heat-shock protein expression. Mol Pharmacol. 63:581-589.

Sies, H. 1986. Biochemistry of oxidative stress. Angew Chem Int Ed. 25:1058-1071. 
Sies, H. 1974. Biochemistry of the peroxisome in the liver cell. Angew Chem Int Ed Engl. 13:706-718.

Simpson, P.J. and Lucchesi, B.R. 1987. Free radicals and myocardial ischemia and reperfusion injury. J Lab Clin Med. 110(1):13-30.

Sinclair, B.J., Stinziano, J.R., Williams, C.M., MacMillan, H.A., Marshall, K.E. and Storey, K.B. 2013. Real-time measurement of metabolic rate during freezing and thawing of the wood frog, Rana sylvatica: implications for overwinter energy use. $J$ Exp Biol. 216:292-302.

Sobotta, M.C., Barata, A.G., Schmidt, U., Mueller, S., Millonig, G. and Dick, T.P. 2103. Exposing cells to $\mathrm{H} 2 \mathrm{O} 2$ : a quantitative comparison between continuous low-dose and one-time high-dose treatments. Free Radic Biol Med. 60:325-335

Storey, K.B. 1984. Freeze tolerance in the frog, Rana sylvatica. Experientia. 40:12611262.

Storey, K.B. 1990. Life in a frozen state: adaptive strategies for natural freeze tolerance in amphibians and reptiles. Am J Physiol. 258:R559-R568.

Storey, K.B. and Storey, J.M. 2004. Physiology, biochemistry and molecular biology of vertebrate freeze tolerance: the wood frog. In: Life in the Frozen State (Benson, E., Fuller, B., and Lane, N., eds.) CRC Press, Boca Raton, pp. 243-274.

Vucetic, M., Stancic, A., Otasevic, V., Jankovic, A., Korac, A., Markelic, M., Velickovic, K., Golic, I., Buzadzic, B., Storey, K.B. and Korac, B. 2013. The impact of cold acclimation and hibernation on antioxidant defenses in the ground squirrel (Spermophilus citellus): an update. Free Radic Biol Med. 65:916-24.

Willmore, W.G. and Storey, K.B. 1997. Antioxidant systems and anoxia tolerance in a freshwater turtle Trachemys scripta elegans. Mol Cell Biochem. 170(1-2):177-85.

Winterbourn, C.C. 2008. Reconciling the chemistry and biology of reactive oxygen species. Nat Chem Biol. 4:278-286

Winterbourn, C.C. 2013. The biological chemistry of hydrogen peroxide. Methods Enzymol. 528:3-25 
Wood, Z.A., Poole, L.B. and Karplus, P.A. 2003. Peroxiredoxin evolution and the regulation of hydrogen peroxide signaling. Science. 300:650-653.

Young, I.S. and Woodside, J.V. 2001. Antioxidants in health and disease. J Clin Pathol. $54: 176-186$

Yumoto, I., Fukumori, Y. and Yamanaka, T. 1990. Purification and characterization of catalase from a facultative alkalophilic Bacillus. J Biochem. 108:583-587.

Zweier, J.L. and Talukder, M.A. 2006. The role of oxidants and free radicals in reperfusion injury. Cardiovasc Res. 70(2):181-190. 
Table 4.1. Typical purification and yield of Rana sylvatica muscle CAT.

\begin{tabular}{cccccc}
\hline Purification Step & $\begin{array}{c}\text { Total } \\
\text { Protein } \\
(\mathbf{m g})\end{array}$ & $\begin{array}{c}\text { Total } \\
\text { Activity } \\
(\mathbf{m U})\end{array}$ & $\begin{array}{c}\text { Specific } \\
\text { Activity } \\
(\mathbf{m U} / \mathbf{m g})\end{array}$ & $\begin{array}{c}\text { Fold } \\
\text { Purification }\end{array}$ & $\begin{array}{c}\text { Yield } \\
\text { (\%) }\end{array}$ \\
\hline Crude extract & 110.4 & 2418 & 21.9 & - & 100 \\
Hydroxylapatite & 1.10 & 1666 & 1513 & 69.1 & 68.9 \\
Cibacron Blue & 0.85 & 1599 & 1876 & 85.7 & 66.2 \\
DEAE $^{+}$ & 0.12 & 276 & 2308 & 105.4 & 11.4 \\
\hline
\end{tabular}


Table 4.2. Kinetic parameters of CAT purified from muscle of control and frozen $R$. sylvatica. * - Significantly different between control and frozen values, $\mathrm{p}<0.05$. $\mathrm{n}=8$.

\begin{tabular}{lll}
\hline Enzyme parameters & Control & 24h Frozen \\
\hline $\mathrm{K}_{\mathrm{m}} \mathrm{H}_{2} \mathrm{O}_{2}(\mathrm{mM})$ & $20.7 \pm 0.87$ & $13.2 \pm 0.50^{*}$ \\
$\mathrm{~V}_{\max }(\mathrm{U} / \mathrm{mg})$ & $2308 \pm 18.5$ & $3412 \pm 55.8^{*}$ \\
$\mathrm{~T}_{\mathrm{m}}\left({ }^{\circ} \mathrm{C}\right)$ & $56.3 \pm 0.10$ & $56.7 \pm 0.17$ \\
\hline
\end{tabular}



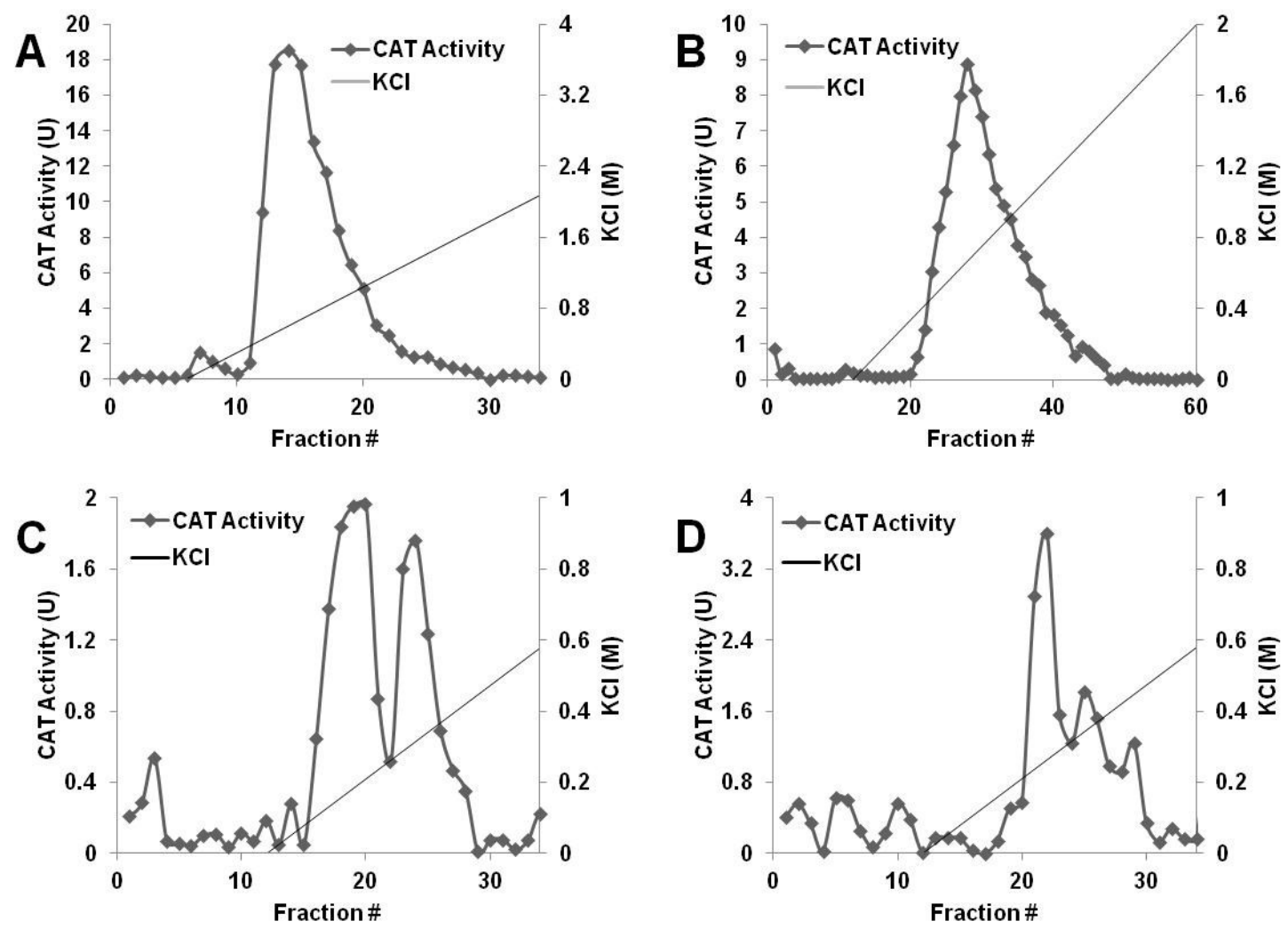

Figure 4.1. (A) Typical elution profile for CAT on a hydroxyapatite column. (B) Typical elution profile for CAT on a Cibacron blue column. (C) Typical elution profile for CAT from control muscle on a $\mathrm{DEAE}^{+}$column. (D) Typical elution profile for CAT from frozen muscle on a $\mathrm{DEAE}^{+}$column. Solid line indicates $[\mathrm{KCl}]$. 


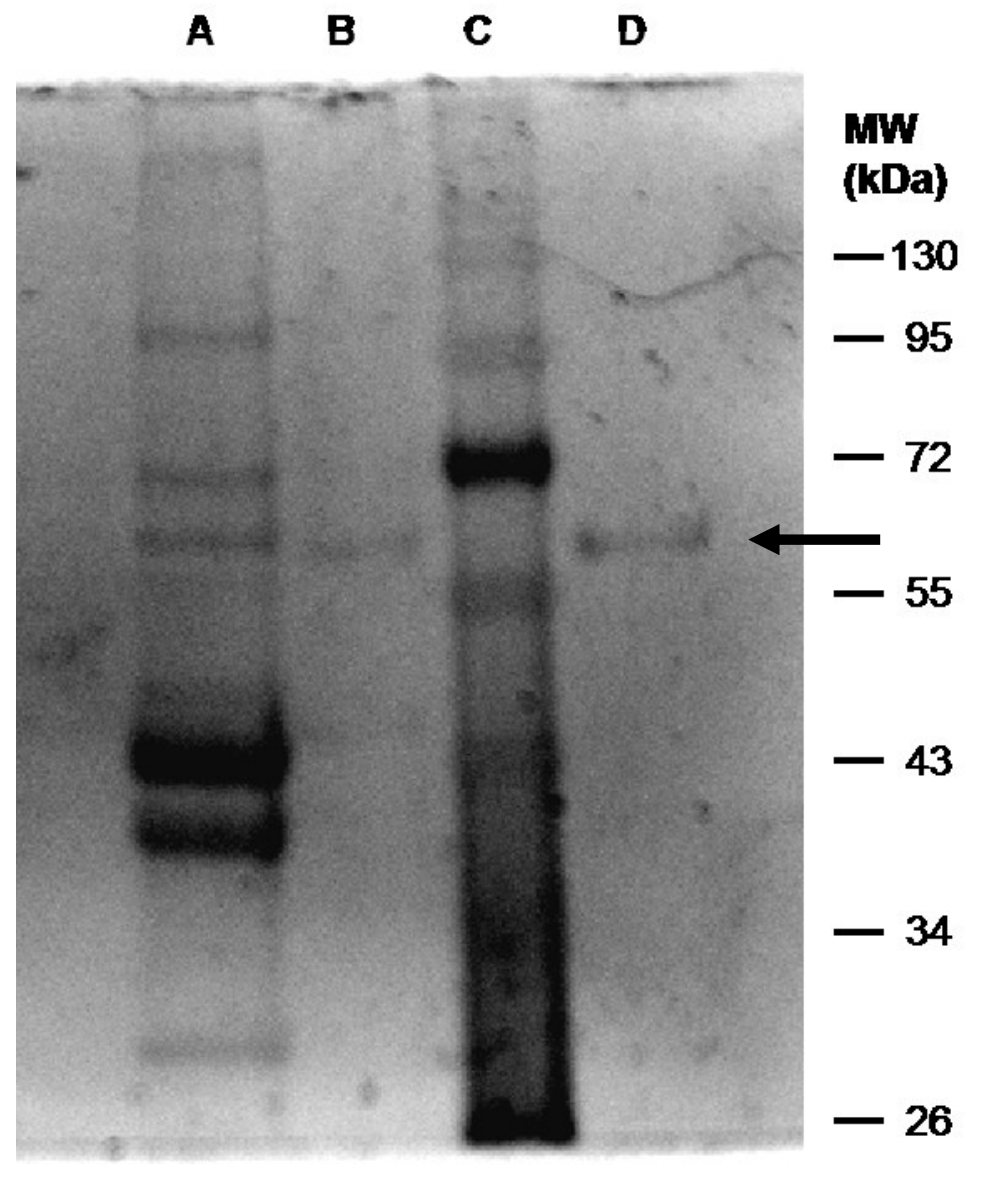

Figure 4.2. Stepwise purification ofCAT samples from the muscle of control R. sylvatica. (A) CAT-containing eluant after hydroxylapatite chromatography, (B) CAT-containing eluant after Cibacron blue chromatography, (C) molecule weight standards, and (D) purified CAT from $\mathrm{DEAE}^{+}$chromatography. CAT protein is the prominent band at $\sim 60$ $\mathrm{kDa}$ indicated by the arrow. 


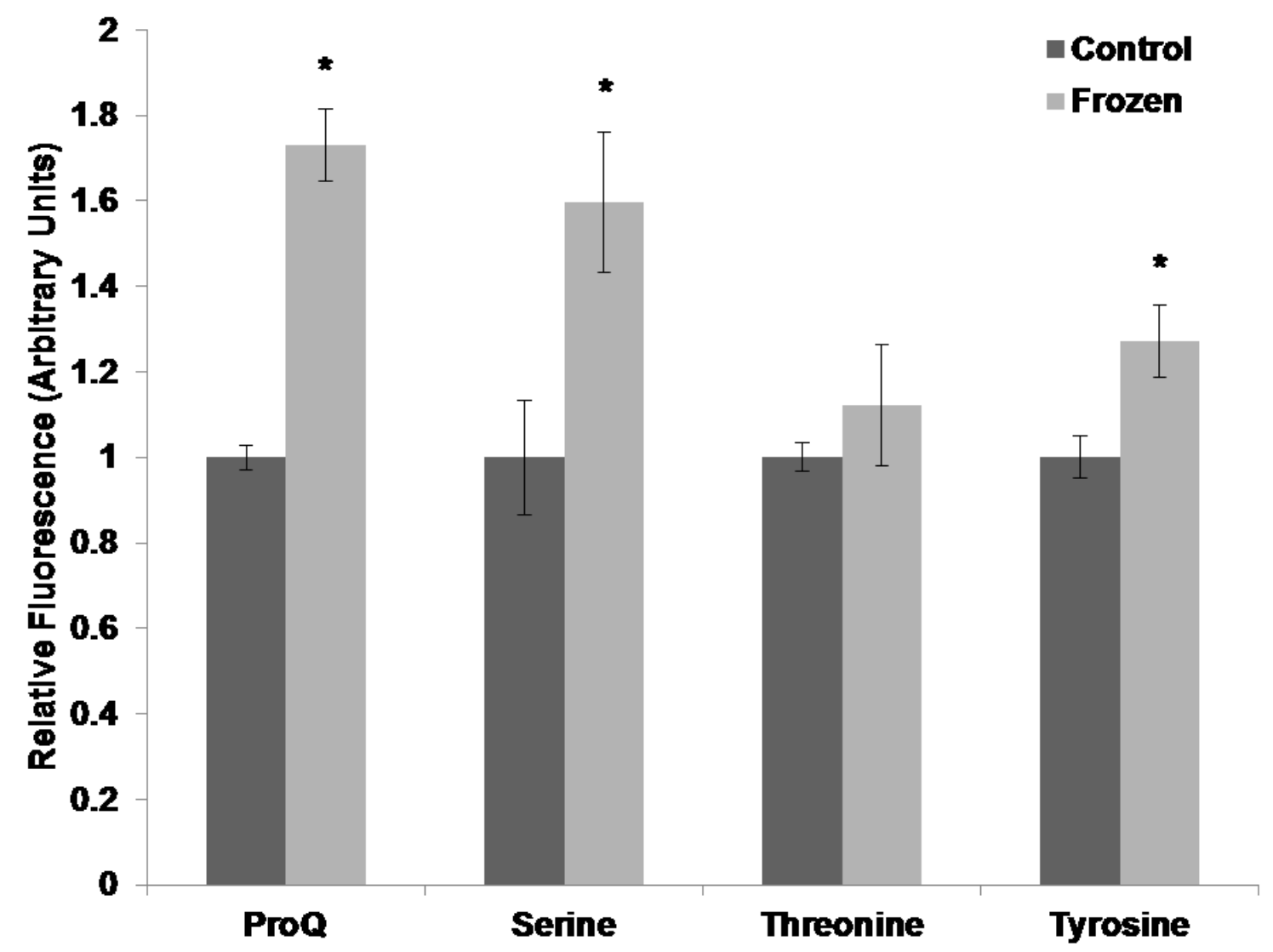

Figure 4.3. Relative phosphorylation levels of CAT as assessed from incubations of purified frog muscle extracts from control and $24 \mathrm{~h}$ frozen frogs with detection using ProQ Diamond phospho-protein stain or Western blotting for site-specific phosphorylation. * - Significantly different from the corresponding control value, $\mathrm{p}<0.05$, $n=6$. 


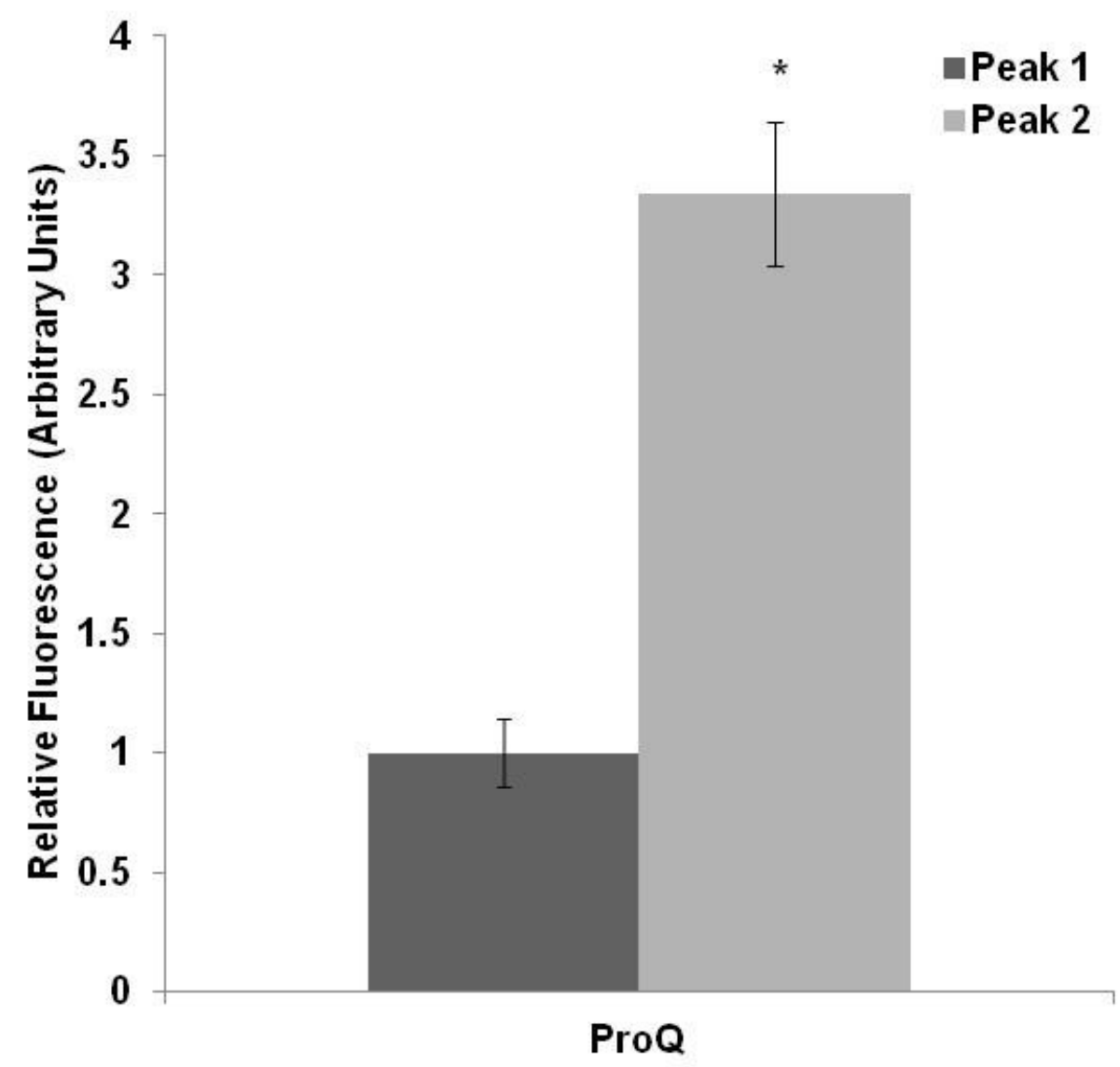

Figure 4.4. Relative phosphorylation levels of control muscle CAT from Peak I and Peak II as assessed by Pro-Q diamond phospho-protein staining. * - Significantly different from the peak 1 value, $\mathrm{p}<0.05, \mathrm{n}=5$. 

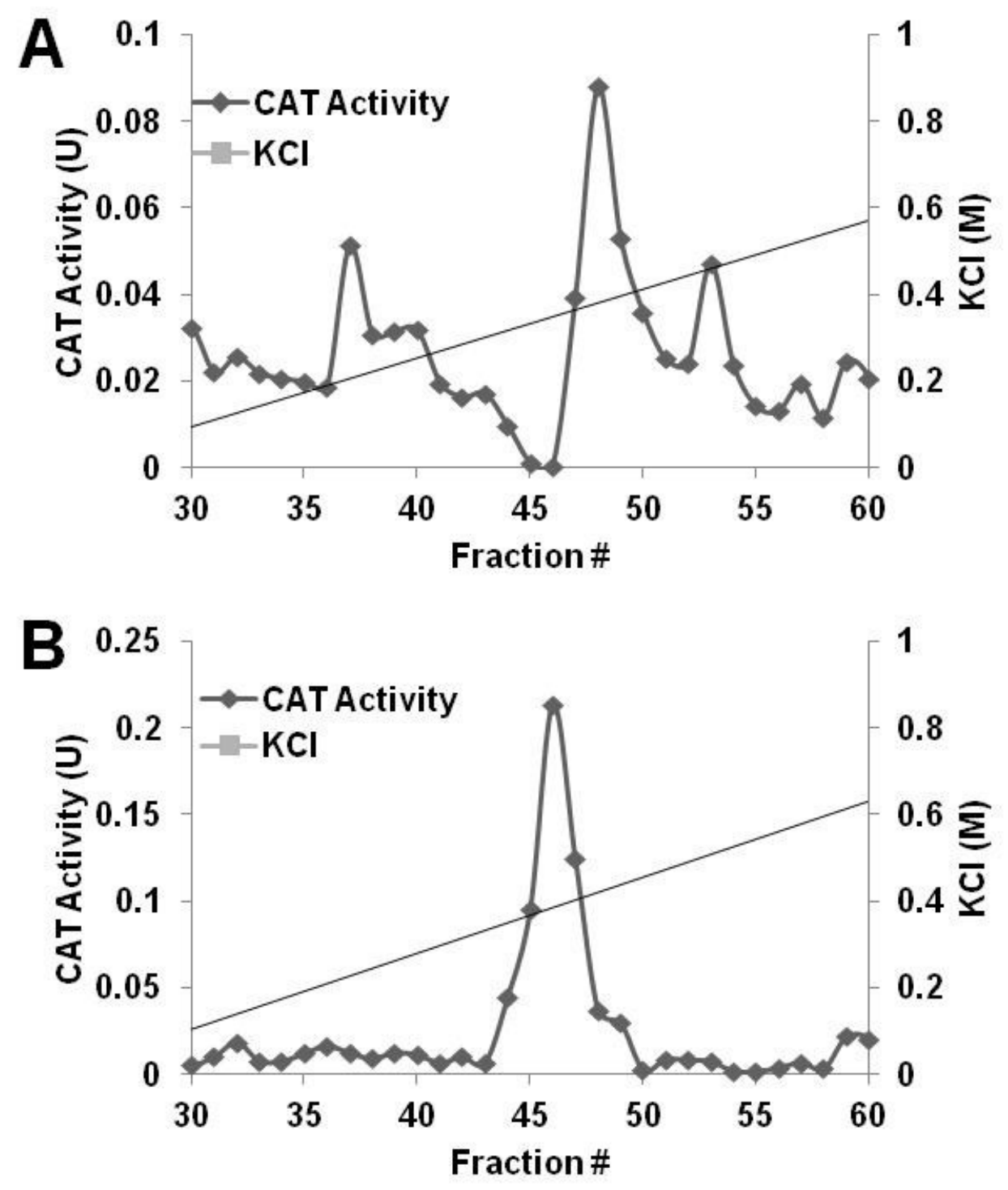

Figure 4.5. $\mathrm{DEAE}^{+}$elution profiles for muscle CAT from control frogs and incubated under conditions that stimulated protein phosphatases (A) or protein kinases (B). Solid line indicates $[\mathrm{KCl}]$. 


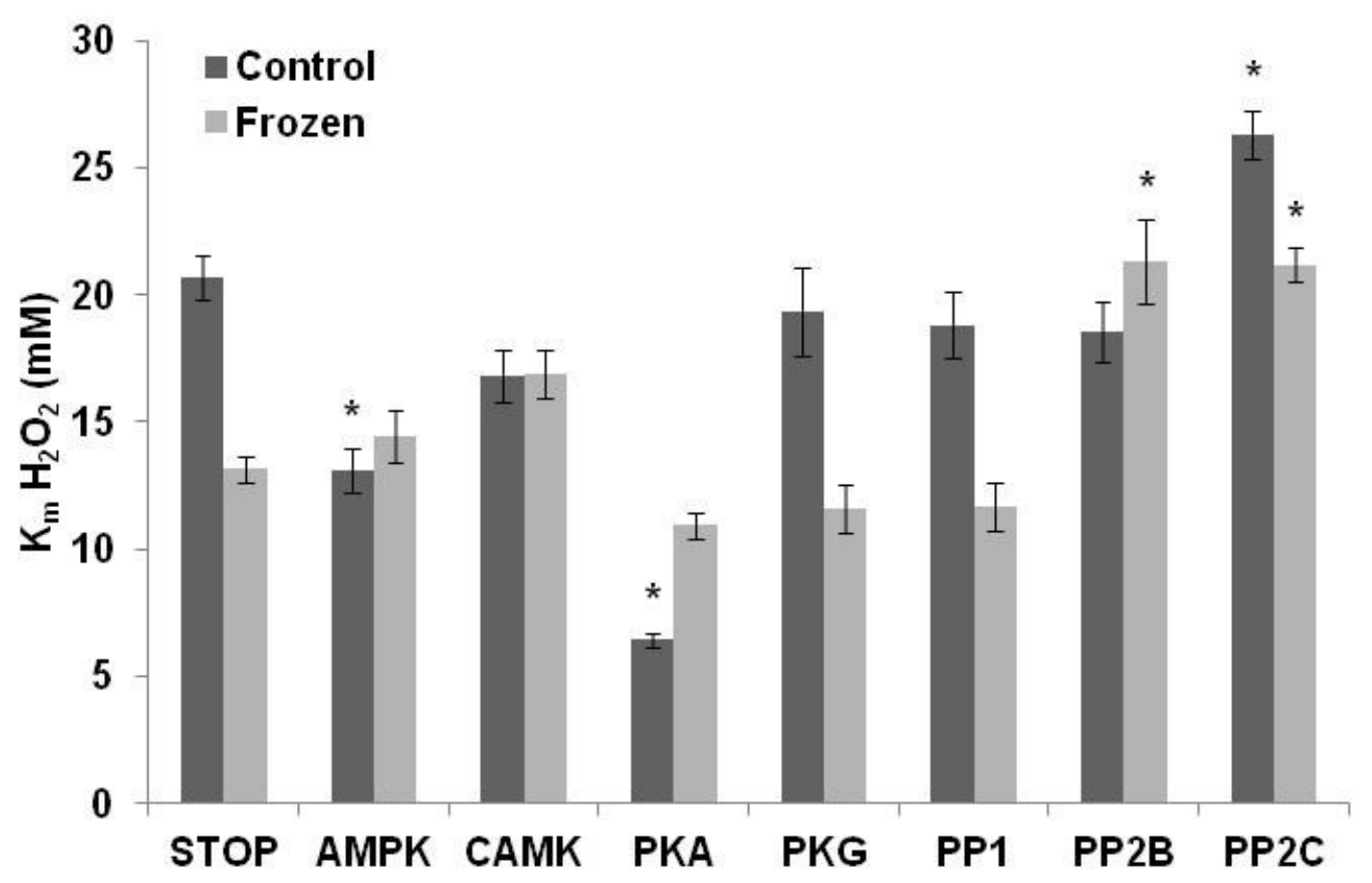

Figure 4.6. Effects of in vitro incubations of purified CAT of muscle under conditions which stimulated the activities of endogenous protein kinases or phosphatases on the resulting $\mathrm{K}_{\mathrm{m}}$ values for $\mathrm{H}_{2} \mathrm{O}_{2}$ of CAT from control and frozen $R$. sylvatica. * Significantly different from corresponding STOP condition using the Dunnett's test, $\mathrm{p}>0.05, \mathrm{n}=8$. 


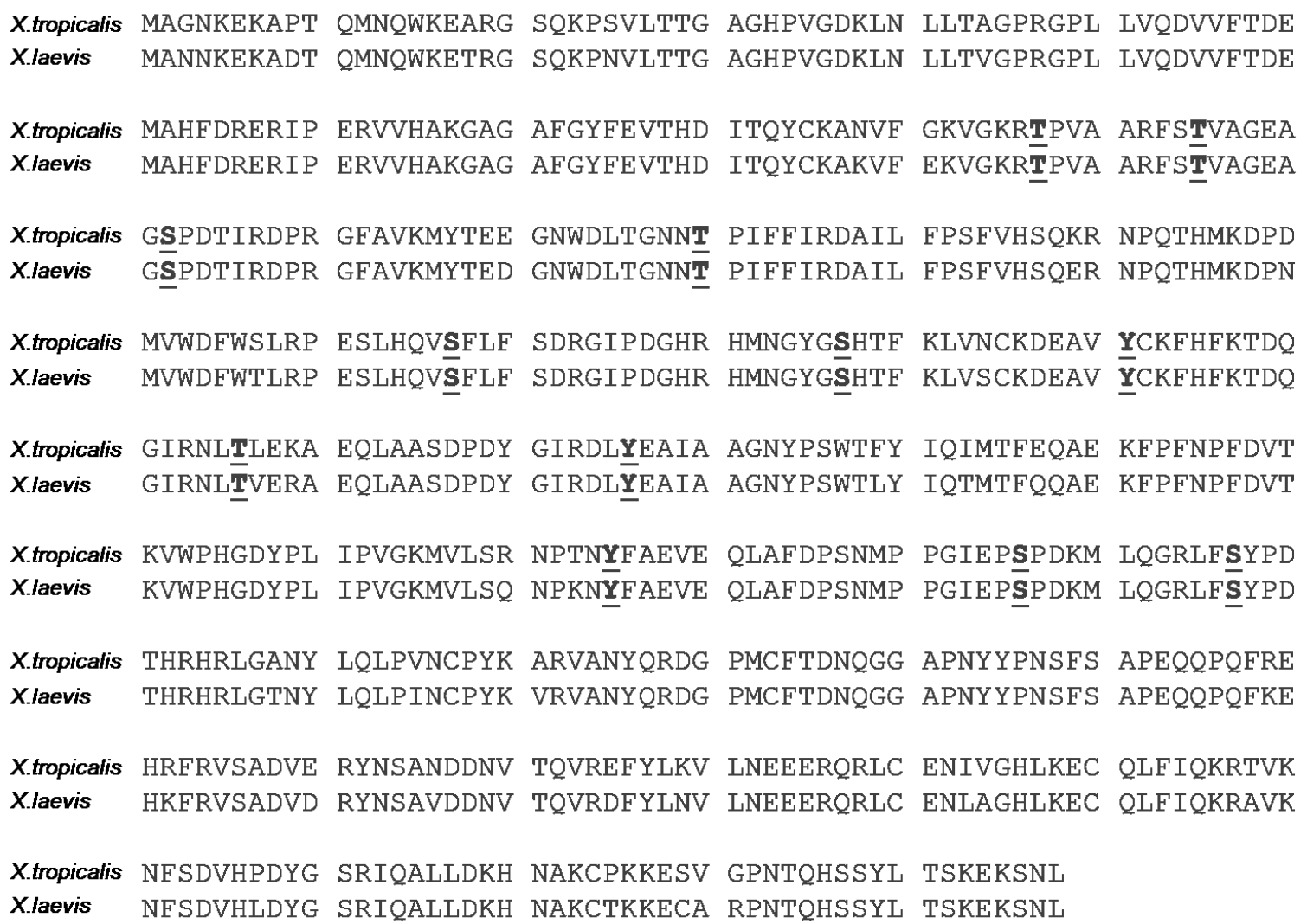

Figure 4.7. A comparison of the predicted phosphorylation sites for CAT from $X$. tropicalis and $X$. laevis which are shared between the two frog species. Predicted phosphorylation sites are shown in bold and underlined. 


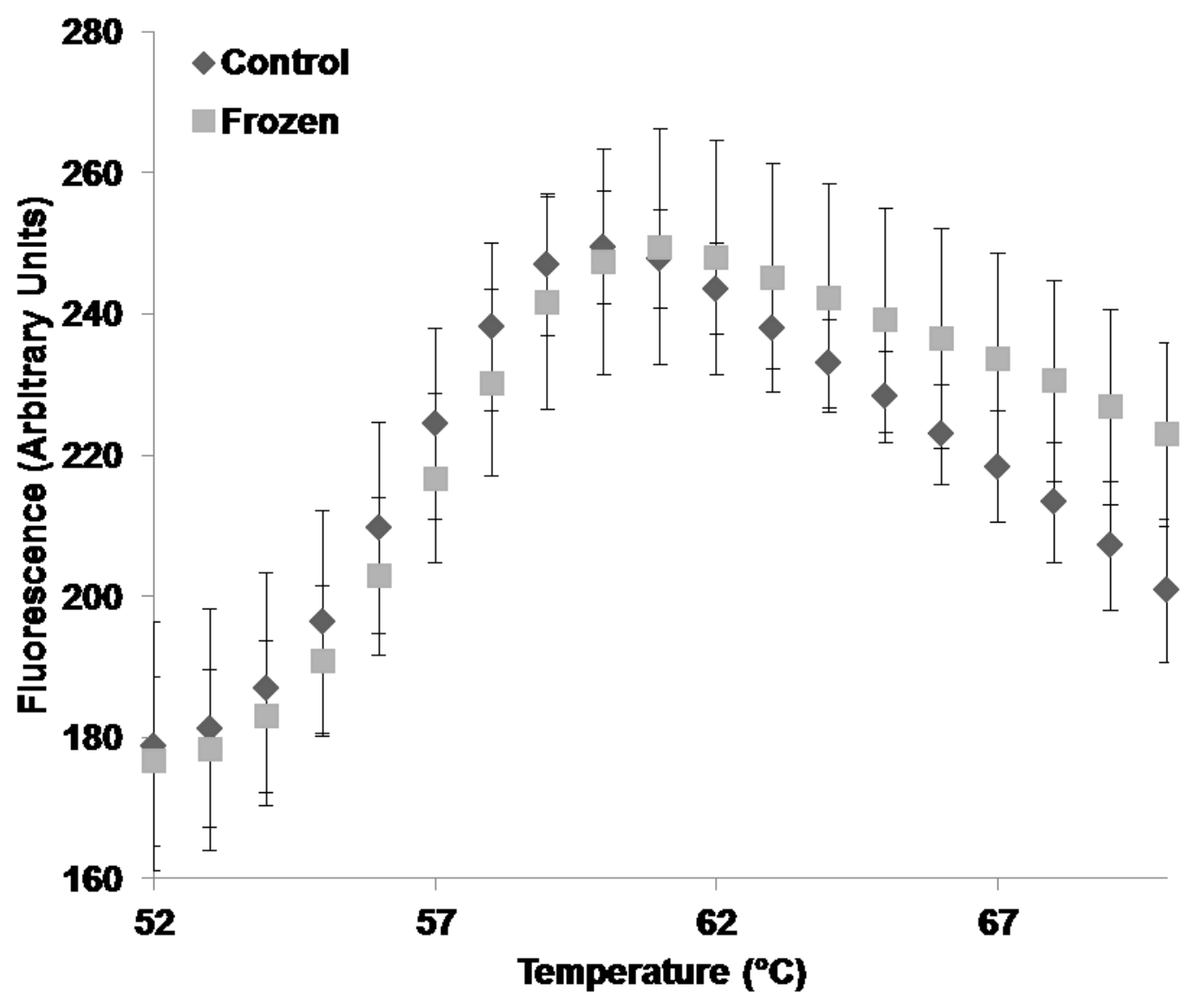

Figure 4.8. Differential scanning fluorimetry analysis of the thermal stability of purified CAT from control and $24 \mathrm{~h}$ frozen frog muscle. CAT from frozen frogs showed no significant difference when compared to CAT from control frogs, $\mathrm{n}=8$. 
Chapter 5:

General Discussion 


\section{General Discussion}

Oxygen radicals are continuously produced by all oxygen-consuming organisms and changes in their expression have been linked to many pathological disease states. All known oxygen-consuming organisms have built-in defenses to protect against attack by oxygen radicals. Protection against damage by ROS can be classified as three distinct groups: i) the prevention of free radical generation, ii) termination of free radical propagation, and iii) repair of the damage incurred. Termination is accomplished through the activities of enzymes tasked with detoxification of ROS and through low molecular weight metabolites that act as scavengers of toxic oxygen species. Although production of ROS is encountered at all times, certain physiological conditions are associated with increased oxidative stress including: hyperoxia (Barga de Quiroga et al., 1988), hypoxia (Bhat et al., 1992), ingestion of toxic substances (Lee and Berenbaum, 1993), exposures to extremes of cold and heat (Barga de Quiroga, 1992), or ultraviolet radiation (Shick et al., 1981). In some cases ROS production actually occurs following physiological stresses, such as the oxidative stress that arises during recovery from ischemia. Endurance of freezing and entry into hibernation or estivation are all accompanied by depression of metabolic rate and oxygen consumption (Storey and Storey, 1990). In these cases, the organism may endure prolonged ischemia or hypoxia. During freezing, animals experience a cutoff of the blood supply to tissues, while hibernation and estivation subjects animals to wide variations in oxygen levels. Ischemia experienced during freethaw episodes is a more stressful state since plasma-borne delivery of oxygen and other substances to tissues is cut off and $\mathrm{CO}_{2}$ and other wastes cannot be removed. Following 
ischemia, reoxygenation of blood, rapidly increased metabolic rate and a burst of ROS production is coupled with increased levels of iron, copper (Chevion et al., 1993) and hypoxanthine (Rubin et al., 1992). Animals that endure freezing have adapted to circumvent the injurious consequences of oxidative stress upon recovery. They do this by continually maintaining higher levels of antioxidants than are present in comparable species that are intolerant of the stress, through stress-mediated alterations of antioxidant enzyme activity, or by up-regulation of antioxidant enzyme gene expression during the initial stress, in anticipation of increased generation of ROS upon recovery. Examples of these strategies can be found in tissues of the wood frog, R. sylvatica, and the spadefoot toad, S. couchii, which maintain high levels of antioxidant enzymes (and alter antioxidant enzyme function) while frozen or estivating, and the estivating land snail, O. lactea, which synthesizes antioxidant enzymes as a defence against stress that occurs when oxygen consumption is rapidly increased upon arousal (Joanisse and Storey, 1996; Grundy and Storey, 1998; Hermes-Lima and Storey, 1998). In all cases these animals experience suppressed metabolic states that are reversed during thawing or arousal with a rapid increase in oxygen consumption. The freeze-thaw transition is functionally analogous to an ischemia/reperfusion event (Joanisse and Storey, 1996), which in mammalian systems is well known to cause substantial free radical damage (Campos et al., 1993; Downey, 1990; Hossain et al., 1995).

Previous studies were conducted on crude tissue extracts in order to test which mechanisms of oxidative damage avoidance were used in wood frogs (Joanisse and Storey, 1996). These studies quantified activities of antioxidant enzymes and the amount of soluble glutathione in wood frogs during freezing (Joanisse and Storey 1996). These 
results provided evidence that frogs seem to enter freezing with thawing in mind; that is, they employ an anticipatory strategy that sets them up during freezing with biochemical adaptations to deal with ROS stress and damage upon thawing reperfusion. The results clearly showed that the maximal activities of select antioxidant enzymes were augmented, and glutathione levels were higher in frozen animals. Thus, it would seem that maintenance and induction of the frog's antioxidant complement of enzymes and soluble glutathione is essential for survival during freezing. In addition, the activity of $\mathrm{XO}$, which generates ROS, was not significantly higher in frozen frogs in comparison to control frogs, and the ratio of XO to XDH remained unchanged (Joanisse and Storey, 1996). The conversion of XDH to XO and the subsequent increase in the ratio of $\mathrm{XO} / \mathrm{XDH}$ are predictive criteria for oxidative stress during ischemia and reperfusion (Hearse et al., 1986), and it would seem that frogs recovering from the frozen state are able to avoid the expected ROS damage upon reperfusion (Joanisse and Storey, 1996). In addition to $\mathrm{XO} / \mathrm{XDH}$ ratios, tests used to measure oxidative damage reported that oxidative damage was noticeably absent in frozen and thawed frogs, as assessed using the TBARS test and the xylenol orange test (Joanisse and Storey, 1996). These data suggest that the frogs are able to prevent the formation of oxygen damaged molecules rather than deal with damaged tissues, which is energetically favorable for the animal. Since the frog has been shown to exit the frozen state in an energy-limited state (Storey and Storey, 1986; Storey, 1987), prevention of the formation of ROS-damaged molecules may be critical since the frog may simply lack the appropriate energy reserves to repair or resynthesize oxidatively damaged molecules in a timely manner upon thawing. 
It is unlikely that increased numbers of oxygen radicals were formed during freezing since oxygen consumption is essentially zero in this state in comparison to the tissues of control frogs. The rate of generation of free radicals is directly proportional to metabolic rate (i.e. oxygen consumption) and should be lower in frozen frogs. However, recovery from freezing involves the rapid increase in metabolic rate which should stimulate the burst production of oxygen radicals. Indeed, hallmarks of oxidative damage including lipid peroxidation and GSSG/GSH ratios increased following arousal from estivation in both land snails, O. lactea (Hermes-Lima and Storey, 1998) and toads, $S$. couchii (Grundy and Storey, 1998). XO/XDH ratios were also significantly higher upon exit from estivation in toads, S. couchii (Grundy and Storey, 1998). In the case of $O$. lactea, increased activities of antioxidant enzymes were observed. However, little was known of their kinetic parameters, and in the case of the estivating toad, antioxidant enzymes activities of some of the enzymes studied in this thesis actually dropped over the estivation period. In both cases, changes in the antioxidant enzymes activity alone were not sufficient to disrupt the formation of oxidative damage due to production of ROS. In stark contrast to the general reduction of antioxidant enzymes in the estivating toad, GST activities were observed to increase (Grundy and Storey, 1998). Increased GST activities were suggested to play a pivotal role in reversing the effects of oxidative damage upon arousal, and it has been suggested that the estivating toad as well as the estivating land snail are more likely to detoxify ROS damage after exit from a metabolically depressed state, rather than prevent ROS formation (Grundy and Storey, 1998; Hermes-Lima and Storey 1998). 
R. sylvatica has demonstrated none of the hallmarks of oxidative stress, and it has been suggested that ROS formation is prevented through constitutively higher antioxidant enzymes and glutathione levels throughout freezing (Joanisse and Storey, 1996). However, increased antioxidant enzymes was also observed in O. lactea, yet lipid peroxides and changes in the GSSG/GSH ratios were observed upon exit from metabolic rate depression (Hermes-Lima and Storey, 1998). The studies designed in this thesis explored the possibility of preventative measures employed by $R$. sylvatica to detoxify oxygen radicals before oxidative damage can occur.

\subsection{Purification of Antioxidant Enzymes}

A common problem for protein biochemists studying the function of native proteins is the phenomena of competing activity profiles. Multiple enzymes can sometimes act upon the same substrates or products which skews data collected when competing enzymes are present in the protein preparation. This is of particular importance for studies of antioxidant enzymes since many of these enzymes have similar functions, or even a second function that mimics another antioxidant enzyme. This can be clearly seen in the case of CAT, which can exhibit GPx activity (Singh et al., 2007), and GST and GPx which have been demonstrated to play similar roles in detoxifying xenobiotics and hydroperoxide adducts (Salinas and Wong, 1999). Another cause for concern is the reactivity of the substrates and products produced in antioxidant enzymecatalyzed reactions. Superoxide, glutathione and hydrogen peroxide (the three main molecules studied in this thesis) have all been linked to a wide range of biochemical 
reactions and pathways in mammalian cells. Therefore, antioxidant enzymes were purified to homogeneity or near-homogeneity in order to ensure that the measured differences between the enzymes from control and frozen frogs were the result of the enzyme of interest, and not linked to competing enzymes. This phenomenon will also be explored when comparing previously collected data of $R$. sylvatica antioxidant enzymes obtained without the aid of protein purification.

\subsection{Superoxide Dismutase}

SOD, an essential antioxidant enzyme, was purified from frog muscle with a final specific activity between 1390-2100 U/mg protein for CuZnSOD and 1550-1570 U/mg protein for MnSOD for the enzyme from both control and frozen animals, with yields of $\sim 11 \%$ and $\sim 20 \%$ respectively. Both the specific activities and yields obtained for each isoform of SOD was in line with values obtained from other animals (Rigo et al., 1975). Superoxide is a very reactive molecule, particularly in the face of elevated amounts of metal or metal-containing proteins. In previous studies of $R$. sylvatica, total SOD activity was measured as rising from $14 \mathrm{U} / \mathrm{mg}$ protein to nearly $40 \mathrm{U} / \mathrm{mg}$ protein over the course of a freeze-thaw cycle (Joanisse and Storey, 1996). This is likely due to an increase in endogenously present molecules, and enzymes such as xanthine oxidase, that can react with superoxide. The assay used in previous studies has also been demonstrated to exhibit greater error and $\mathrm{NAD}(\mathrm{P}) \mathrm{H}$-utilizing methods are prone to errors in biological samples (Berridge et al., 2005). Therefore, it was critical to purify SOD. The purified form of CuZnSOD from frozen frogs exhibited a higher maximal activity in comparison to the 
control form, which is in line with the increases seen with nearly all other SODs studied. CuZnSOD is a more abundant eukaryotic protein than MnSOD. The observed stressresponsive changes in activity for CuZnSOD (but not MnSOD) seen in chapter 2 probably account for the changes in total SOD that are observed in wood frogs and other animals when fluctuations in total SOD activity have been discovered.

The successful separation of isoforms allowed for the independent characterization of MnSOD. Proper characterization of MnSOD has proven elusive, since flash-frozen tissues are prone to mitochondrial destabilization and studies of mitochondria-specific enzymes have been left largely unexplored. Chapter 2 presents one of the first studies of the mitochondrial form of SOD in an animal that undergoes hypometabolism. MnSOD activity remained uniform when comparing the control and frozen states, which would have otherwise been masked by changes in CuZnSOD activity. However, MnSOD demonstrated unique modification and enzyme function in the frozen state, highlighting its possible importance to surviving repeat freeze-thaw cycles in R. sylvatica. Augmented MnSOD activity would increase the protection against superoxide production at the major site where it is formed, the mitochondria. Superoxide production during thawing and the attendant reoxygenation of tissues would likely result mostly from superoxide production from the mitochondria, since the ETC would be primed for radical production in its fully reduced state. In line with this rationale for SOD function, mitochondrial superoxide production has been shown to trigger apoptosis, whereas cytosolic production of superoxide has been linked to many cell signaling events (Thannickal and Fanburg, 2000). This would suggest that CuZnSOD is more likely to have a role in regulating cell signaling events during freeze/thaw, whereas MnSOD is 
more likely to have a role in keeping $\mathrm{O}_{2}{ }^{-} \cdot$ levels in the mitochondria low to stave off apoptotic cell death. This is of special interest to wood frogs since the muscle tissue thaws later than internal organs such as the heart or liver (Rubinsky et al., 1994). Later thawing could mean that the muscle is under prolonged ischemic stress until circulation is restored which could be one reason for the delay in recovery of skeletal muscle functionality as compared with the reinstatement of heart beat and breathing (Layne and First, 1991; Kling et al., 1994). Furthermore, improved affinity for $\mathrm{O}_{2}{ }^{-} \cdot$ by $\mathrm{MnSOD}$ in the frozen frog may aid the peripheral tissue during thawing, allowing for reintroduction of re-oxygenated blood into the tissue without sustaining a buildup of oxidative stress.

\subsection{Catalase}

It is critical to think of the consequences of changes in SOD function and how these will impact the rest of the cell. In this thesis, up-regulation of SOD activity and function was documented in chapter 2, which leads to the inevitable conclusion that $\mathrm{H}_{2} \mathrm{O}_{2}$ levels would increase accordingly. It is for this reason that CAT was explored in detail, since CAT plays a pivotal role in the breakdown of $\mathrm{H}_{2} \mathrm{O}_{2}$ when $\mathrm{H}_{2} \mathrm{O}_{2}$ levels are much higher than normal (Kim et al., 1988). CAT was purified from frog muscle with a final specific activity between $2308-3412 \mathrm{U} / \mathrm{mg}$ protein for the enzyme from both control and frozen animals, with yields of $\sim 11 \%$. Previous studies of CAT from $R$. sylvatica showed no significant changes in CAT activity in whole tissue extracts; however, changes in glutathione peroxidase activities were observed (Joanisse and Storey, 1996). CAT was assayed by directly measuring the decomposition of $\mathrm{H}_{2} \mathrm{O}_{2}$ in solution in the previously 
mentioned study, as well as in chapter 4 of this thesis. Under normal cellular conditions peroxiredoxins, peroxidases, GSTs, as well as CAT all contribute to catalyzing the reduction of $\mathrm{H}_{2} \mathrm{O}_{2}$ (Rabilloud et al., 2002; Wagner et al., 2002; Koo et al., 2002). GSTs are largely ignored when discussing $\mathrm{H}_{2} \mathrm{O}_{2}$ reduction, as only select isoforms exhibit this potential, and those that do show very poor $\mathrm{H}_{2} \mathrm{O}_{2}$ reducing ability. Whole cell extract or whole tissues extract assays are unable to distinguish the source of $\mathrm{H}_{2} \mathrm{O}_{2}$ breakdown, and classical studies are likely measuring the total capacity of these and other $\mathrm{H}_{2} \mathrm{O}_{2}$ reducing enzymes. In chapter 4, CAT was purified to homogeneity, and it was discovered that CAT from the muscle of frozen frogs was modified and its activity and affinity for $\mathrm{H}_{2} \mathrm{O}_{2}$ were augmented. Increased CAT activity is likely required to deal with increases in $\mathrm{H}_{2} \mathrm{O}_{2}$ produced from elevated SOD activity previously outlined in chapter 3 . In this sense, CAT and SOD work in concert to detoxify the main oxygen radicals produced by multiple ischemic episodes encountered during freezing.

Through exploration of the differences in affinity of the different $\mathrm{H}_{2} \mathrm{O}_{2}$ reducing enzymes, it can be concluded that their substrate affinities in a normal mammalian system are as follows: peroxiredoxins $>$ peroxidases $>$ CAT (Cox et al., 2010; Winterbourn, 2008; Flohe, 2010; Winterbourn, 2013; Hall et al., 2011). Peroxiredoxins are likely to work best at low $\mathrm{H}_{2} \mathrm{O}_{2}$ concentrations and are inactivated in high $\left[\mathrm{H}_{2} \mathrm{O}_{2}\right]$, and peroxidases are known to have limited flux. Therefore, when exploring the relative rate of $\mathrm{H}_{2} \mathrm{O}_{2}$ reduction, the order is believed to be reversed as follows: CAT>peroxidases>peroxiredoxins (Flohe, 2010; Winterbourn, 2013; Hall et al., 2011). This poses an interesting potential point of further study since the affinity of frog muscle peroxidases/peroxiredoxins is not known in either control or frozen frogs. However, 
human GPx has a $\mathrm{K}_{\mathrm{m}}$ value for $\mathrm{H}_{2} \mathrm{O}_{2}$ that ranges from 9-19 mM (Zheng et al., 2008), which is below the measured $\mathrm{K}_{\mathrm{m}}$ for $\mathrm{H}_{2} \mathrm{O}_{2}$ of CAT from control frogs, yet encompasses the measured value for CAT from frozen frogs, as reported in chapter 4 . The diffusion of $\mathrm{H}_{2} \mathrm{O}_{2}$ away from the site of production and across membranes using $\mathrm{H}_{2} \mathrm{O}_{2}$ gradients has been discussed (Antunes and Cadenas, 2000; Mueller et al., 2009; Sobatta et al., 2013). Although this is merely speculative, it could very well be that CAT from frozen frogs is activated as a protective 'vacuum' in the face of elevated $\mathrm{H}_{2} \mathrm{O}_{2}$, drawing $\mathrm{H}_{2} \mathrm{O}_{2}$ away from the peroxidases (with lower, or similar affinity) to the peroxisome where CAT resides. This could potentially help to detoxify $\mathrm{H}_{2} \mathrm{O}_{2}$ that is produced in the greatly dehydrated cells of frozen tissue. Indeed, if $65 \%$ of total body water is frozen as extracellular ice, the intracellular concentrations of all solutes in the remaining cell water can be automatically elevated by 3 -fold apart from any additional effect of stress-induced increased synthesis of $\mathrm{H}_{2} \mathrm{O}_{2}$ or other products. Hence, $\mathrm{H}_{2} \mathrm{O}_{2}$ concentrations could rise substantially during prolonged freezing due to freeze concentration of the cell and/or during thawing reperfusion due to a burst of ROS production during reoxygenation. Furthermore, CAT might become the favored route for $\mathrm{H}_{2} \mathrm{O}_{2}$ detoxification in frozen tissues because peroxidases or peroxiredoxins might be compromised if the supply of the reduced cofactors needed for their reaction, glutathione or thioredoxin, runs short during long term freezing.

\subsection{Glutathione Reductase}

Glutathione reductase is not a traditional antioxidant enzyme; it is considered 
more of a secondary antioxidant enzyme because it recycles an antioxidant molecule, converting GSSH back to GSH. However, GR does seem to play an important role in the antioxidant defense system of the frozen frog. As previously reported, GSH levels are much higher in R. sylvatica than in non-tolerant species (Joanisse and Storey, 1996), and as such, a more active GR was expected in frozen frogs in order to keep GSSG/GSH ratios intact. Initial experiments performed in chapter 3 suggested that GR was, in fact, not regulated at all in frozen animals. However, when explored in the face of elevated levels of common metabolites, GR exhibited changes in kinetic parameters. This provides a complex picture of regulation in the frozen animal. Many of the metabolites explored in chapter 4 are known to, or thought to, change throughout the course of freeze-thaw cycles. Specifically, glucose and urea are known to vary greatly in $R$. sylvatica between the control and frozen states (Storey and Storey, 2004). It is interesting that high-glucose shows an effect on GR, as constitutively high antioxidant enzymes have recently been reported for hypoglycemic states (Dey and Lakshmanan, 2013). Glutathione has been shown to play a protective role in hypoglycemia, demonstrating positive effects on oxidative stress and hypoglycemia mediated damage in diabetes (Rochette et al, 2014; Dey and Lakshmanan, 2013). Clearly the interaction between glutathione and glutathione-using enzymes with respect to variations in glucose levels is an area that requires further attention. Chapter 3 provides yet another interesting link between glucose and oxidative stress, and it appears that GR from frog muscle exists in a glucose sensitive form, with an amelioration of function in the face of elevated glucose. 


\subsection{Concluding Remarks}

In conclusion, this thesis provides an in-depth analysis of the front-line antioxidant defense systems in the muscle of the freeze tolerant frog, $R$. sylvatica. Each successive chapter explores the mediation of ROS production from the primary source, the mitochondria, and the byproducts as they migrate away from the source of production. Through phosphorylation-mediated increases in the function of the mitochondrial superoxide scavenger, MnSOD, the frog is likely able to eliminate superoxide before it can cause serious harm to the muscle tissue. However, increased SOD activity results in an increase in $\mathrm{H}_{2} \mathrm{O}_{2}$ production, potentially to a point that is lethal to most animals (particularly in freeze dehydrated cells). This means that under conditions such as ischemia/reperfusion, primary $\mathrm{H}_{2} \mathrm{O}_{2}$ reducing peroxiredoxins would likely be inactivated in the face of greatly increased $\mathrm{H}_{2} \mathrm{O}_{2}$ levels. $\mathrm{H}_{2} \mathrm{O}_{2}$ is generated in a site specific manner and the local concentration of $\mathrm{H}_{2} \mathrm{O}_{2}$ is modulated by its generation and subsequent removal. The diffusion of $\mathrm{H}_{2} \mathrm{O}_{2}$ away from the site of production and across membranes creates a $\mathrm{H}_{2} \mathrm{O}_{2}$ gradient (Antunes and Cadenas, 2000). Furthermore, the sites of $\mathrm{H}_{2} \mathrm{O}_{2}$ removal, via catalase in the peroxisomes, glutathione peroxidase and peroxiredoxins in the cytosol and other organelles further drives this diffusion gradient from the site of production to the site of removal (Antunes and Cadenas, 2000; Mueller et al., 2009; Sobotta et al., 2013). Increases in the affinity for $\mathrm{H}_{2} \mathrm{O}_{2}$ and activity of CAT, seemingly as a result of protein phosphorylation of CAT, is likely to aid the breakdown of elevated $\mathrm{H}_{2} \mathrm{O}_{2}$ levels encountered as a result of multiple freeze-thaw episodes or of long-term sustained freezing events. Finally, increased glutathione turnover is achieved via positive effects of glucose and other effectors on the secondary antioxidant enzyme 
GR. In summary, then, R. sylvatica has shown a unique method of dealing with ROS production, employing a preventative measure of defense in lieu of the more widespread post-ROS damage repair mechanisms seen in many other vertebrates experiencing variations in oxygen availability. 


\section{References}

Antunes, F. and Cadenas, E. 2000. Estimation of $\mathrm{H}_{2} \mathrm{O}_{2}$ gradients across biomembranes. FEBS Lett. 475:121-126.

Bara de Quiroga, G., Gil, P. and Lopez-Torrez, M. 1988. Physiological significance of catalase and glutathione peroxidases, and in vivo peroxidation, in selected tissues of the toad, Discoglossus pictus, during acclimation to normobaric hyperoxia. J Comp Physiol B. 158:583-590.

Berridge, M.V., Herst, P.M. and Tan, A.S. 2005. Tetrazolium dyes as tools in cell biology: new insights into their cellular reduction. Biotechnol Annu Rev. 11:127-52.

Bhat, G.B., Tinsley, S.B., Tolsen, K., Pate,1 J.M. and Block, E.R. 1992. Hypoxia increases the susceptibility of pulmonary artery endothelial cells to hydrogen peroxide injury. $J$ Cell Physiol. 151:228-238.

Campos, R., Maureira, F., Garrido, A. and Valenzuela, A. 1993. Different glutathione redox status and lipid peroxidation in the cortex and the medulla of the rat kidney subjected to ischemia-reperfusion. Comp Biochem Physiol. 105:157-163.

Chevion, M., Jiang, Y., Har-El, R., Berenshtein, E., Uretzky, G. and Kitrossky, N. (1993) Copper and iron are mobilised following myocardial ischemia: Possible predictive criteria for tissue injury? Proc Nat Ann Sci USA. 90:1102-1106.

Cox, A.G., Winterbourn, C.C. and Hampton, M.B. 2010. Mitochondrial peroxiredoxin involvement in antioxidant defence and redox signalling. Biochem J. 425:313-325.

Dey, A. and Lakshmanan, J. 2013. The role of antioxidants and other agents in alleviating hyperglycemia mediated oxidative stress and injury in liver. Food Funct. 4(8):1148-84.

Downey, J.M. 1990. Free radicals and their involvement during long-term myocardial ischemia-reperfusion. Annu Rev Physiol. 52:487-504.

Flohé, L. 2010. Changing paradigms in thiology: from antioxidant defense toward redox regulation. Meth Enzymol. 473:1-39. 
Grundy, J.E. and Storey, K.B. 1998. Antioxidant defenses and lipid peroxidation damage in estivating toads, Scaphiopus couchiii. J Comp Physiol B. 168:132-142.

Hall, A., Nelson, K., Poole, L.B. and Karplus, P.A. 2011. Structure-based insights into the catalytic power and conformational dexterity of peroxiredoxins. Antioxid Redox Signal. 15:795-815.

Hearse, D.J., Manning, A.S., Downey, J.M. and Yellon, D.M. 1986. Xanthine oxidase: a critical mediator of myocardial injury during ischemia and reperfusion? Acta Physiol Scand Suppl, 548:65-78

Hermes-Lima, M., Storey, J.M. and Storey, K.B. 1998. Antioxidant defenses and metabolic depression. The hypothesis of preparation for oxidative stress in land snails. Comp Biochem Physiol B. 120:437-448.

Hossain, M.A., Hamamoto, I., Todo, S., Maeba, T. and Tanaka, S. (1995) Comparison of warm and cold ischemia of the canine small intestine. Eur Surg Res. 27:234-240.

Joanisse, D.R. and Storey, K.B. (1996) Oxidative damage and antioxidants in Rana sylvatica, the freeze tolerant wood frog. Am J Physiol. 271:R545-R553.

Kim, K., Kim, I.H., Lee, K.Y., Rhee, S.G. and Stadtman, E.R. 1988. The isolation and purification of a specific "protector" protein which inhibits enzyme inactivation by a thiol/Fe(III)/O2 mixed-function oxidation system. J Biol Chem. 263:4704-4711.

Kling, K.B., Costanzo, J.P. and Lee, R.E. 1994. Post-freeze recovery of peripheral nerve function in the freeze-tolerant wood frog, Rana sylvatica. J Comp Physiol B. $164(4): 316-320$.

Koo, K.H., Lee, S., Jeong, S.Y., Kim, E.T., Kim, H.J., Kim, K., Song, K. and Chae, H.Z. 2002. Regulation of thioredoxin peroxidase activity by $\mathrm{C}$-terminal truncation. Arch. Biochem Biophys. 397:312-318.

Lee, K. and Berenbaum, M.R. 1993. Food utilization and antioxidant enzyme activities of black swallowtail in response to plant photoxins. Arch Insect Biochem Physiol. 23:79-89. 
Layne, J.R. and First, M.C. 1991. Resumption of physiological functions in the wood frog (Rana sylvatica) after freezing. Am J Physiol. 261:R134-137.

Rabilloud, T., Heller, M., Gasnier, F., Luche, S., Rey, C., Aebersold, R., Benahmed, M., Louisot, P. and Lunardi, J. 2002. Proteomics analysis of cellular response to oxidative stress. Evidence for in vivo overoxidation of peroxiredoxins at their active site. J Biol Chem. 277:19396-19401.

Rigo, A., Viglino, P. and Rotilio, G. 1975. Kinetic study of o2-dismutation by bovine superoxide dismutase. Evidence for saturation of the catalytic sites by $\mathrm{O}-2$. Biochem. Biophys. Res. Commun. 63:1013-1018.

Rochette, L., Zeller, M., Cottin, Y. and Vergely, C. 2014. Diabetes, oxidative stress and therapeutic strategies. Biochim Biophys Acta. S0304-4165(14)00215-3.

Rubin, B.B., Liauw, S., Tittley, J., Romashin, A.D. and Walker, P.M. 1992. Prolonged adenine nucleotide resynthesis and reperfusion injury in postischemic skeletal muscle. Am J Physiol. 262(31):H1538-H1547.

Rubinsky, B., Lee, C.Y., Bastacky, J. and Onik, J. (1987) The process of freezing and the mechanism of damage during hepatic cryosurgery. Cryobiology. 27:85-97.

Salinas, A.E. and Wong, M.G. (1999) Glutathione S-transferases--a review. Curr Med Chem. 6(4):279-309.

Shick, J.M., Lesser, M.P. and Stochaj, W.R. 1991. Ultraviolet radiation and photooxidative stress in Zooxanthellate Anthozoa: the sea anemone, Phyllodiscuc semoni, and the Octocoral Clavularia sp. Symbiosis. 10:145-173.

Singh, R, Wiseman, B, Deemagarn, T, Jha, V, Switala, J. and Loewen, P.C. 2008. Comparative study of catalase-peroxidases (KatGs). Arch Biochem Biophys. 471(2):207-14.

Sobotta, M.C., Barata, A.G., Schmidt, U., Mueller, S., Millonig, G. and Dick, T.P. 2103. Exposing cells to $\mathrm{H}_{2} \mathrm{O}_{2}$ : a quantitative comparison between continuous low-dose and one-time high-dose treatments. Free Radic Biol Med. 60:325-335. 
Storey, K.B. 1987. Organ-specific metabolism during freezing and thawing in a freeze tolerant frog. Am J Physiol. 253, R292-R297.

Storey, K.B. and Storey, J.M. 1986. Freeze tolerant frogs: Cryoprotectants and tissue metabolism during freeze/thaw cycles. Can J Zool. 64, 49-56.

Storey, K.B. (1990) Life in a frozen state: adaptive strategies for natural freeze tolerance in amphibians and reptiles, Am J Phys. 258:R559-R568.

Storey, K.B. (2004) Vertebrate freeze tolerance: role of freeze-responsive gene expression. In: Life in the Cold: Evolution, Mechanisms, Adaptation, and Application. 12th International Hibernation Symposium. (Barnes, B.M. and Carey, H.V., eds.) Biological Papers of the University of Alaska, \#27, Fairbanks. pp. 299306.

Thannickal, V. and Fanburg, B. 2000. Reactive oxygen species in cell signalling. Am J Physiol. 279:L1005-L028.

Wagner E., Luche S., Penna L., Chevallet M., Van Dorsselaer A., Leize-Wagner E. and Rabilloud T. 2002. A method for detection of overoxidation of cysteines: peroxiredoxins are oxidized in vivo at the active-site cysteine during oxidative stress. Biochem J. 366:777-785

Winterbourn, C.C. 2008. Reconciling the chemistry and biology of reactive oxygen species. Nat Chem Biol. 4:278-286.

Zheng, K., Board, P.G., Fei, X., Sun, Y., Lv, S., Yan, G., Liu, J., Shen, J. and Luo, G. 2008. A novel selenium-containing glutathione transferase zeta1-1, the activity of which surpasses the level of some native glutathione peroxidases. Int J Biochem Cell Biol. 40:2090-2097 
Appendix A:

List of Publications 
Childers CL, Dawson NJ, Storey KB. (2015) Purification and properties of glutamate dehydrogenase from the African clawed frog, Xenopus laevis. (Completed).

Dawson NJ, Childers CL, Storey KB. (2014) Using native denaturation and differential scanning fluorimetry to asses protein stability; an exploration into subtle differences in protein isoforms. (Submission in progress).

Dawson NJ, Katzenback BA, Storey KB. (2014) Free-radical first responders: The characterization of MnSOD and CuZnSOD regulation during freezing of the freeze-tolerant North American wood frog, Rana sylvatica (syn Lithobates sylvaticus). (Submission in progress, Biochim Biophys Acta Gen Subj).

Dawson NJ, Katzenback BA, Storey KB. (2013-2014) Purification and characterization of a urea sensitive lactate dehydrogenase from the liver of the African clawed frog, Xenopus laevis. J Comp Physiol B. (DOI: 10.1007/s00360-014-0824-1).

Shahriari A, Dawson NJ, Bell RAV, Storey KB. (2013) Stable suppression of lactate dehydrogenase activity in the foot muscle of Littorina littorea and the potential role of acetylation as a novel regulatory mechanism. Enz Res Article ID 461374.

Dawson NJ, Biggar K, Storey KB. (2013) Characterization of fructose-1,6-bisphosphate aldolase during anoxia in the tolerant turtle, Trachemys scripta elegans: An assessment of enzyme activity, expression and structure. PLOS ONE 8(7): e68830.

Dawson NJ, Bell RAV, Storey KB. (2013) Purification and properties of white muscle lactate dehydrogenase from the anoxia-tolerant turtle, the red eared slider, Trachemys scripta elegans Enz Res Article ID 784973.

Dawson NJ, Biggar K, Storey KB. (2012) Real-time protein unfolding; a simple method for determining the kinetics of native protein denaturation $\left(\mathrm{K}_{\mathrm{ND}}\right)$ using a quantitative real-time thermocycler. BioTechniques 53:231-238.

Dawson NJ, Storey KB. (2012) Regulation of tail muscle hexokinase in the anoxiatolerant freshwater crayfish, Orconectes virilis. HOAJ Biol. 1(1).

Bell R, Dawson NJ, Storey KB. (2012) Insights into the in vivo regulation of glutamate dehydrogenase from the foot muscle of an estivating land snail. Enz Res. Article ID 317314 .

Dawson NJ, Storey KB. (2011) An enzymatic bridge between carbohydrate and amino acid metabolism: regulation of glutamate dehydrogenase by reversible phosphorylation in a severe hypoxia-tolerant crayfish. J Comp Physiol B. 182(3): $331-40$. 
Dawson NJ, Storey KB. (2011) Regulation of tail muscle arginine kinase by reversible phosphorylation in an anoxia-tolerant crayfish. J Comp Physiol B. 181(7): 851-9. 


\section{Appendix B:}

Communications at scientific meetings 
Dawson NJ, Katzenback BA, Storey KB. (2014) Free-radical first responders: The characterization of MnSOD and CuZnSOD regulation during freezing of the freeze-tolerant North American wood frog, Rana sylvatica. Canadian Oxidative Stress Consortium, June 11-13, 2014, Carleton University, Ottawa, Ontario. Poster Presentation.

Dawson NJ, and Storey KB. (2013) Threonine phosphorylation of catalase from the freeze tolerant frog, Rana sylvatica; a preparatory mechanism. CRYO2013, $50^{\text {th }}$ Annual Meeting, Society for Cryobiology, Bethesda, Maryland, July 28-31, 2013. Poster Presentation.

Dawson NJ, Biggar KK, and Storey KB. (2012) Real-time protein unfolding: A method for determining the kinetics of native protein denaturation using a quantitative real-time thermocycler. $2^{\text {nd }}$ China Canada Systems Biology Symposium and 19th Methods in Protein Structure Analysis Conference June 25-28, 2012, Ottawa Convention Centre, Ottawa, Ontario. Poster Presentation.

Dawson NJ, and Storey KB. (2012) Threonine phosphorylation of catalase from the freeze tolerant frog, Rana sylvatica; A preparatory mechanism. $2^{\text {nd }}$ China Canada Systems Biology Symposium and 19th Methods in Protein Structure Analysis Conference June 25-28, 2012, Ottawa Convention Centre, Ottawa, Ontario. Poster Presentation.

Dawson NJ, and Storey KB. (2011) An anoxic energy reserve: Purification and properties of argine kinase from the tail muscle of Oronectes virilis. $26^{\text {th }}$ Annual meeting, Federação de Sociedades de Biologia Experimental (FeSBE), Rio de Janeiro, Brazil, August 24-27. Poster Presentation.

Dawson NJ, and Storey KB. (2011) An enzymatic bridge between carbohydrate metabolism and amino acid metabolism: Regulation of glutamate dehydrogenase in the tail muscle of Orconectes virilis. $26^{\text {th }}$ Annual meeting, Federação de Sociedades de Biologia Experimental (FeSBE), Rio de Janeiro, Brazil, August 2427. Poster Presentation.

Dawson NJ, and Storey KB. (2011) Oxidative damage; the allosteric regulation of glutathione reductase in the freezing frog, Rana sylvatica. Canadian Society of Zoology Annual Meeting. Ottawa, ON. Oral Presentation.

Dawson NJ, and Storey KB. (2010) An anoxic energy reserve: Purification and properties of argine kinase from the tail muscle of Oronectes virilis. $7^{\text {th }}$ Annual Ottawa Carleton Institute of Biochemistry Symposium. Ottawa, ON. Poster Presentation. 
Dawson NJ, and Storey KB. (2009) An enzymatic bridge between carbohydrate metabolism and amino acid metabolism: Regulation of glutamate dehydrogenase in the tail muscle of Orconectes virilis. Canadian Society of Zoology Annual Meeting. Toronto, ON. Poster Presentation.

Dawson NJ, and Storey KB. (2009) Purification and properties of argnine kinase from the freshwater crayfish, Orconectes vrilis; regulation of muscle energetic during anoxia by reversible phosphorylation. $12^{\text {th }}$ Annual Chemistry and Biochemistry Graduate Research Conference, Concordia University, Montreal, Que. Oral Presentation.

Dawson NJ, and Storey KB. (2008) An enzymatic bridge between carbohydrate metabolism and amino acid metabolism: Regulation of glutamate dehydrogenase in the tail muscle of Orconectes virilis. $5^{\text {th }}$ Annual Ottawa Carleton Institute of Biochemistry Symposium. Ottawa, ON. Poster Presentation.

Dawson NJ, and Storey KB. (2007) GDH regulation by reversible phosphorylation during estivation of the land snail, Otala lacteal.

Dawson NJ, and Koschinsky M. (2006) A Study of the Folding Kinetics of Various Apo(a) Isoform Sizes. Queen's University Undergraduate Research Conference. Oral Presentation. 
Appendix C:

Contributions to Chapters 
Chapter 1 General Introduction

- Chapter 1 was completed in its entirety by Neal Dawson.

Chapter 2 Free-radical first responders: The characterization of $\mathrm{CuZnSOD}$ and MnSOD regulation during freezing of the freeze tolerant North American wood frog, Rana sylvatica.

- Chapter 2 was completed by Neal Dawson and Barbara Katzenback. Barbara Katzenback contributed the transcript and protein data for MnSOD. All other sections were completed by Neal Dawson.

Chapter 3 Passive regeneration of glutathione: Purification and properties of glutathione reductase regulation from the freeze tolerant North American wood frog, Rana sylvatica.

- Chapter 3 was completed in its entirety by Neal Dawson.

Chapter 4 A hydrogen peroxide safety valve: The reversible phosphorylation of catalase from the freeze tolerant North American wood frog, Rana sylvatica.

- Chapter 4 was completed in its entirety by Neal Dawson.

\section{Chapter 5 General Discussion}

- Chapter 5 was completed in its entirety by Neal Dawson. 